\title{
THE DEVELOPMENT AND PROGNOSIS OF NON-Q WAVE MYOCARDIAL INFARCTION IN THE THROMBOLYTIC ERA
}

by

Shaun Geoffrey Goodman, BSc, MD, FRCPC

\begin{abstract}
A thesis submitted in conformity with the requirements for the Degree of Master of Science (Clinical Epidemiology), Graduate Department of Community Health, University of Toronto
\end{abstract}

() Copyright by Shaun Geoffrey Goodman, 1998 
National Library of Canada

Acquisitions and Bibliographic Services

395 Wellington Street Ottawa ON K1A ONA Canada
Bibliothèque nationale du Canada

Acquisitions et services bibliographiques

395, rue Wellington Ottawa ON K1A ONA Canada
The author has granted a nonexclusive licence allowing the National Library of Canada to reproduce, loan, distribute or sell copies of this thesis in microform, paper or electronic formats.

The author retains ownership of the copyright in this thesis. Neither the thesis nor substantial extracts from it may be printed or otherwise reproduced without the author's permission.
L'auteur a accordé une licence non exclusive permettant à la

Bibliothèque nationale du Canada de reproduire, prêter, distribuer ou vendre des copies de cette thèse sous la forme de microfiche/film, de reproduction sur papier ou sur format électronique.

L'auteur conserve la propriété du droit d'auteur qui protège cette thèse. $\mathrm{Ni}$ la thèse ni des extraits substantiels de celle-ci ne doivent être imprimés ou autrement reproduits sans son autorisation. 


\begin{abstract}
THE DEVELOPMENT AND PROGNOSIS OF NON-Q WAVE MYOCARDIAL INFARCTION IN THE THROMBOLYTIC ERA

Shaun Goodman, BSc, MD, FRCPC
\end{abstract}

Degree of Master of Science (Clinical Epidemiology), Graduate Department of Community Health, University of Toronto, 1998

Up to $50 \%$ of all patients with acute myocardial infarction (MI) sustain a non-Q wave infarction characterized by electrocardiographic changes restricted to the ST segment or $T$ waves. Published information describing the natural history of non-Q as compared to $Q$ wave $\mathrm{Ml}$ patients is derived almost exclusively from studies in an era prior to the widespread use of thrombolytic therapy. Based on a retrospective analysis of 5 randomized, controlled studies performed in the thrombolytic era, administration of thrombolytic therapy to patients with acute MI presenting with ST segment elevation results in a significantly greater subsequent development of non- $Q$ as compared to $Q$ wave MI. Further, patients who receive thrombolysis and develop a non-Q have a better prognosis than those who develop a $\mathrm{Q}$ wave $\mathrm{Ml}$ following thrombolysis. Finally, patients who receive thrombolysis and develop a non- $Q$ wave $\mathrm{Ml}$ have a better prognosis than those who develop a non- $Q$ following standard medical therapy. 


\section{ACKNOWLEDGEMENTS}

I am extremely grateful:

1. To the investigators and steering committee members of the five randomized trials of thrombolytic therapy for sharing their data with me, and in particular, Charles Maynard, PhD, for providing information from the Western Washington Randomized Intracoronary Streptokinase Trial and Western Washington Intravenous Streptokinase in Acute Myocardial Infarction Randomized Trial; Harry Selker, MD, Joni Beshansky, RN, MPH, and John Griffith, PhD, for providing additional information from the Western Washington studies; Rolf Schroder, MD, and Thomas Bruggemann, MSc, for providing information from the Intravenous Streptokinase in Acute Myocardial Infarction study; Paul Armstrong, MD, and Lois Adams, BSc, for providing information from the Tissue Plasminogen Activator: Toronto study; and, Allan Skene, MD, Robert Wilcox, $M D$, and Andrew Charlesworth, MD, for providing information from the Late Assessment of Thrombolytic Efficacy study.

2. To the statisticians who have supported all of the analyses performed in this thesis, including Aiala Barr, PhD, Kathy Sykora, MSc, Eileen Lee, MSc, Erluo Chen, MB, MPH, and, Lois Adams, BSc;

3. To Lisa Goodman, BA, and Susan Francis, BA, for their editorial assistance;

4. To Galen Wagner, MD, for his unwavering support of this and many other related non-Q wave/electrocardiography projects;

5. To Marvin and Carol Goodman, Tara and David Abrams, Lisa Goodman and John Fleming, for their emotional support and for not asking any more frequently than semi-annually when this thesis would finally be completed;

6. To Benjamin Goodman and Christel Helwig, for giving up more time than everyone else to allow for the completion of this thesis and for reminding me there is life beyond this thesis;

7. To David Fitchett, MD, and Donald Redelmeier, MD, for their thoughtful review and critique; 
8. To my supportive, insightful, and patient thesis committee, including Antoni Basinski, MD, PhD, Anatoly Langer, MD, MSc, Paul Armstrong, MD, and David Naylor, MD, DPhil; and,

9. To my thesis supervisor David Naylor, MD, DPhil, who was charged with the formidable task of getting a cardiologist to finish a degree in clinical epidemiology. 


\section{TABLE OF CONTENTS}

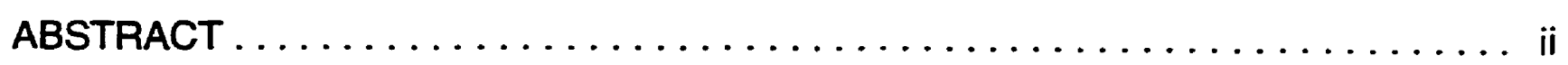

ACKNOWLEDGEMENTS $\ldots \ldots \ldots \ldots \ldots \ldots \ldots \ldots \ldots \ldots \ldots \ldots$ iii

TABLE OF CONTENTS $\ldots \ldots \ldots \ldots \ldots \ldots \ldots \ldots \ldots \ldots \ldots \ldots$

LIST OF TABLES $\ldots \ldots \ldots \ldots \ldots \ldots \ldots \ldots \ldots \ldots \ldots \ldots \ldots \ldots \ldots \ldots \ldots \ldots$

LIST OF FIGURES $\ldots \ldots \ldots \ldots \ldots \ldots \ldots \ldots \ldots \ldots \ldots \ldots \ldots \ldots \ldots \ldots \ldots \ldots \ldots$

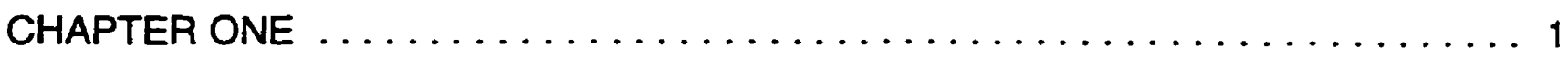

THESIS OUTLINE $\ldots \ldots \ldots \ldots \ldots \ldots \ldots \ldots \ldots \ldots \ldots \ldots \ldots$.

Background Rationale . . . . . . . . . . . . . . . . 1

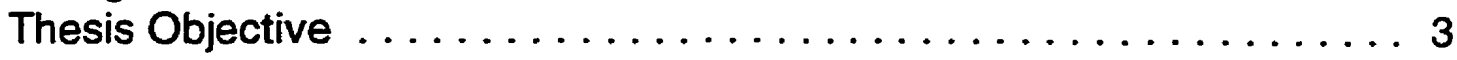

Thesis Hypotheses . . . . . . . . . . . . . . . . . 3

General Methods and Statistical Analysis ................ 3

CHAPTER TWO $\ldots \ldots \ldots \ldots \ldots \ldots \ldots \ldots \ldots \ldots \ldots \ldots \ldots \ldots \ldots \ldots \ldots \ldots \ldots \ldots$

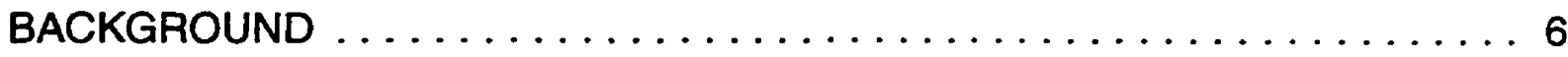

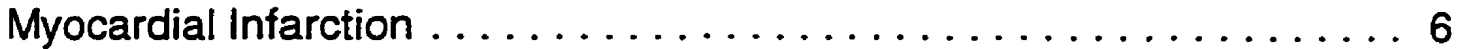

Transmural versus Nontransmural or Subendocardial Infarction - A

Pathologic Classification ................ 7

Q Wave versus Non-Q Wave Infarction - An Electrocardiographic

Classification ....................... 9

Pathological and Electrocardiographic Correlation of Infarction . . . . 11

$Q$ Wave versus Non-Q Wave Infarction - Pathophysiologic

Differences .......................... 11

Q Wave versus Non-Q Wave Infarction - Prognostic Differences ... 15

Short Term Outcome ..................... 15

Long Term Outcome ..................... 17

Non-Q Wave Infarction - Changes in Incidence Over Time ....... 21

The Potential Impact of Thrombolytic Therapy on the Development and Prognosis of Non-Q Wave Infarction . . . . . . . . 29

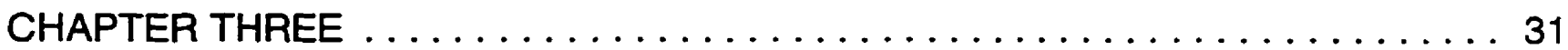

LITERATURE REVIEW ............................ 31

Rationale for Review of Non-Q and Q Wave Infarction in the Pre-

Thrombolytic Era ...................... 31

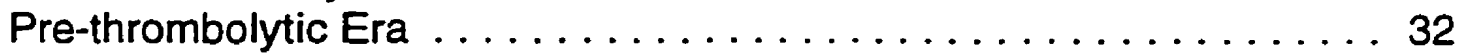

Article Selection ....................... 32

Study Inclusion and Exclusion Criteria . . . . . . . . . 32 
End Point Definition $\ldots \ldots \ldots \ldots \ldots \ldots \ldots \ldots \ldots \ldots \ldots \ldots \ldots \ldots \ldots \ldots$

Data Analysis ......................... 34

Results - Pre-Thrombolytic Era . . . . . . . . . . . . . . 35

Study Selection ....................... 35

Short Term Mortality ..................... 43

Short Term Reinfarction . . . . . . . . . . . . . . . . 48

Long Term Mortality ....................... 52

Long Term Reinfarction ................... 56

Discussion - Pre-Thrombolytic Era . . . . . . . . . . . . . 60

Summary of the Results from the Current Analyses . . . . . . 60

Comparison with Previous Analyses . . . . . . . . . . 60

Limitations of the Analyses . . . . . . . . . . . . . 61

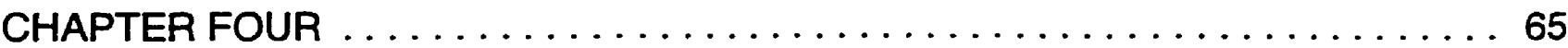

LITERATURE REVIEW ...................... 65

Rationale for Review of Non-Q and Q Wave Infarction in the

Thrombolytic Era ......................65

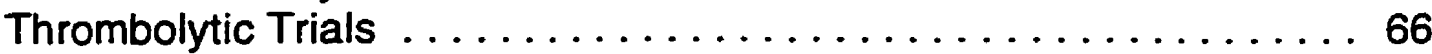

Article Selection .....................66 66

Results - Non-Q and Q Wave Infarction in the Thrombolytic Era .... . 66

Less $Q$ Wave Development and R Wave Regression Following

Thrombolysis ....................66 66

Non-Q Wave Development Following Thrombolysis . . . . . 70

Limitations of Previous Studies ............... 73

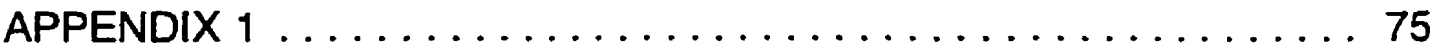

Non-Q Wave Infarction in Early Thrombolytic Trials

(Late 1960 s to Early 1980s) ............... 75

Non-Q Wave Infarction in the Thrombolytic Era (Mid-1980s

to Present) ...................... 76

CHAPTER FIVE $\ldots \ldots \ldots \ldots \ldots \ldots \ldots \ldots \ldots \ldots \ldots \ldots \ldots . \ldots \ldots$

THE DEVELOPMENT AND PROGNOSIS OF NON-Q WAVE MYOCARDIAL

INFARCTION FOLLOWING THROMBOLYTIC THERAPY ....... 82

Rationale for Additional Analysis of Non-Q Wave Development and

Prognosis in the Thrombolytic Era . . . . . . . . . . . 82

Thrombolytic Trial Selection .................... 83

Electrocardiographic Analysis ............... 84

Review of Thesis Objective and Hypotheses ............ 84

Statistical Analysis ...................... 85

Results - Non-Q and Q Wave Infarction in Randomized Controlled

Trials of Thrombolytic Therapy . . . . . . . . . . . 86

Overview of the Trials . . . . . . . . . . . . . . 86 
Western Washington Randomized Trial of Intracoronary

Streptokinase ................... 87

Intravenous Streptokinase in Acute Myocardial Infarction

(ISAM) Study ..................... 87

Western Washington Randomized Trial of Intravenous

Streptokinase ...................... 88

The Tissue Plasminogen Activator: Toronto (TPAT) Study . . . 89

The Late Assessment of Thrombolytic Efficacy (LATE) Study . 89

Non-Q Wave Development .................. 90

Logistic Regression Analysis For Q Wave

Development .................. 93

Non-Q vs. Q Wave Infarction - Outcome by Infarct Type ..... 96

In-Hospital Mortality . ................... 96

In-Hospital Reinfarction ................. 98

One Year Mortality . . . . . . . . . . . . . . . 98

One Year Reinfarction ................. 98

Non- $Q$ vs. $Q$ Wave Infarction - Outcome by Treatment ...... 99

In-Hospital Mortality ................... 99

In-Hospital Reinfarction . . . . . . . . . . . . . 102

One Year Mortality .................... 105

Logistic Regression Analyses For 1 Year Mortality . . . . 107

One Year Reinfarction . . . . . . . . . . . . . . . 109

Revascularization ................... 111

Medical Therapy .................... 113

Summary of Results . . . . . . . . . . . . . . . . . . . 114

Discussion ............................... 115

Study Limitations . . . . . . . . . . . . . . . . . 118

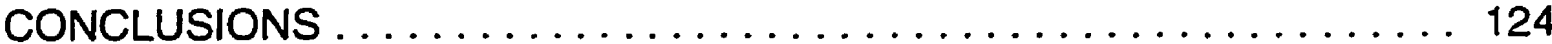

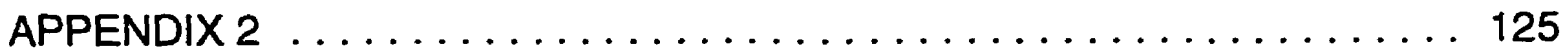

Modified Selvester Criteria for the Definition of $Q$ wave or $Q$ wave

equivalent Ml .......................... 125

Minnesota Q Wave Code Criteria ................... 125

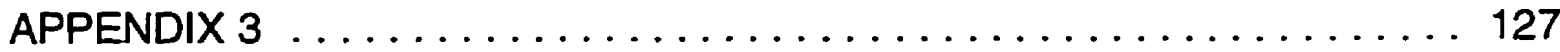

Western Washington Randomized Trial of Intracoronary

Streptokinase ....................... 127

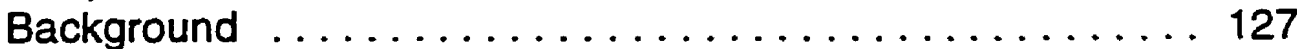

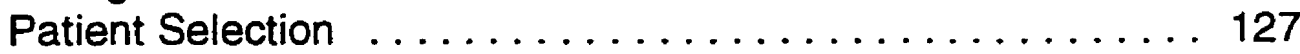

Study Design and Treatment . . . . . . . . . . . 127

Follow-Up ................................ 129

Intravenous Streptokinase in Acute Myocardial Infarction (ISAM)

Study ............................... 129

Background .......................... 129

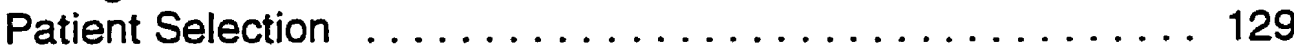


Study Design and Treatment . . . . . . . . . . . . . . 130

Follow-Up .......................... 130

Western Washington Randomized Trial of Intravenous

Streptokinase ....................... 130

Background .......................... 130

Patient Selection . . . . . . . . . . . . . . . . 131

Study Design and Treatment . . . . . . . . . . . . . 132

Follow-Up . . . . . . . . . . . . . . . . . . . . . 132

The Tissue Plasminogen Activator: Toronto (TPAT) Study . . . . 132

Background ....................... 132

Patient Selection ........................ 133

Study Design and Treatment ................ 133

Follow-Up . . . . . . . . . . . . . . . . . . . . . . 134

The Late Assessment of Thrombolytic Efficacy (LATE) Study . . . . . 134

Background ....................... 134

Patient Selection ..................... 135

Study Design and Treatment ............... 135

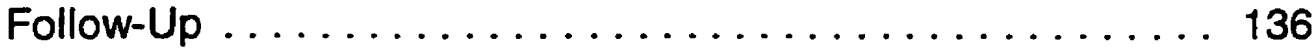

REFERENCES ............................ 137 


\section{LIST OF TABLES}

TABLE 1 - Randomized Controlled Trials of Thrombolytic Therapy in Acute Myocardial Infarction for Analysis . . . ................ 5

TABLE 2 - Incidences of Non-Q-Wave Infarction According to Source of Patient

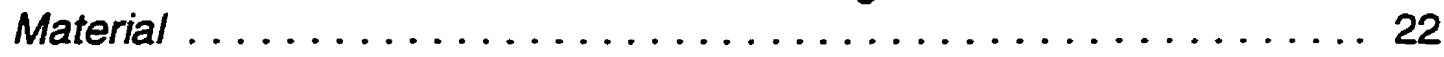

TABLE 3 - Short Term Mortality . . . . . . . . . . . . . . . . . . 36

TABLE 4 - Short Term Reinfarction ............................ 38

TABLE 5 - Long Term Mortality ............................ 39

TABLE 6 - Long Term Reinfarction ........................ 41

TABLE 7 - ECG patterns of $R$ wave evolution and $Q$ wave development . . . . . 69

TABLE 8 - Non-Q Wave Development in Studies of Thrombolytic Therapy . . . . . . 71

TABLE 9 - Non-Q Wave MI Development ...................... 91

TABLE 10 - Summary of the Results of Backward, Stepwise Logistic Regression Analyses by Trial . . . . . . . . . . . . . . . . . . . . . . . 95

TABLE 11 - In-Hospital Mortality and Reinfarction by Infarct Type and Treatment . 103

TABLE 12 - 1 Year Mortality and Reinfarction by Infarct Type and Treatment . . . . 106

TABLE 13 - In-Hospital and 1 Year Coronary Revascularization . . . . . . . . . . 112

TABLE 14 - Treatment at Discharge in the LATE Study . . . . . . . . . . . . . 113 


\section{LIST OF FIGURES}

FIGURE 1 - Pathologic Classification of Infarct Type ............... 8

FIGURE 2 - Electrocardiographic Classification of Infarct Type . . . . . . . . . 10

FIGURE 3 - Infarct Related Artery Patency by Infarct Type .............. 13

FIGURE 4 - In-Hospital and Long Term Mortality by Infarct Type ....... . . . 16

FIGURE 5 - Recurrent Angina by Infarct Type .................... 19

FIGURE 6 - Recurrent Infarction by Infarct Type . . . . . . . . . . . . 20

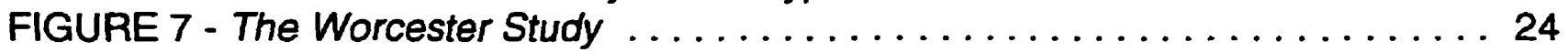

FIGURE 8 - The Minnesota Heart Study ...................... 26

FIGURE 9 - The U.S. Military Study . . . . . . . . . . . . . . . . 28

FIGURE 10 - Short Term Mortality ........................ 44

FIGURE 11 - Combined Mortality ........................ 47

FIGURE 12 - Short Term Reinfarction ..................... 49

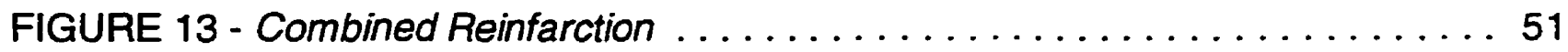

FIGURE 14 - Long Term Mortality ......................... 54

FIGURE 15 - Long Term Reinfarction ..................... 58

FIGURE 16 - Timing of Q Wave Development Post-Thrombolysis . . . . . . . 78

FIGURE 17 - Non-Q Wave Development . . . . . . . . . . . . . . . . . 92

FIGURE 18 - Non-Q vs. $Q$ Wave MI In-hospital and 1 Year Mortality and Reinfarction - Stratified Meta-Analysis . . ............. 97

FIGURE 19 - $Q$ vs. Non- $Q$ Wave In-Hospital and 1 Year Mortality and Reinfarction -

Stratified According to Thrombolytic vs. Control/Placebo Treatment . . . . . . 101

FIGURE 20 - Thrombolytic vs. Control/Placebo Treatment Between $Q$ and

Non-Q Wave MI Patients - In-hospital and 1 Year Mortality and

Reinfarction .............................. 104

FIGURE 21 - Pooled One Year Mortality According to Treatment and ECG Group . 108 


\section{CHAPTER ONE}

\section{Outline of Chapter One}

The purpose of this chapter is to:

1. Discuss the background rationale, objectives, and hypotheses of the thesis; and,

2. Provide the general methods of the thesis.

\section{THESIS OUTLINE}

\section{Background Rationale}

Between 20 and $50 \%$ of all patients admitted to a hospital with acute myocardial infarction (MI) sustain a non-Q wave infarction characterized by electrocardiographic changes which are restricted to the ST segment or $T$ waves. Compared with $Q$ wave infarction, those patients with non Q-wave MI have lower short term mortality (9.2\% vs. $17.1 \%)$, but are at higher risk for in-hospital ( $11.3 \%$ vs. $5.0 \%)$ and long term ( $17.5 \%$ vs. $6.2 \%)$ reinfarction.' Non- $Q$ wave $M I$ patients have a long term mortality rate that may equal or even surpass ( $28.5 \%$ vs. $21.3 \%$ ) that of Q-wave $M .^{1-3}$ However, this information on the development and natural history of non-Q Ml is derived primarily from studies in an era prior to the widespread use of thrombolytic therapy.

Limited data from more recent studies ${ }^{4.5}$ suggests that thrombolytic therapy may lead to a greater frequency of non-Q as compared to $Q \mathrm{Ml}$ development. Some studies tracking the incidence of $\mathrm{MI}$ have demonstrated a striking increase in the attack rates of non- $Q$ wave over time, ${ }^{6-8}$ suggesting that perhaps as many as $50 \%$ of all infarctions in the 1990 s are of the non- $Q$ wave variety. ${ }^{7}$ Based on these observations and the well-established decrease in the magnitude of myocardial damage seen following treatment with thrombolysis, several authors have suggested that more widespread use of thrombolytic therapy (in the late 1980s and 1990s) in patients who present with chest pain and ST segment elevation has led to more frequent non-Q wave $\mathrm{Ml}$ development. ${ }^{9-11}$

If indeed an "epidemic" of non-Q wave Ml development is occurring following thrombolytic therapy, it would be important to determine whether this new subgroup is 
subject to the same adverse prognosis as was seen among pre-thrombolytic non- $Q \mathrm{MI}$ patients. Although thrombolysis can dissolve occlusive thrombus in an infarct-related coronary artery, this therapy does not remove the underlying atherosclerotic lesion. Thus, patients with recently lysed thrombus may be at risk for recurrent ischemic events because of viable myocardium subserved by an artery with a residual narrowing. If so, then some of the long-term benefits of thrombolytic therapy may be overstated since lysis-induced non-Q wave MI patients may experience similar high rates of reinfarction and death as those seen among spontaneously occurring non- $Q$ wave Ml patients. Further, it may be possible to identify subgroups of patients who receive thrombolytic therapy who are at particular risk of further adverse events and therefore merit early intervention.

Thus, the rate of development and subsequent prognosis in non- $Q$ wave patients in the age of thrombolysis is an important clinical and public health issue since: (1) the incidence of non-Q wave Ml appears to be increasing; and, (2) it is unclear whether a greater number of non-Q wave $\mathrm{Ml}$ patients post-thrombolysis will require additional health care resources (e.g., invasive diagnostic and interventional procedures) in order to prevent a less favourable subsequent prognosis (i.e., increased risk for recurrent infarction and death).

\section{Thesis Objective}

The objective of this thesis is to determine whether the incidence and prognosis of non- $Q$ wave myocardial infarction among patients presenting with ST segment elevation and receiving thrombolytic therapy is different from those who do not receive thrombolysis.

\section{Thesis Hypotheses}

The specific hypotheses among patients presenting with ST segment elevation (STI) are: (1) the incidence of non-Q MI (vs. Q wave MI) will be higher in those receiving thrombolytic therapy as compared with a placebo; (2) the one year mortality for patients receiving thrombolysis will be lower in those who develop a non- $Q$ as compared with a $Q$ wave $\mathrm{Ml}$; and, (3) the one year mortality for non-Q wave Ml patients 
will be lower in those receiving thrombolytic therapy as compared to placebo.

\section{General Methods and Statistical Analysis}

The first part of the thesis will include a review, critical appraisal, and metaanalysis of more than 100 published studies examining the development and subsequent prognosis (short- and long-term reinfarction and mortality) of patients who develop a $Q$ or non- $Q$ wave in both the pre- and post-thrombolytic eras. The details of the literature search strategy, article selection (inclusion and exclusion criteria), review and quality assessment process, methods and outcome measures of the meta-analyses are described in Chapters Three and Four.

The second part of the thesis will be a retrospective analysis of five randomized, placebo-controlled trials of thrombolysis (see Table 1) in patients presenting with ST segment elevation in acute Ml, partitioned according to whether there was $Q$ or non- $Q$ wave development. The main outcome measures include: (1) the rate of transformation of $S T$ I to $Q$ and non-Q wave Ml following the administration of thrombolytic therapy as compared to control; and, (2) the rate of in-hospital death and reinfarction, and one year death and reinfarction among patients presenting with STI who subsequently develop a $Q$ or non- $Q$ wave $M I$ following thrombolysis as compared to control. 
TABLE 1

Randomized Controlled Trials of Thrombolytic Therapy in Acute Myocardial Infarction for Analysis

\begin{tabular}{|c|c|c|c|c|c|c|}
\hline Trlal & Publication(8) Source & Study Years & Randomized Therapy & Time to Treatment & Patlents (n) & $\begin{array}{l}\text { Patlonts with } \\
\text { STI (n) }\end{array}$ \\
\hline $\begin{array}{l}\text { Western Washington } \\
\text { Randomized } \\
\text { Intracoronary } \\
\text { Streplokinase Trial } \\
\text { (WWIC) }\end{array}$ & $\begin{array}{c}\text { Am Heart J } \\
\text { 1982;104:899-911 \& } \\
\text { NEJM 1983;309:1477- } \\
82 \text { \& NEJM } \\
\text { 1985;312:1073-8 }\end{array}$ & $1981-83$ & $\begin{array}{c}\text { Intracoronary } \\
\text { stroptokinase } \\
(286,000 \pm 77,800 \text { units } \\
\text { over } 72 \pm 24 \text { minutes }) \text { vs. } \\
\text { control } \\
\end{array}$ & $\leq 12$ hours & 250 & 237 \\
\hline $\begin{array}{c}\text { Prospective Trial of } \\
\text { Intravenous } \\
\text { Streptokinase in Acute } \\
\text { Myocardial Infarction } \\
\text { (ISAM) }\end{array}$ & $\begin{array}{c}\text { NEJM 1986;314:1465- } \\
71 \text { \& Circulation } \\
\text { 1987;76(suppl II):II-44. } \\
51 \text { \& JACC 1987;9:197- } \\
203\end{array}$ & $1982-85$ & $\begin{array}{c}\text { Intravenous } \\
\text { streptokinase ( } 1.5 \text { million } \\
\text { units over } 1 \text { hour) vs. } \\
\text { placebo }\end{array}$ & $\leq 6$ hours & 1,741 & 1,516 \\
\hline $\begin{array}{l}\text { Western Washington } \\
\text { Intravenous } \\
\text { Streptokinase in Acule } \\
\text { Myocardial Infarction } \\
\text { Randomized Trial } \\
\text { (WWIV) }\end{array}$ & Circulation $1988 ; 345-52$ & $1983-86$ & $\begin{array}{c}\text { Intravenous } \\
\text { streptokinase ( } 1.5 \text { million } \\
\text { units over } 1 \text { hour) vs. } \\
\text { control }\end{array}$ & $s 6$ hours & 368 & 368 \\
\hline $\begin{array}{l}\text { Tissue Plasminogen } \\
\text { Activator: Toronto } \\
\text { (TPAT) Placebo- } \\
\text { Controlled Randomized } \\
\text { Trial in Acute Myocardial } \\
\text { Infarction } \\
\end{array}$ & JACC 1989;13:1469-76 & 1987 & $\begin{array}{l}\text { Intravenous tissue } \\
\text { plasminogen activator } \\
(0.51 \cdot 0.57 \mathrm{MU} / \mathrm{kg} \text { over } \\
7-11 \text { hours) vs. placebo }\end{array}$ & $\leq 3.75$ hours & 115 & 115 \\
\hline $\begin{array}{l}\text { Late Assessment of } \\
\text { Thrombolytic Efficacy } \\
\text { (LATE) study }\end{array}$ & Lancel 1993;342:759-66 & 1989-92 & $\begin{array}{c}\text { Intravenous tissue } \\
\text { plasminogen activator } \\
\text { (100 mg over } 3 \text { hours) } \\
\text { vs. placebo }\end{array}$ & $6-24$ hours & 5,711 & 2,769 \\
\hline
\end{tabular}




\section{CHAPTER TWO}

\section{Outline of Chapter Two}

The purpose of this chapter is to:

1. Review the pathophysiology of acute myocardial infarction (MI) and the traditional pathologic and electrocardiographic classifications used in acute Ml;

2. Review the pathophysiologic differences between $Q$ and non- $Q$ wave $M I$ as the basis for observed differences in prognosis among these two groups;

3. Present evidence suggesting that the incidence of non- $Q$ wave MI may be increasing over time, perhaps in part due to more widespread use of thrombolytic therapy; and,

4. Review briefly the limited amount of published information on the impact of thrombolytic therapy on the development and subsequent prognosis of non- $Q$ wave $\mathrm{MI}$, and outline the need for a meta-analysis of randomized controlled trials of thrombolysis to further address this important public health issue.

\section{BACKGROUND}

\section{Myocardial Infarction}

The vast majority of myocardial infarctions (MI) result from atherosclerosis of the coronary arteries, usually with superimposed coronary thrombosis. The genesis of the coronary atherosclerotic lesion is a complex process and a number of risk factors have been associated with the development of atherosclerosis. Regardless of the etiology and pathogenesis of the atherosclerotic process, the end results are plaques that cause luminal narrowing of the coronary arterial tree. The luminal stenosis reduces the blood supply to the myocardium, and in the setting of acute $\mathrm{Ml}$, plaque rupture causes platelet aggregation and activation of the clotting cascade, leading to coronary thrombus and total occlusion of the artery. ${ }^{12,13}$ Below a certain critical level of blood flow, myocardial cells supplied by the occluded coronary artery become ischemic; if restoration of flow to the jeopardized myocardium is not achieved within a brief time frame (somewhere between 20 minutes and two hours), irreversible damage (i.e., MI) 
occurs.

Transmural versus Nontransmural or Subendocardial Infarction - A Pathologic Classification

Historically, two major types of acute MI have been described: the "transmural" infarction and the "non-transmural" or "subendocardial" infarction. ${ }^{2}$ This classification scheme is based on pathologic differences, depending on whether the tissue necrosis extends throughout the entire thickness of the wall of the myocardium (i.e., transmurally), or is confined to the subendocardial area (see Figure 1). 
FIGURE 1 - Pathologic Classification of Infarct Type

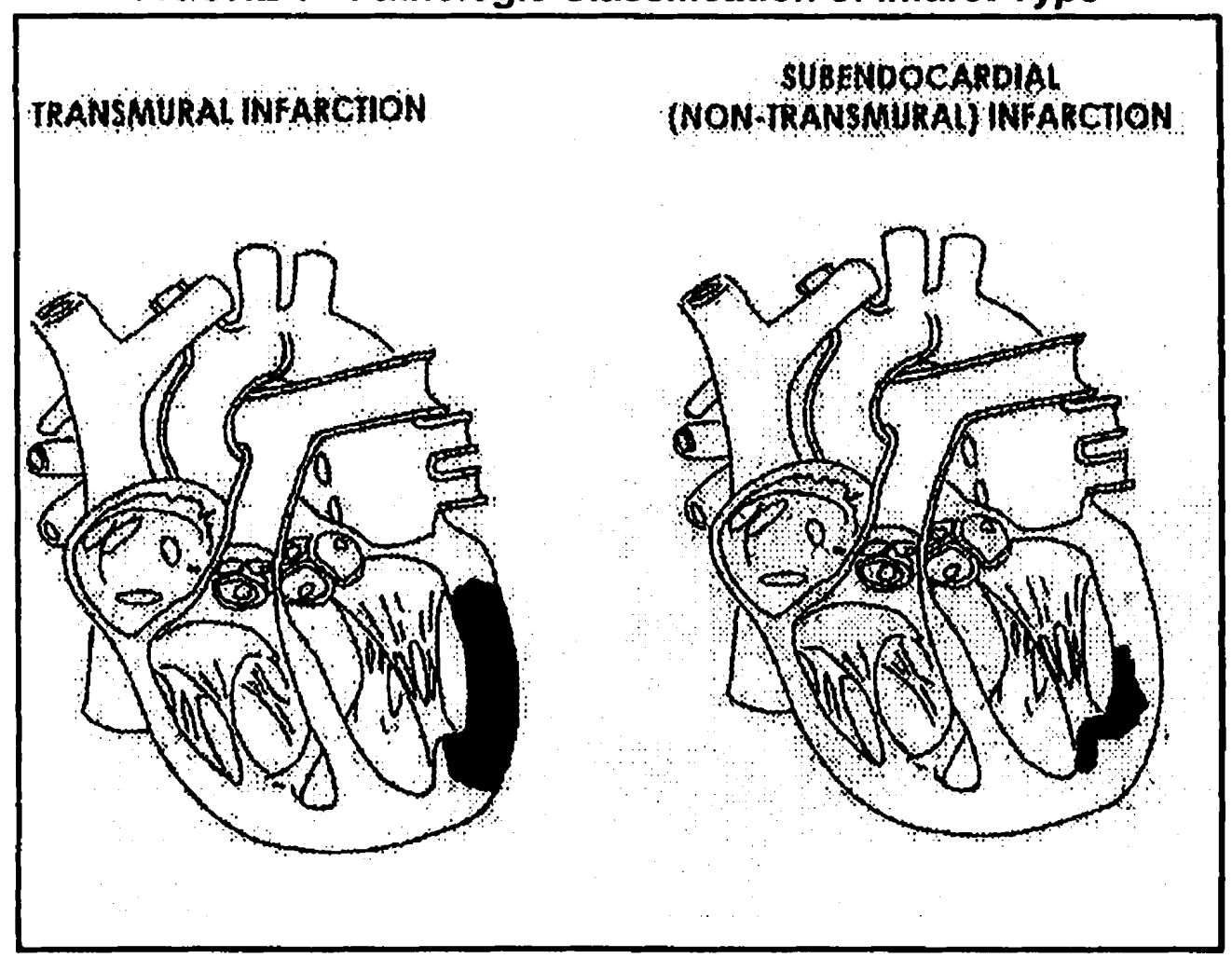

Transmural infarction indicates myocardial tissue necrosis extending throughout the entire thickness of the left ventricular wall (figure on left). In contrast, subendocardial infarction indicates myocardial tissue necrosis that does not extend transmurally (i.e., non-transmural), and (as seen in the figure on the right) is often confined to the inner one-third or subendocardial area). 
Q Wave versus Non-Q Wave Infarction - An Electrocardiographic Classification In addition to this pathologic distinction, which is not available to the clinician at the bedside, there is an electrocardiographic classification made on the basis of the occurrence of abnormal $Q$ waves on the surface electrocardiogram (ECG). For example, infarcts that alter the sequence of ventricular depolarization in such a way that $Q$ waves (or $Q$ wave "equivalents") are produced, are designated transmural. If the QRS is unchanged and only ST-T wave changes occur, the infarct is considered non-transmural or subendocardial (see Figure 2). ${ }^{14}$ 
FIGURE 2 - Electrocardiographic Classification of Infarct Type

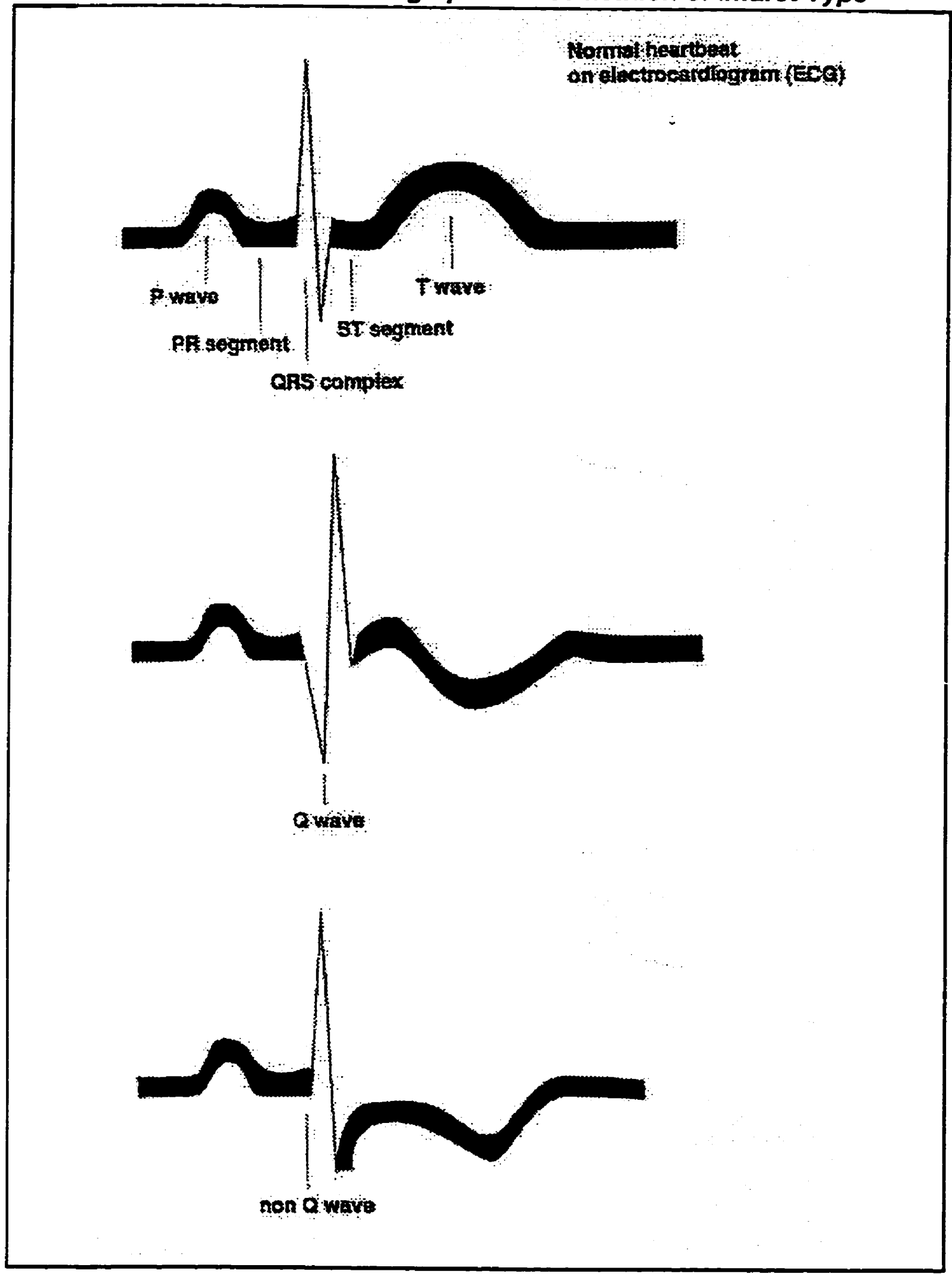




\section{Pathological and Electrocardiographic Correlation of Infarction}

While some early experimental ${ }^{15.16}$ and clinicopathologic ${ }^{17-22}$ work suggested that the ECG nomenclature consistently implied a pathologic correlation in the mural extent of infarction, the majority of studies ${ }^{23-45}$ have refuted this hypothesis. This may be due in part to the fact that the issue of classifying MIs on the basis of thickness of the left ventricular wall involved by necrosis has never been resolved. ${ }^{46}$ For example, although a transmural infarction has often been regarded as any infarction extending through the full thickness of the left ventricle at some point, ${ }^{47,48}$ other investigators ${ }^{49,50}$ have accepted greater than one-half of wall thickness as fulfilling the criterion for transmurality. In the most recent correlation of ECG and pathologic findings, Antaloczy et al ${ }^{45}$ examined 100 autopsy subjects and compared transmural (full thickness of the ventricular wall) and subendocardial (inner one-third to one-half of the ventricular wall) infarctions. These investigators reported that pathologic $Q$ waves (or $Q$ wave equivalent in the setting of posterior infarction) were present in $67 \%$ of patients with transmural necrosis and in $30 \%$ with subendocardial necrosis.

Given the nonspecificity of electrocardiographic criteria for differentiating transmural and nontransmural infarction, Spodick ${ }^{51}$ proposed the use of terminology that was strictly based upon the ECG: $Q$ wave versus S-T (or non-Q wave) infarction. The justification for this electrocardiographic stratification of infarct types is based upon a large body of literature validating pathophysiologic, clinical, and prognostic differences between $Q$ and non- $Q$ wave $M 1^{51,52}$

\section{$Q$ Wave versus Non-Q Wave Infarction - Pathophysiologic Differences}

Total coronary occlusion by thrombus is found in the overwhelming majority of cases in the early (0-6) hours after the onset of $Q$ wave $M I^{53}$ The incidence of total occlusion decreases with time (from hours to the next several days), consistent with spontaneous clot lysis. However, by the time at which an electrocardiographic classification of $Q$ or non- $Q$ wave infarction can be reliably undertaken (approximately 24 hours after the onset of $\mathrm{MI}$ ), as many as $85 \%$ of patients have total occlusion of the infarct-related artery. ${ }^{53}$ 
In contrast, patients with non-Q wave MI have a significantly higher frequency of patent infarct-related coronary arteries early in the course of infarction (see Figure 3). $2,54-58$ 
FIGURE 3 - Infarct Related Artery Patency by Infarct Type

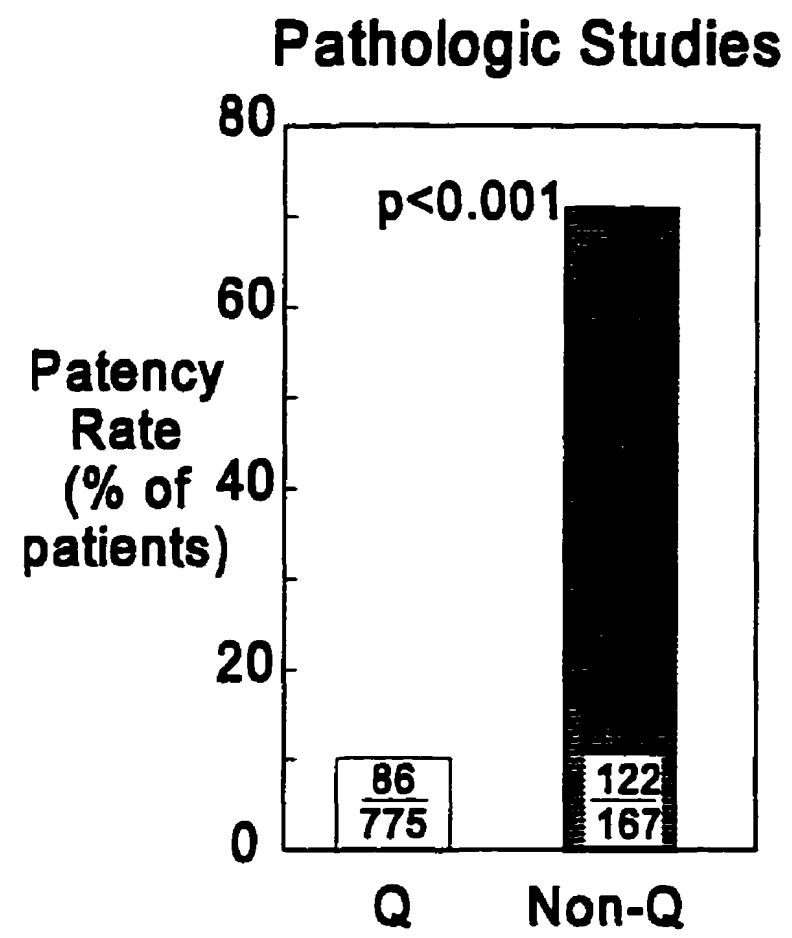

Angiographic Studies

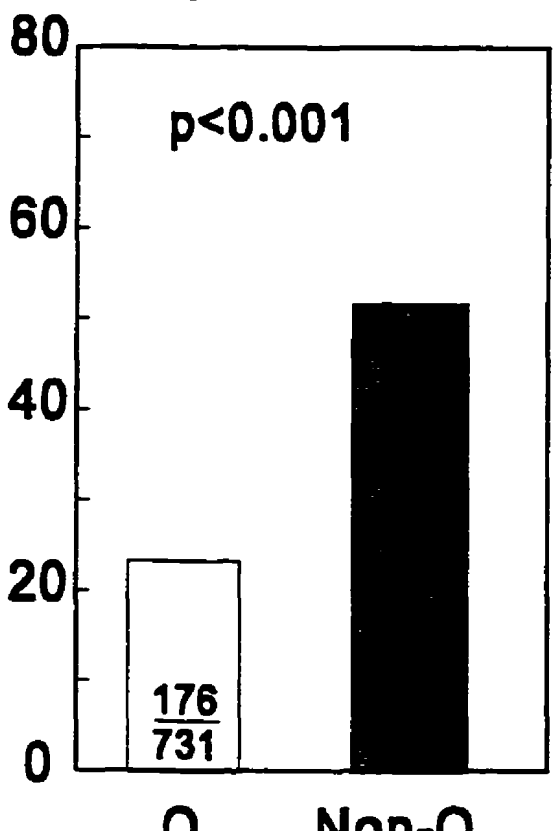

The infarct related artery patency rate is significantly greater among non- $Q$ wave (hatched bars) as compared to $Q$ wave (open bars) based on pathologic and angiographic studies. The numerator and denominator within each bar refer to the number of patients with a patent artery and the total number of patients studied, respectively. Adapted from Gibson ${ }^{3}$ 
Although very early angiography has been undertaken in a smaller number of patients who go on to develop a non- $Q$ wave $\mathrm{Ml}$, available angiographic and pathologic evidence indicate that, like patients who develop $Q$ wave infarcts, they also have a high frequency of coronary thrombosis. However, early recanalization due to endogenous thrombolysis with resultant nonocclusive thrombus limits the extent of myocardial necrosis. Evidence supporting timely reperfusion arises from the consistent observation that cardiac enzyme concentrations in plasma peak earlier and are significantly lower among non-Q as compared to $Q$ Ml patients. ${ }^{2.59-61}$ In addition, contraction band necrosis, the histologic hallmark of reperfusion, and hemorrhage are more often found in patients dying of non- $Q$ wave $M I$ than of $Q$ wave MI. ${ }^{43}$ Significantly lower levels of plasminogen activator inhibitor activity, an indicator of enhanced endogenous thrombolytic capacity, are found in non- $\mathrm{Q}$ wave $\mathrm{Ml}$; this finding of augmented fibrinolytic activity was associated with a significantly greater infarct-related artery patency. ${ }^{57}$ Finally, patients who develop non-Q wave $M I$ frequently have ST segment elevation, ${ }^{52.61-63}$ an electrocardiographic marker of complete infarct-related artery occlusion; ${ }^{53,64}$ in the absence of endogenous or medically induced thrombolysis, the subsequent development of $Q$ waves is the rule. ${ }^{65}$

In addition to early spontaneous reperfusion, it has been suggested that the coronary collateral circulation may also play a role in protecting patients from extensive myocardial necrosis. In this setting, flow to the area of myocardium normally supplied by the occluded infarct-related artery is instead provided by the presence of collateral vessels. While there is very little data collected prospectively that conclusively establishes a protective effect of coronary collaterals in patients who develop non- $Q$ wave $\mathrm{Ml}$, the majority of studies suggest that number and/or extent of visualized collaterals is greater among non- $Q$ as compared to $Q$ wave $M I$ patients. ${ }^{53.54 .61 .66}$ Thus, collateralization may preserve at least a portion of the jeopardized myocardium, limiting necrosis while allowing for endogenous thrombolysis of the occlusive clot, and possibly preventing the development of a $Q$ wave. 


\section{Q Wave versus Non-Q Wave Infarction - Prognostic Differences}

\section{Short Term Outcome}

The clinical course and prognosis differ among patients who do and do not manifest $Q$ waves after infarction. Before the widespread use of cardiac enzyme measurements to confirm the occurrence of infarction, Mls in which new $Q$ waves developed were thought to have a much worse prognosis than those in which only ST segment and/or $T$ wave changes on the ECG occurred. Thus, initial reports from the 1960 s demonstrated a high in-hospital mortality among $Q$ as compared to non- $Q$ wave $\mathrm{Ml}^{67.68}$ with some authors concluding that non-Q Ml represented a "mild" infarction with a subsequent benign prognosis and advocating early hospital discharge. ${ }^{69-72}$

Since the early 1960s, there have been more than 50 reports in the literature comparing the clinical outcome of patients with $Q$ and non-Q wave MI. Gibson published an analysis of data combined from a selected group of studies in $1988,{ }^{2}$ $1989,{ }^{3}$ and $1991,{ }^{1}$ which provides an overview of the existing literature up until the late 1980s. While there are many limitations to these "combined event" analyses and several additional papers (describing outcomes in an additional 8,000 patients) were published since his earlier reviews, Gibson's work represents the most recent and comprehensive collection of studies to-date (further discussion regarding the limitations of combining the data from these studies and the rationale for an up-dated, metaanalytic approach will be presented in Chapter 3 ).

When data from 34 short term studies were combined by Gibson, ${ }^{1}$ the in-hospital mortality rate for patients with $Q$ wave $M I(n=14,890)$ was $18.3 \%$ as compared to $9.3 \%$ among non- $Q$ wave $M l$ patients $(n=4,794 ; p<0.001)$ (see Figure 4). 
FIGURE 4 - In-Hospital and Long Term Mortality by Infarct Type

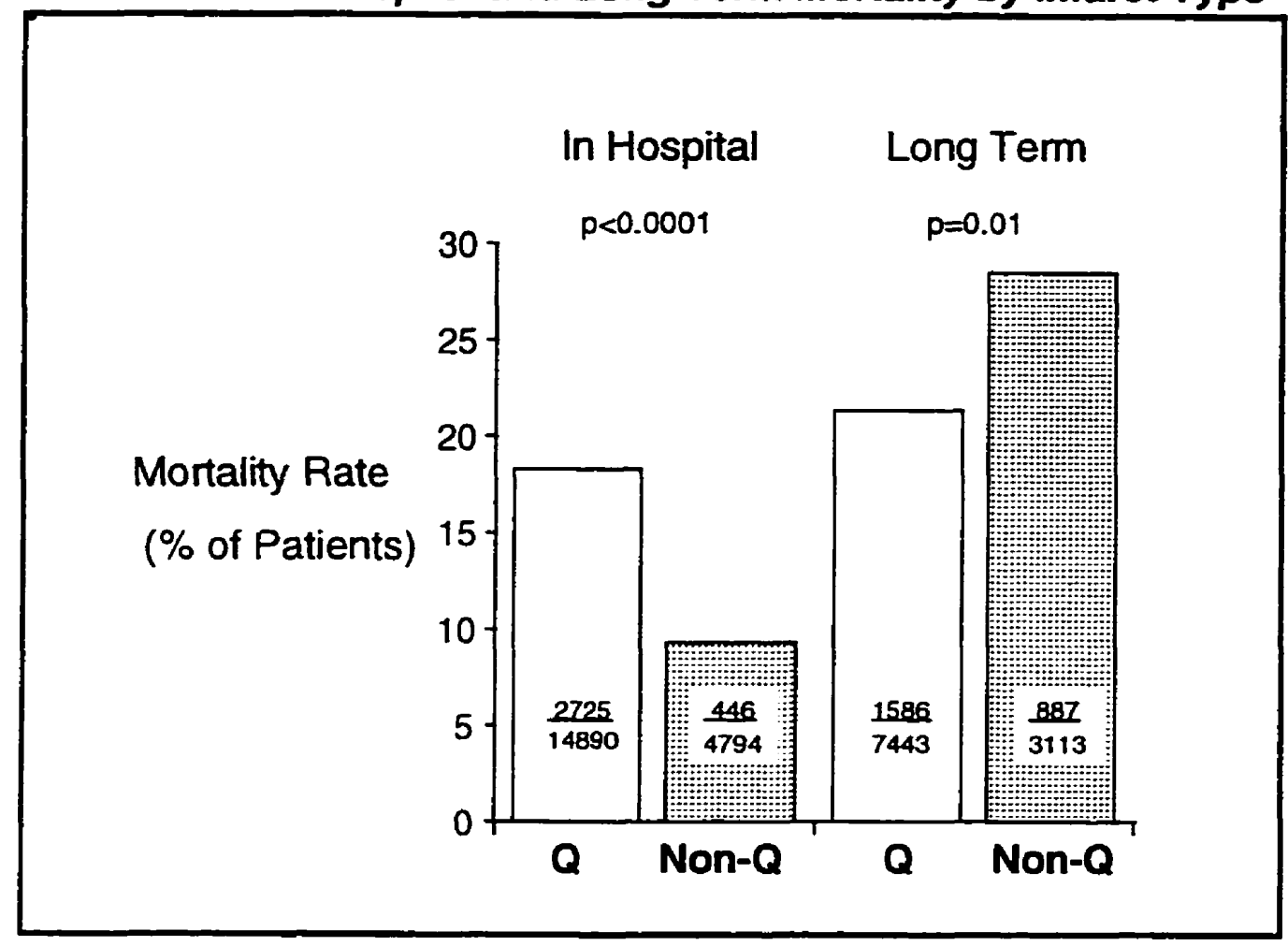

The in-hospital mortality rate is significantly lower among non- $Q$ wave (hatched bars) as compared to $Q$ wave (open bars) patients based on a combination analysis of 34 studies. In contrast, the long term mortality is significantly higher among non- $Q$ wave patients based on a combined analysis of 27 studies. The numerator and denominator within each bar refer to the number of patients dying and the total number of patients studied, respectively. Adapted from Gibson ${ }^{t}$ 
Multiple investigators have demonstrated that the amount of infarct-related myocardial necrosis is less with non- $Q$ wave than with $Q$ wave $M I$. This has been shown repeatedly with a wide variety of measurements, including cardiac enzyme estimation, ${ }^{61.63 .73-83} 99 \mathrm{~m}$-Technetium-pyrophosphate imaging, ${ }^{84.94}$ 201-Thallium scintigraphy, ${ }^{61,63.95,96}$ two-dimensional echocardiography, ${ }^{97-99}$ radionuclide and contrast ventriculography, ${ }^{61,63.95 .100-102}$ and by positron emission tomography. ${ }^{103.104}$ In view of these findings and the well-documented relationship between short-term prognosis and infarct size, it is perhaps not surprising that patients with non-Q wave Ml, in general, have a lower frequency of congestive heart failure, ${ }^{73.82 .105-109}$ and better short-term survival than their $Q$ wave counterparts.

\section{Long Term Outcome}

More frequent spontaneous resolution of occlusive coronary thrombus and/or better protection from collaterals results in less extensive injury and better left ventricular function among non-Q MI patients. Thus, it is logical to expect long-term follow-up studies to demonstrate lower mortality among patients with non- $Q$ wave infarcts. However, review of the literature actually demonstrates a similar (others have suggested a higher $\left.{ }^{2}\right)$, case fatality rate for non- $Q$ wave $M I$. Based on data from 27 long term studies combined by Gibson, ${ }^{1}$ the aggregate mortality rate was $21.3 \%$ for $Q$ wave $(n=7,443)$ and $28.5 \%$ for non- $Q$ wave $M I(n=3,113 ; p=0.001)$ (see Figure 4). Further, in the majority of studies that provide both short- and long-term data, it is generally seen that non- $Q$ wave $\mathrm{MI}$ patients have the same or higher long-term mortality, despite a lower initial (i.e., in-hospital) mortality, compared to $Q$ wave MI. ${ }^{6,74.75,80,81,95,106.110-117}$ These results have led to the conclusion that the early survival advantage of the non- $Q$ wave $\mathrm{Ml}$ group is lost in the months or years following hospital discharge. ${ }^{2}$

The reason why non- $Q$ wave MI patients lose their initial prognostic advantage may relate to the pathophysiologic mechanism that led to less necrosis and a better outcome in the first place. Despite the early spontaneous recanalization that occurs in non- $Q$ wave $M I$, resolution of thrombus is incomplete, leaving a residual high grade stenosis at the site where coronary arterial occlusion had occurred. While the patient 
who initially develops a non-Q wave $M I$ is able to "abort" or "interrupt" the process of infarction, ${ }^{10.52}$ the residual mass of viable but jeopardized myocardium within the perfusion zone of the infarct-related vessel places him at greater subsequent risk for recurrent myocardial ischemia, infarction, and death.

This pathophysiologic mechanism is supported by non-invasive testing and subsequent clinical follow-up. In a series of studies ${ }^{60.61,63,118}$ evaluating patients with exercise testing and 201-Thallium scintigraphy, it has been demonstrated that the proportion of patients with thallium redistribution (i.e., ischemia) within the perfusion zone of the infarct-related artery are greater in the non- $Q$ as compared to the $Q$ wave group. In two studies using positron emission tomography (PET) to evaluate coronary blood flow and myocardial metabolism, significant morphologic differences in the tomographic appearance have been documented. ${ }^{103.104}$ In the first study, patients with $Q$ wave infarcts were found to have large, confluent regions of homogeneously diminished tissue metabolism extending from the subendocardial to the subepicardial surface. In contrast, PET reconstructions from patients with non-Q wave $\mathrm{Ml}$ showed less regional depression but greater spatial heterogeneity in metabolism. This latter finding suggests the presence of ischemic, infarcted, and normal myocardium interspersed with one another. In the second study, the authors demonstrated preserved metabolic integrity (i.e., residual tissue viability) in $91 \%$ of areas with non- $Q$ wave $\mathrm{Ml}$ as compared with $36 \%$ in Q wave $\mathrm{MI}$.

Since the non- $Q$ wave infarct may represent an incomplete infarction, these patients remain at higher risk for recurrent ischemia and reinfarction. This is supported by combined data from 19 studies demonstrating a higher rate of recurrent angina (see Figure 5) and reinfarction (see Figure 6) among non- $Q$ as compared to $Q$ wave $\mathrm{MI}$ patients. ${ }^{1}$ 


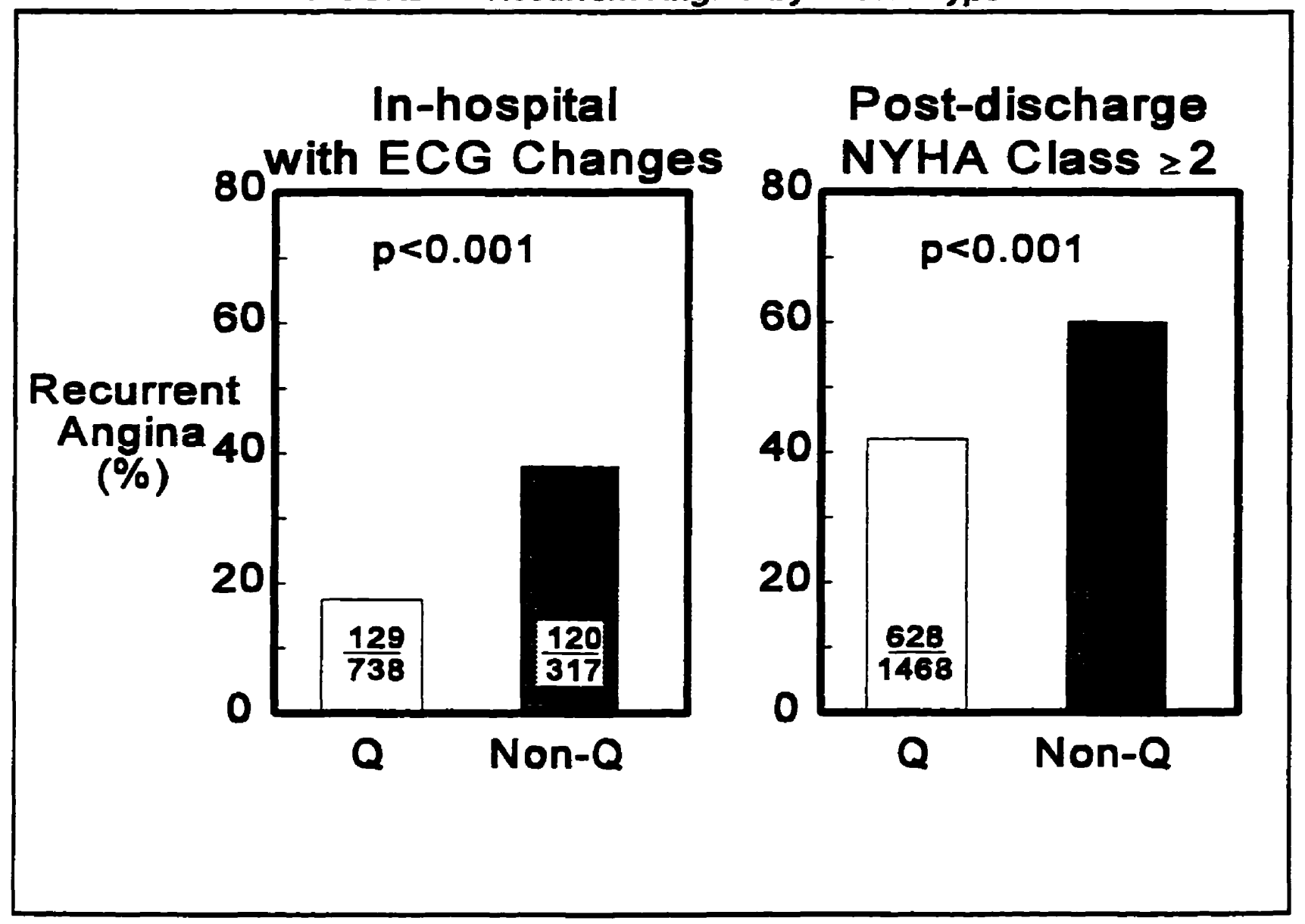

The rate of recurrent angina based on in-hospital recurrent chest pain with ECG changes (left panel) and post-discharge chest pain (New York Heart Association $\{N Y H A\}$ Class 2 or more)(right panel) is significantly greater among non- $Q$ wave (hatched bars) as compared to $Q$ wave (open bars) based on a combined analysis from 19 studies. The numerator and denominator within each bar refer to the number of patients with recurrent angina and the total number of patients studied, respectively. Adapted from Gibson ${ }^{2}$ 


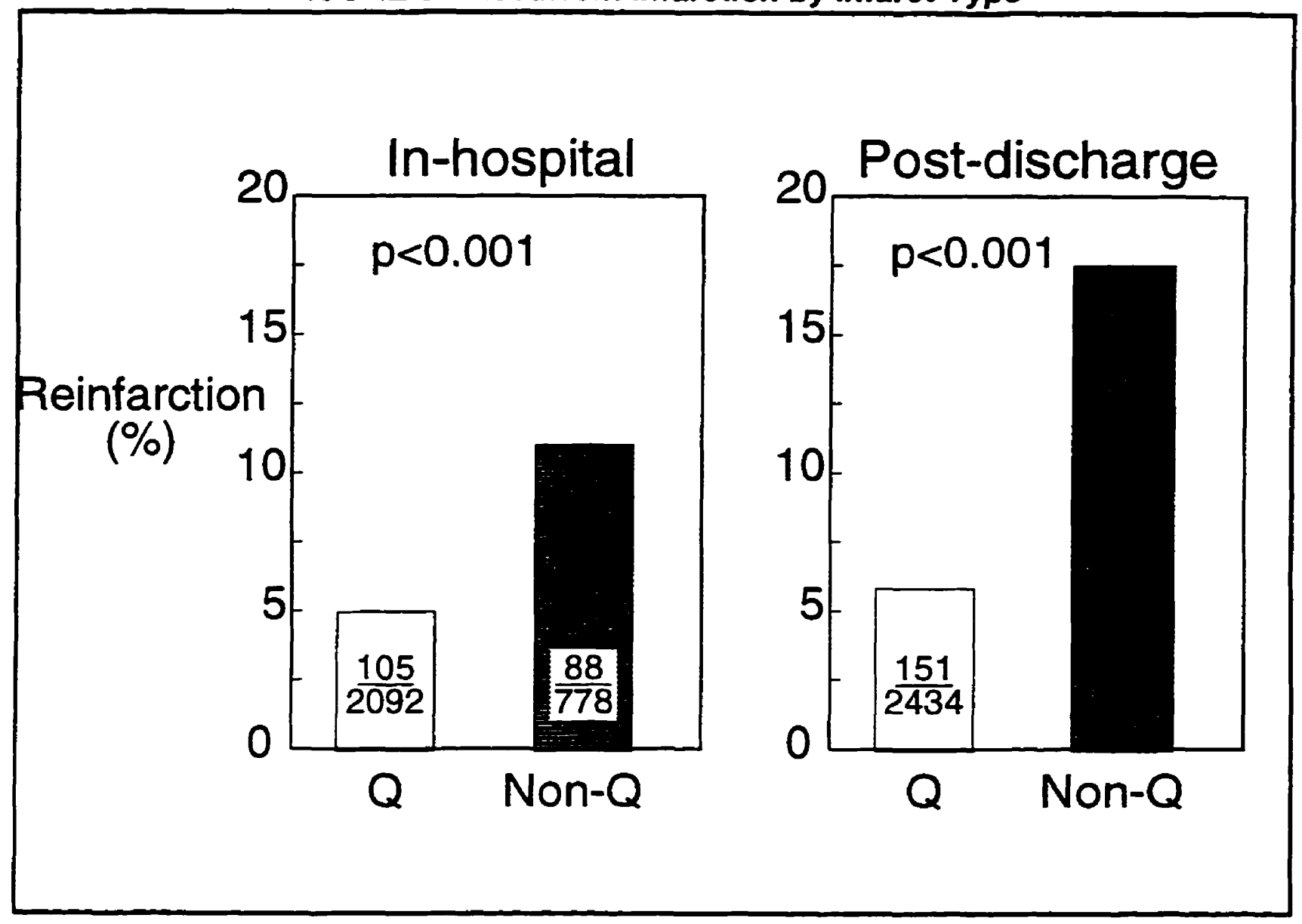

The rate of recurrent in-hospital (left panel) and post-discharge (right panel) myocardial infarction is significantly greater among non- $Q$ wave (hatched bars) as compared to $Q$ wave (open bars) based on a combined analysis from 19 studies. The numerator and denominator within each bar refer to the number of patients with reinfarction and the total number of patients studied, respectively. Adapted from Gibson' 
One well-designed, prospective study ${ }^{119}$ confirmed reinfarction in all cases by reelevation of a specific cardiac enzyme (creatine kinase-MB fraction) by measuring this enzyme every 12 hours throughout the hospital stay (mean interval of 18 days). These investigators found a recurrence rate of $43 \%$ after non-Q wave as compared to only $8 \%$ after $Q$ wave infarction; the vast majority of these reinfarctions were associated with $S T$ segment elevation (suggesting complete coronary occlusion). Further, when the serial ECG data from these patients were analysed and combined with the results of radionuclide ventriculography (obtained at day two and at hospital discharge), it was demonstrated that the location of reinfarction was in the same original area of injury. This observation, which has significant implications for the understanding of the pathogenesis of reinfarction, has subsequently been confirmed by other investigators. ${ }^{61,112.120 .121}$ It has also been shown that the occurrence of infarct extension was associated with a substantial reduction in left ventricular function ${ }^{119}$ and a 2.5 to 4fold increase in hospital mortality. ${ }^{81.119}$ Indeed, infarct extension after an initial non-Q wave $\mathrm{Ml}$ was the strongest univariate and multivariate predictor of 1 year mortality in one study. ${ }^{119}$ These findings may help to explain why the non-Q Ml patients lose their initial survival advantage and have a long-term mortality rate that is similar to or even higher than the $Q$ wave group.

\section{Non-Q Wave Infarction - Changes in Incidence Over Time}

The incidence of non- $\mathrm{Q}$ wave $\mathrm{Ml}$ in studies conducted between 1966-1982 ranges from $6.1 \%$ to $41.3 \%$ (with a mean of $27.2 \%$ from combined data). ${ }^{2}$ These rates are dependent on several factors, including the patient population surveyed, the ECG definition and/or cardiac enzyme diagnosis of non- $Q$ wave. When the patient population is stratified according to geographical (e.g., studies from the United States, Canada, or non-North American countries) or type of hospital setting (universityaffiliated, suburban, or community-wide surveys), the combined data demonstrates remarkably similar infarct rates (see Table 2 ). ${ }^{2}$ 
TABLE 2

Incidences of Non-Q-Wave infarction According to Source of Patient Material

\begin{tabular}{|c|c|c|}
\hline \multirow{2}{*}{ Source } & \multicolumn{2}{|c|}{ Number of Patients } \\
\hline & Total & $\begin{array}{c}\text { Non-Q-Wave } \\
(\%)\end{array}$ \\
\hline $\begin{array}{l}\text { U.S. Studies } \\
\text { University-affiliated medical centres }(8)^{73-75,114,122-124} \\
\text { Suburban hospitals }(5)^{79,95,109} \\
\text { Community-wide surveys (59) } \\
\text { U.107.110 } \\
\text { U.S.-Canadian (4) }{ }^{81} \\
\text { Non-U.S. Studies (8) }{ }^{68,80,82,106,108,113}\end{array}$ & $\begin{array}{r}2,401 \\
476 \\
5,034 \\
1,236 \\
2,873 \\
\end{array}$ & $\begin{array}{r}634(26.4) \\
125(26.3) \\
1,605(31.9) \\
277(22.4) \\
670(23.3) \\
\end{array}$ \\
\hline
\end{tabular}

Figures in parentheses indicate number of hospitals. Adapted from Gibson ${ }^{2}$

Two community-wide surveys ${ }^{6.125}$ have evaluated the time trends of the incidence and prognosis of $Q$ and non-Q wave MI. The Worcester Heart Attack Study ${ }^{6}$ was a community-wide study of patients hospitalized with validated acute $\mathrm{Ml}$ in all 16 hospitals in the Worcester, Massachusetts metropolitan area, during the calendar years 1975,1978 , and 1981. These investigators demonstrated an increase in the ageadjusted hospital $\mathrm{Ml}$ attack rates of both $\mathrm{Q}$ and non- $\mathrm{Q}$ wave $\mathrm{Ml}$, with relative increases between 1975 and 1981 of $29 \%$ and $93 \%$, respectively. The authors suggested that the striking increase in the attack rates of non-Q wave MI (see Figure 7), particularly those with small infarctions as reflected by peak cardiac enzyme levels, could be the result of increased diagnostic sensitivity and/or recognition of MI. This was supported by the finding that the use of a more specific cardiac enzyme (CK-MB) increased from $5 \%$ of cases in 1975 to $58 \%$ of cases in 1981 . Importantly, non-Q MI patients had a significantly decreased risk of dying during hospitalization as compared to those with $Q$ wave $\mathrm{Ml}(12 \%$ vs. $25.2 \%, p<0.05)$ overall as well as for each of the three time periods 
studied $(p<0.05)$. However, for patients discharged alive from the hospital, there were no significant differences in long-term survival rates according to Ml type over an 8year follow-up period. 
FIGURE 7 - The Worcester Study

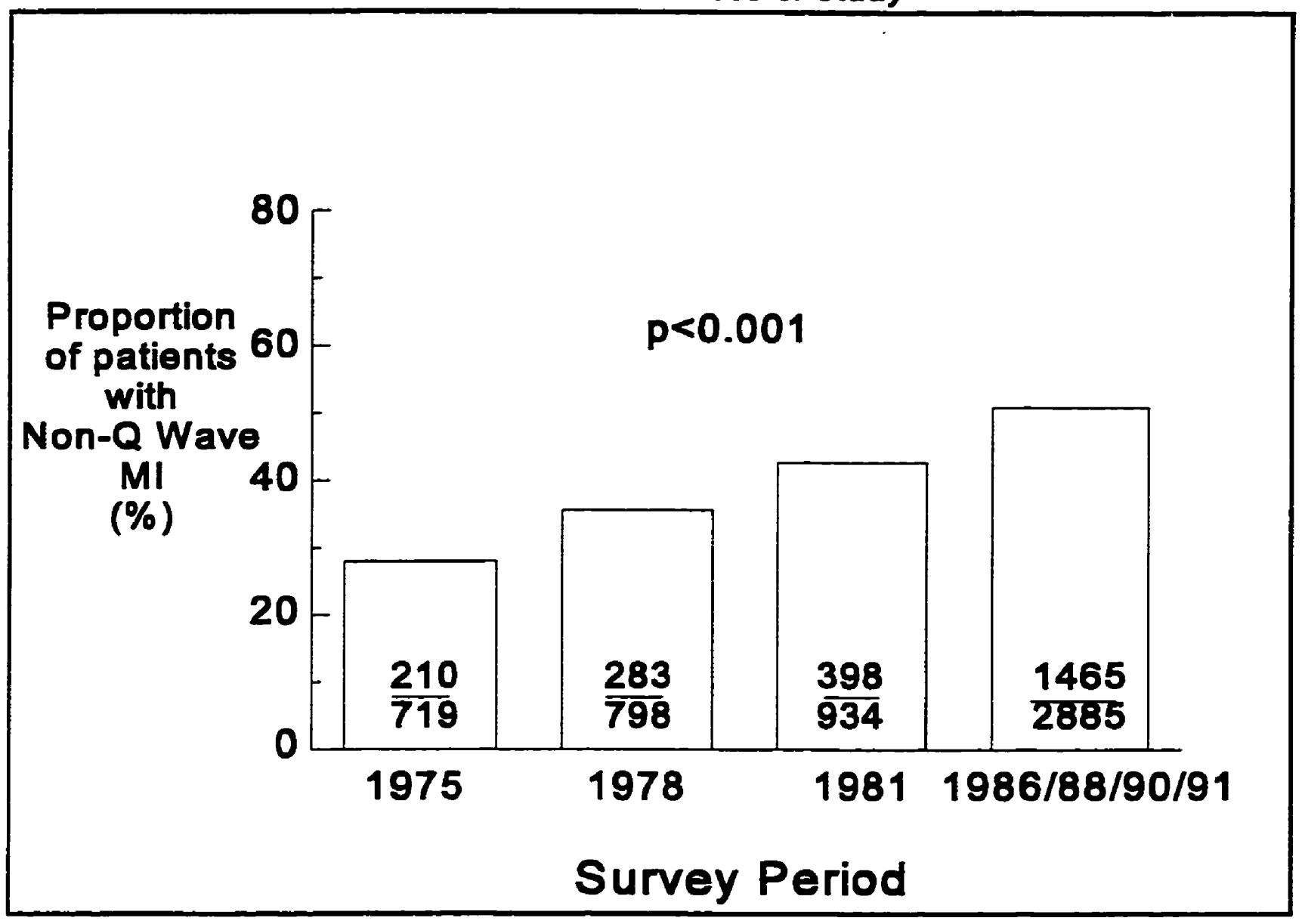

The proportion of patients presenting to 16 Worcester, Massachusetts, U.S. hospitals with non- $Q$ wave myocardial infarction during the calendar years $1975,1978,1981$, and 1986/1988/1990/1991 (combined) suggesting an increase over time. The numerator and denominator within each bar refer to the number of patients sustaining a non-Q MI and the total number of MI patients studied (age-adjusted), respectively. Adapted from Goldberg et $\mathrm{al}^{6}$ and Yarzebski et $\mathrm{al}^{7}$ 
The Minnesota Heart Survey ${ }^{125}$ used a $50 \%$ random sample of all hospital discharges of patients with acute coronary disease from 35 of 36 hospitals in 1970 and 30 of 31 hospitals in 1980 in the Minneapolis-St. Paul metropolitan area. Basing the diagnosis of $\mathrm{MI}$ on the ECG, history of chest pain, autopsy and less specific cardiac enzymes (AST and LDH), the investigators noted no change in the age-adjusted attack rates for both $Q$ and non- $Q$ wave $M l$ during the 1970 and 1980 periods. However, with the availability of more specific cardiac enzymes (CK and CK-MB), there was a significant increase for both $Q(16.8 \%, p<0.01)$ and non-Q wave $(94 \%, p<0.001) \mathrm{MI}$ rates from 1970 to 1980 (see Figure 7). The authors suggested that their data was an example of stage migration, or the "Will Rogers phenomenon" described by Feinstein et $a l,{ }^{126}$ who cautioned against the possibility of reaching fallacious conclusions about trends when diagnostic tests improve over time. 
FIGURE 8 - The Minnesota Heart Study

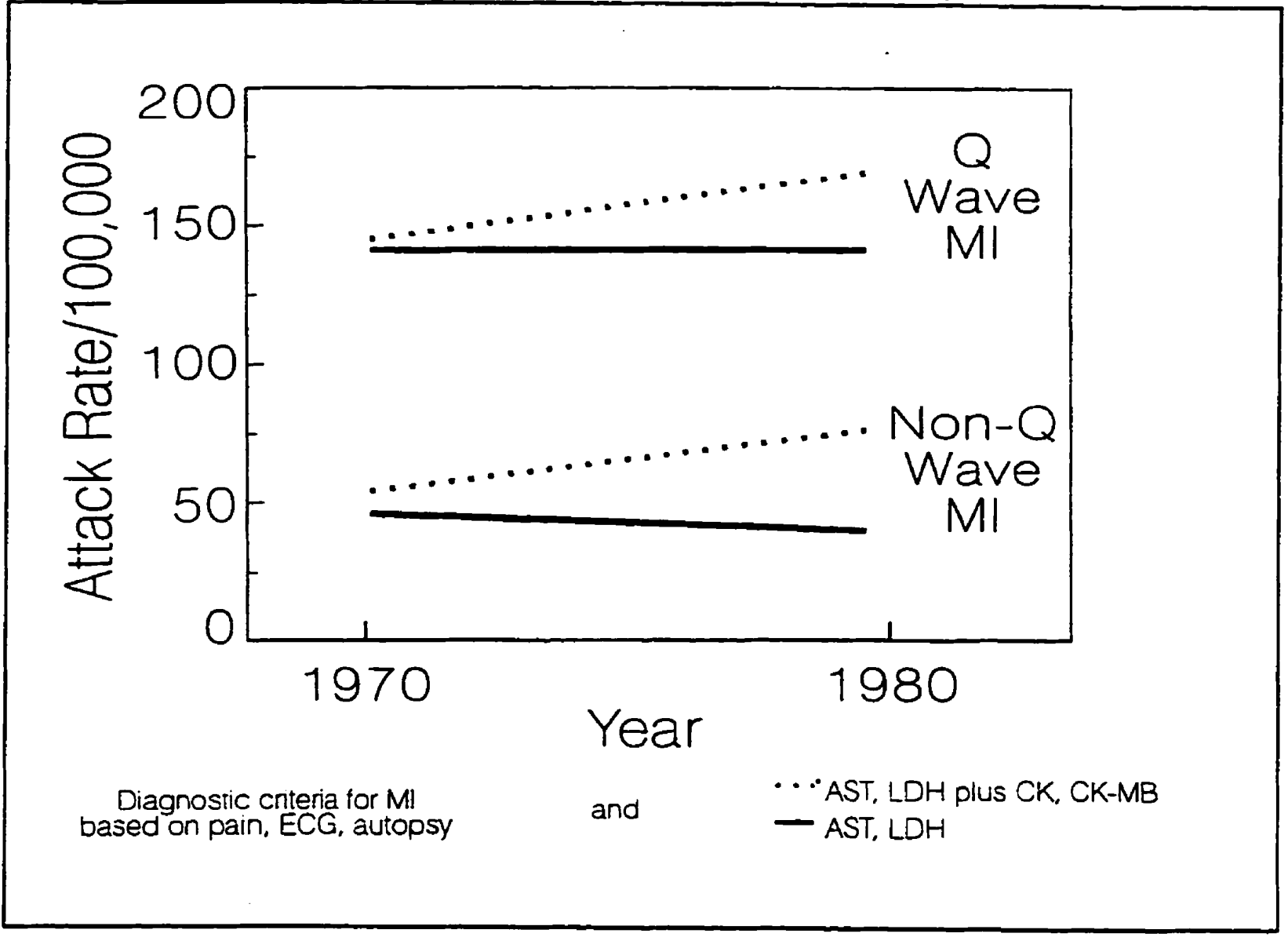

Plot of acute myocardial infarction (MI) attack rates (per 100,000 people) demonstrating the impact of more sensitive cardiac enzymes (creatine kinase [CK] and CK-MB; broken line) as compared to less sensitive markers (solid line) on secular tends. Inclusion of the more sensitive enzymes that were available in 1980 had a larger impact on trends of non- $Q$ wave $M I$ attack rates than on $Q$ wave rates. Adapted from Edlavitch et $\mathrm{al}^{125}$ 
Despite concern about observed increases in incidence due to the utilization of more sensitive diagnostic testing, more recent studies (employing consistent and sensitive enzymatic criteria) do suggest a trend toward a rise in the occurrence of nonQ MI. ${ }^{7.8}$ Additional data from the Worcester study group ${ }^{7}$ during 1986, 1988, 1990, and 1991 suggested that the proportion of $Q$ and non- $Q$ wave $M l$ among 2,885 patients admitted to 16 hospitals was $49 \%$ and $51 \%$, respectively (see Figure 6 ). A study from the U.S. military health care system ${ }^{8}$ also identified a significant shift in the relative incidence of $Q$ and non- $Q$ wave $\mathrm{Ml}$ from 1985 to 1990 ( $p<0.001$; see Figure 9 ). Although the percentage (26\%) of patients with coronary heart disease presenting with MI remained unchanged during these time periods, $Q$ wave Mls accounted for $15 \%$ of admissions in 1985 but only $7.5 \%$ in 1990 (a 48\% decrease). Non-Q wave $\mathrm{Ml}$ showed a reciprocal change increasing from $11.4 \%$ to $18 \%$ (a $43 \%$ increase). While the authors did not report on in-hospital case fatality rates by type of infarct, the overall mortality rate decreased by $44 \%(p<0.002)$ during the study period. 
FIGURE 9 - The U.S. Military Study

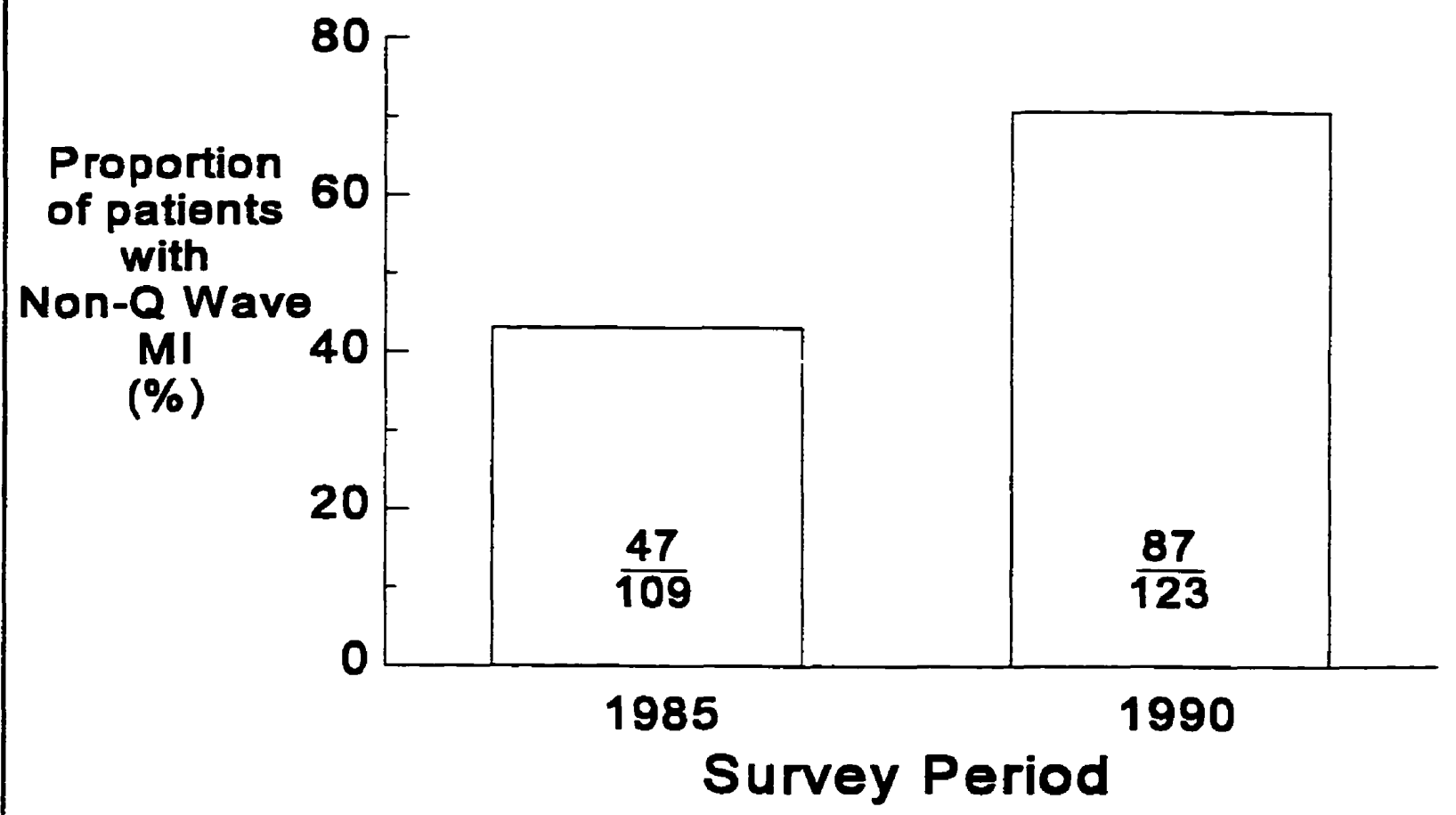

The proportion of patients presenting to Brooke Army Medical Center, Fort Sam Houston, Texas, U.S. with non-Q wave myocardial infarction (MI) during the first eight months of the calendar years 1985 and 1990 suggesting an increase over time (despite identical clinical, electrocardiographic, and enzymatic methods of diagnosing MI). The numerator and denominator within each bar refer to the number of patients sustaining a non- $Q$ MI and the total number of MI patients studied, respectively. Adapted from Wellford et $\mathrm{al}^{8}$ 
The Potential Impact of Thrombolytic Therapy on the Development and Prognosis of Non-Q Wave Infarction

While the reason(s) for the apparent rise in the development of non- $Q$ wave $M I$ (and concomitant decrease in the rate of $Q$ wave infarction) are uncertain, it has been suggested that more widespread use of thrombolytic therapy (in the late 1980s) in patients who present with chest pain and ST segment elevation has led to more frequent development of non-Q wave MI.-11 The early administration of thrombolytic agents produces partial recanalization of a total thrombotic coronary occlusion, which then culminates in an "aborted" or "interrupted" infarction. The net effect of such therapy is a reduction in the magnitude of myocardial necrosis in patients whose acute MI was destined to be more extensive, with the subsequent development of $Q$ waves, in the absence of early coronary reperfusion. ${ }^{127}$

Electrocardiographic evolution of $Q$ waves (or $Q$ wave equivalents) following thrombolytic administration has been documented in a small number of patients (see Table 7, Chapter 4). Early studies evaluated the impact of thrombolysis on the depth and number of $Q$ waves and the amplitude of $R$ waves (with a significant loss of $R$ wave amplitude being considered a $Q$ wave equivalent in certain ECG leads). ${ }^{128-131} \mathrm{~A}$ significant reduction in the number of $Q$ waves and preservation of $R$ wave amplitude was demonstrated following administration of thrombolytic therapy as compared to a placebo in two and three studies, respectively. ${ }^{130-132}$

More recent studies suggest that the development of non- $Q$ wave $M l$ occurs in $10.4 \%$ to $43 \%$ (see Table 8, Chapter 4 ) in the setting of thrombolysis, ${ }^{4.558,133-145}$ particularly in those patients who achieve early and sustained infarct-related artery patency. The subsequent prognosis of non- $Q$ wave $M I$ patients following thrombolytic therapy remains uncertain with the majority of studies not reporting on clinical outcomes, ${ }^{4.5 .133-139}$ some suggesting similar outcome when compared with $Q$ wave MI, ${ }^{140,141.144 .146}$ and other reports suggesting either higher reinfarction ${ }^{142.145}$ and/or mortality $^{142}$ or lower mortality ${ }^{143,145}$ rates among the non-Q wave group. ${ }^{142}$

Unfortunately, evaluation of the impact of thrombolytic therapy on the rate of 
non- $\mathrm{Q}$ wave $\mathrm{Ml}$ development and subsequent prognosis based on the abovementioned studies is severely limited by the lack of a placebo group in all but four studies..$^{5.133,134,139}$ Limitations of these studies include small sample size, lack of standardized timing of ECG classification and $Q$ wave definitions, and failure to report on clinical outcomes. Particularly since non- $Q$ wave $M I$ in the pre-thrombolytic era has been reported in up to $23 \%$ of patients presenting with ST segment elevation, ${ }^{63}$ it is difficult to interpret studies in the thrombolytic era without a control group for comparison. While the value of thrombolysis in patients with acute MI and ST segment elevation is well established, ${ }^{147}$ there is some concern that the interrupted or aborted non- $Q$ wave $\mathrm{Ml}$ following thrombolytic administration may be analogous to the incomplete, "naturally occurring" non- $Q$ wave $M l$ that results from spontaneous thrombolysis. ${ }^{10,148}$ The conceptual link between the naturally occurring and pharmacologically reperfused non-Q wave MI suggests that the initial coronary reperfusion associated with myocardial salvage will contribute to a more favourable short-term prognosis as compared with $\mathrm{Q}$ wave $\mathrm{MI}$. However, the patent but residually stenotic infarct-related artery may result in a higher late cardiac event rate unless pharmacologic thrombolysis can reduce the remaining thrombotic burden and contribute to the healing and remodelling of the ruptured coronary artery plaque. Indeed, despite successful reperfusion with thrombolysis and aggressive use of antithrombotic therapy (e.g., heparin and aspirin) and revascularization (angioplasty or bypass surgery), reinfarction or death occurs in 15\% of patients during 1 year follow-up, respectively. ${ }^{149}$ Whether the patients with non-Q wave $\mathrm{Ml}$ account for the majority of the subsequent cardiac events is unknown. 


\section{CHAPTER THREE}

\section{Outline of Chapter Three}

The purpose of this chapter is to:

1. Outline the rationale for review of non- $Q$ vs. $Q$ wave infarction in the prethrombolytic era;

2. Describe the methods for selection and analysis of studies in the prethrombolytic era;

3. Describe the results of the analyses of short-and long-term outcome in studies from the pre-thrombolytic era;

4. Discuss the similarities and differences of these results as compared to previous analyses;

5. Discuss the limitations of the previous and current analyses.

\section{LITERATURE REVIEW}

Rationale for Review of Non-Q and $Q$ Wave Infarction in the Pre-Thrombolytic Era Despite initial reports from the 1960s suggesting that the prognosis following a non-Q wave MI was excellent, ${ }^{67,68}$ several studies in the 1970 s led many authors to conclude that the "mild coronary" 69 without $Q$ waves was not as benign as originally believed. Following publication of studies indicating higher rates of reinfarction and equivalent or worse subsequent mortality among non- $Q$ as compared to $Q$ wave $M I$ patients, ${ }^{73-75}$ numerous editorials challenged the "myth" of the uncomplicated course of non-Q wave MI. ${ }^{150-152}$ Many review articles and editorials published in the 1970s, 1980s, and early 1990 s reached similar conclusions regarding the prognosis of non- $Q$ wave MI. 2.3.9.11.14.46,51.52.105.153-164 Unfortunately, while many of these publications identified the confusion surrounding the pathologic (transmural vs. nontransmural) and electrocardiographic ( $Q$ vs. non- $Q$ wave) classifications of $M I$, they often failed to address these differences when comparing the outcomes from different studies. While some reviews discussed the limitations of pooling event data from apparently heterogenous studies, ${ }^{1-3}$ only on $e^{162}$ specifically addressed the methodologic quality or 
excluded studies that lacked appropriate patient selection (clinical, electrocardiographic, and enzymatic) criteria. Unfortunately, Andre-Fouet et al ${ }^{162}$ did not outline the method of identification and selection of studies included in his review. Further, the most recent studies in the review were published in 1987; several additional studies describing outcomes in a further 8000 patients have since been published. ${ }^{115-117.165-176}$ Therefore, a systematic review, critical appraisal, and metaanalysis were undertaken.

\section{Pre-thrombolytic Era}

\section{Article Selection}

The English-language medical literature was searched for articles that compared mortality and/or reinfarction rates after $Q$ and non- $Q$ wave myocardial infarction. Articles were found through a MEDLINE search (from January 1966 through June 1995) by using as search terms the Medical Subject Headings (MeSH) "myocardial infarction," "myocardial infarction mortality," "myocardial infarction complications," and the textwords "transmural," "non-transmural," "subendocardial," "q wave," and "non-q wave." Another source of articles included the reference lists of all articles obtained to identify additional research not found in the computerized bibliographic database searching.

\section{Study Inclusion and Exc/usion Criteria}

Articles were included if follow-up information was reported and study entry criteria included specific information that stated or allowed for $Q$ and non- $Q$ wave $\mathrm{MI}$ classification. Earlier studies describing "transmural" and "non-transmural" or "subendocardial" were included if the definition allowed for a $Q /$ non-Q classification. The clinical, electrocardiographic, and enzymatic eligibility criteria for the studies varied considerably; however, cases in which the myocardial infarction. was self-reported or not defined by some type of typical symptom(s), serial ECG changes, and/or enzyme elevations were excluded. Studies published in abstract form only, ${ }^{76.177-179}$ with an

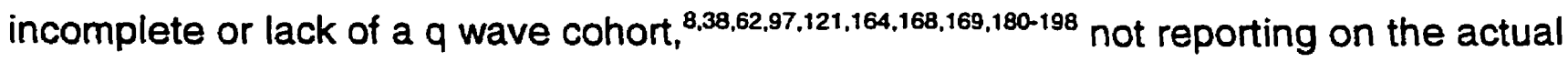
number of patients with non-Q and $Q$ wave $M I$ and/or lacking clinical follow- 
up, $8,63,69,77,109,118,164,195,199-212$ containing patients reported in another publication for a similar study endpoint, ${ }^{38.119 .165,193-195.204 .213-222}$ conducted in an outpatient setting, ${ }^{223-228}$ in which ECG classification of infarct type was undertaken less than 24 hours, ${ }^{68,229,230}$ or containing patients who received thrombolytic therapy ${ }^{56,231-234}$ and/or underwent revascularization ${ }^{56}$ for treatment of the acute $\mathrm{Ml}$, were excluded.

Studies included in the overview were then further subjected to methodologic quality assessment with emphasis on patient selection (clinical, electrocardiographic, and enzymatic) criteria. A select group of studies without any ambiguity in selection criteria and excluding: (1) clinical trials examining medical therapy; (2) populationbased studies with age-adjusted event rates; (3) studies where patients had to survive CCU or hospital discharge to be selected; (4) studies where all patients had to routinely undergo specific investigation (e.g., invasive or non-invasive testing) to be selected; and (5) studies with non-consecutive enrollment or utilizing a matched cohort, were identified for repeat analysis. The abovementioned studies were excluded from the select meta-analysis since they would be more likely to introduce bias. For example, clinical trials evaluating the impact of one or more medical treatments on patient outcome have specific patient entry criteria (e.g., limitations on age, exclusion of patients with certain comorbid factors) that would tend to select a very homogenous but non-representative group of $Q$ vs. non- $Q$ wave $M I$ patients, thus reducing the generalizability of the results to the general MI population. Further, some medical treatments have been shown to reduce reinfarction and/or mortality (e.g., beta-blockers as compared with placebo in patients with $Q$ wave $\mathrm{MI}$ ) and would potentially confound an analysis of outcomes between $Q$ and non- $Q$ groups.

As a history of prior $\mathrm{Ml}$ is often more frequently seen among non- $Q$ as compared to $Q$ wave patients, ${ }^{2}$ studies were also stratified according to whether or not prior MI was an exclusion criterion.

\section{End Point Definition}

In most reports the outcomes were in-hospital and/or post-discharge. A smaller number of studies included outcomes among coronary care unit or hospital survivors 
(mean duration usually not reported). ${ }^{171.172,174,175,235-243}$ Short and long term follow-up studies included both in-hospital and post-discharge event rates where available. In other words, the analyses considered all deaths and reinfarctions, and not just those events in patients who survived to hospital discharge. Arbitrarily, a short term study was defined as a trial with at least three months follow-up and a long term study as a trial with greater than three months follow-up. The main end points of the analyses were short term mortality and reinfarction.

In some studies evaluating short-term outcome, the end points were mortality in the coronary care unit, ${ }^{80,108.112}$ in the first 15 days, ${ }^{167}$ in the first 21 days, ${ }^{120,244}$ in the first 28 days, ${ }^{245}$ at 30 days, ${ }^{107.111}$ or at three months. ${ }^{235}$ In-hospital and post-discharge reinfarction was also reported in a number of studies, with some evaluating short term rates at 15 days, ${ }^{167} 21$ days, ${ }^{120}$ or three months. ${ }^{235}$ Reinfarction was defined by reelevation of cardiac enzymes in most short term studies and chest pain and typical electrocardiographic changes with enzymatic criteria (if available) in most long term studies. The majority of studies evaluating long term outcomes included follow-up beyond 1 year; some reports evaluated outcomes at six ${ }^{120}$ and nine months. ${ }^{114}$

For the purposes of calculating event rates and relative risk, age-adjusted mortality and reinfarction rates reported by individual studies ${ }^{6,107,111.125}$ were "converted" to an absolute number of events based on the absolute number of patients in the study population. In other words, in studies where the absolute (unadjusted) number of events were not provided, an "estimated" number was calculated by multiplying the percentage of the (age-adjusted) event rate published by the absolute number of patients. No attempt was made to solicit missing, ambiguous, or more recent data from the authors of the studies.

The vast majority of studies failed to comment upon the number of patients lost to follow-up; in order to be consistent across the studies, no adjustment in event rates was made, even in those studies where this data was reported.

\section{Data Analysis}

The relative risk of death and reinfarction (with $95 \%$ confidence intervals) were 
calculated for all short and long term studies. The method described by Greenland and Robins ${ }^{246}$ was used to test for homogeneity under the null hypothesis that the relative risks were consistent across studies. The corrected Mantel-Haenszel chi-square tes ${ }^{247}$ ( 1 degree of freedom, two-tailed) was used to test whether the relative risks differed systematically from a value of 1 . In addition, a simple combined analysis (including those studies where no events occurred and therefore a relative risk for the individual study could not be calculated) similar to the method employed by Gibson in previous analyses ${ }^{1-3}$ was undertaken for short and long term mortality and reinfarction.

In view of the wide range of long term trials follow-up, the studies in the current analysis were also stratified according to the number of months of follow-up (4-12 months, $13-35$ months, and $\geq 36$ months).

\section{Results - Pre-Thrombolytic Era}

Study Selection

The studies included in the present review are listed in Table 3 (short-term mortality), Table 4 (short-term reinfarction), Table 5 (long-term mortality), and Table 6 (long-term reinfarction). Most were single center studies; some included patients from two or more hospitals ${ }^{79,81,123,165,172,237,244,248}$ or were community/population

based. $6,107,110,111.125,238$ Eight studies were randomized clinical trials examining the use of medical therapy. ${ }^{116.167,173,175,176,242,243,249}$

Several studies excluded patients with previous infarction. . $^{80,95,106,107,111,116,123,166,170,172,173,175,176,237,239,244,249-252}$ Several studies also excluded older age groups: $>60$ years, ${ }^{80}>65$ years, ${ }^{78,238,241}>66$ years, ${ }^{61}>69$ years, ${ }^{176,242} 70$ years, ${ }^{106,120,172}>74$ years, ${ }^{249}>75$ years, ${ }^{167,237}>76$ years, ${ }^{116,173}$ and $>80$ years of age. ${ }^{170,175}$ Two studies excluded women. ${ }^{80,253}$ 


\begin{tabular}{|c|c|c|c|c|c|c|c|c|c|c|}
\hline (0) 0 & 82 & $(1,9) z 2$ & OEt & กวo-ut & soh & กอง & uleds 'euojojdeg & $18 \cdot G L 61$ & 8861 & 0.1100 \\
\hline$(g z t) \theta$ & 86 & $(9 \cdot 1 z) \triangleleft z$ & 111 & $\mid$ |E||dsou-U| & ou & nכo & pugksew 'ejowilleg & pepodes lou & SL61 & ${ }_{106 \mid y}$ \\
\hline$(6,1) 1$ & $0 L$ & $(Z 11) 6 Z$ & 692 & $\mid$ |e|dsou-U| & ou & กวว & pueperZ MeN 'eusnoqlow & $8 \angle \cdot 6 \angle 61$ & 0861 & cillexog \\
\hline$\left(g^{\prime} g\right) /$ & 81 & $(1: s+) 12$ & $6 \mathrm{EI}$ & |ri|dsou & ou & s|घ||dsou & ResJer MeN 'UOSJejed & $b \angle 61$ & $6 \angle 61$ & :powuty \\
\hline (0) 0 & 19 & $(1.8) 81$ & $\varepsilon 2 z$ & $|8||d s o y-u|$ & $\operatorname{sen}$ & noo & PUEjEeZ MON 'elunoqIOW & $8 L-\varepsilon \angle 61$ & 2861 & 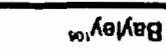 \\
\hline$\left(0^{\circ} 6\right) 9$ & $\angle 9$ & $(z \cdot 0 z) 9 z$ & 621 & กวว.แI & ou & กכร & 'sseW 'บ0180日 & $L L \cdot L 61$ & 1861 & 2uselnH \\
\hline$\left(g^{\prime} 91\right)_{62}$ & $\theta \angle 1$ & (1.11) IS & $65 b$ & frudsoy-ul & ou & กอכ & BU\|OJEJ 4HON 'WrUna & $\angle L-1<6 !$ & 0861 & ithuourw \\
\hline$(z \varepsilon) \bullet$ & $\forall \boldsymbol{t Z I}$ & $(1 \cdot 11) 69$ & 129 & |Bu|dsou-U| & $\operatorname{sen}$ & sกวo & Hnossiw' $\operatorname{sino7}$ is & $9 \angle \cdot 1<61$ & 0861 & se10JEABUEYL \\
\hline$\left(S^{\prime} L\right) \varepsilon$ & $0 t$ & $(2 \cdot 9 l)$ bz & 861 & $|8||d s 04-U|$ & ou, & |E\|||dsou & Inפ|DOUUOJ 'UEABH MEN & $1 \angle \theta t$ & $9 \angle 61$ & \&4houreว \\
\hline$\left(b^{\prime}\langle 1) 09\right.$ & $9 D E$ & $(g, 11)$ OEL & 2211 & $|e \|| d s 0 y-u \mid$ & ou & s|E\||dsou & 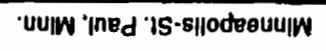 & $0861: 0<61$ & 1661 & 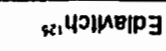 \\
\hline$\left(\varepsilon^{\prime} 6\right)$ & Eb & $(0.01) 9$ & 10 & |ej|dsou-u| & sex & กอง & 'SSEW 'UOISOB & $2 \angle \cdot 0<6 \downarrow$ & $\forall<6 !$ & $e^{\text {salpew }}$ \\
\hline (0) 0 & 8 & (0) 0 & ZS & $\mid$ |E\|dsou-u| & $\operatorname{sen}$ & กכo & YHOR MON'Y10人 MON & $0<61$ & $\varepsilon \angle 61$ & menumis \\
\hline$(0.9) \varepsilon$ & 09 & $\left(\theta^{\prime} 2 z\right)<\varepsilon$ & 291 & $|B||d s o u-t| \mid$ & sen & |8||dsou & AEMUON 'UEPIS & peuodes jou & $0 \angle 61$ & $m \cup 0859 \mu \mathrm{J}$ \\
\hline (0) 0 & 2s & $\left(l^{\prime} \cdot 8 z\right) 91$ & ss & |E्|dsou-U! & ou & กวo & A|By 'esid & 58.6961 & 9861 & $.8^{\theta 18 q 99.7}$ \\
\hline$(\varepsilon \cdot g l) \varepsilon l$ & 98 & 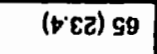 & $8 \angle 2$ & shep oE & sex & tol|E|ndod & 'ssew' 'urgubu|urests & $\angle 8.8961$ & 2661 & $i^{106 / \theta g}$ \\
\hline$(1 \cdot 2 z) 81$ & 82 & $(1 ' 61) 62$ & $2 \xi \mathfrak{l}$ & $|E \|||d s 04-U|$ & $\operatorname{sen}$ & กวอ & 'IIIEJ 'OJS|JURIJ UES & $0 L-8961$ & $\varepsilon \angle 61$ & 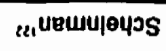 \\
\hline$(0.61) 91$ & $D 11$ & $\left(\theta^{\prime} 61\right)$ be & $1<1$ & |zudsou-4| & ou & กอง & 'SsEW 'UOIsog & pejodes lou & $\angle 961$ & QUMO \\
\hline$(8.61) 99$ & 682 & $\left(8^{\circ} 92\right)$ ssz & 656 & |endsou-U| & ou & g(e)dsou & 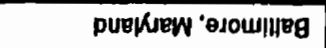 & $1 \angle 61: \angle 9 \cdot 9961$ & $8 \angle 61$ & 011 oprzs \\
\hline$(L L) 16$ & 201 & $\left(b^{\prime} c z\right) \perp 9 b$ & $0 \angle 61$ & SRep IZ & ou & s|E\|ddsou & |OEJS| & 9961 & SLBI & $m e^{1040 S}$ \\
\hline$(9 \cdot 8) 8 E$ & ott & $\left(L^{\prime} 81\right) 0 \angle 1$ & $\angle 0 B$ & sfep os & ou & $8 \mid \mathrm{B} \| \mathrm{ds} 04$ & 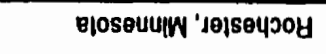 & $6 L \cdot 0961$ & $586 t$ & ${ }_{10 .}$ A Anoutos \\
\hline$\left(g^{\prime} b\right) \geq$ & $\omega$ & $\left(\varepsilon^{\prime} L Z\right) 69$ & 912 & sfep 82 & pepodes lou & |lendsoy & pur|loss 'Mo6sejo & 19.8961 & 2961 & ind $100 \mathrm{~d}$ \\
\hline (\%) sul1800 & $u$ & $(\%)$ sujeed & u & & & & & & & \\
\hline SABM O- & & BABM & & & & & & & & \\
\hline \multicolumn{4}{|c|}{ sivelsed lo sequinn } & dn.Molloy & enpoedsosd & บ0|185007 & N110 & (s)pop酎 (pnis & 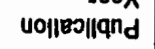 & touाn $\forall|s| y$ \\
\hline
\end{tabular}

र!! 


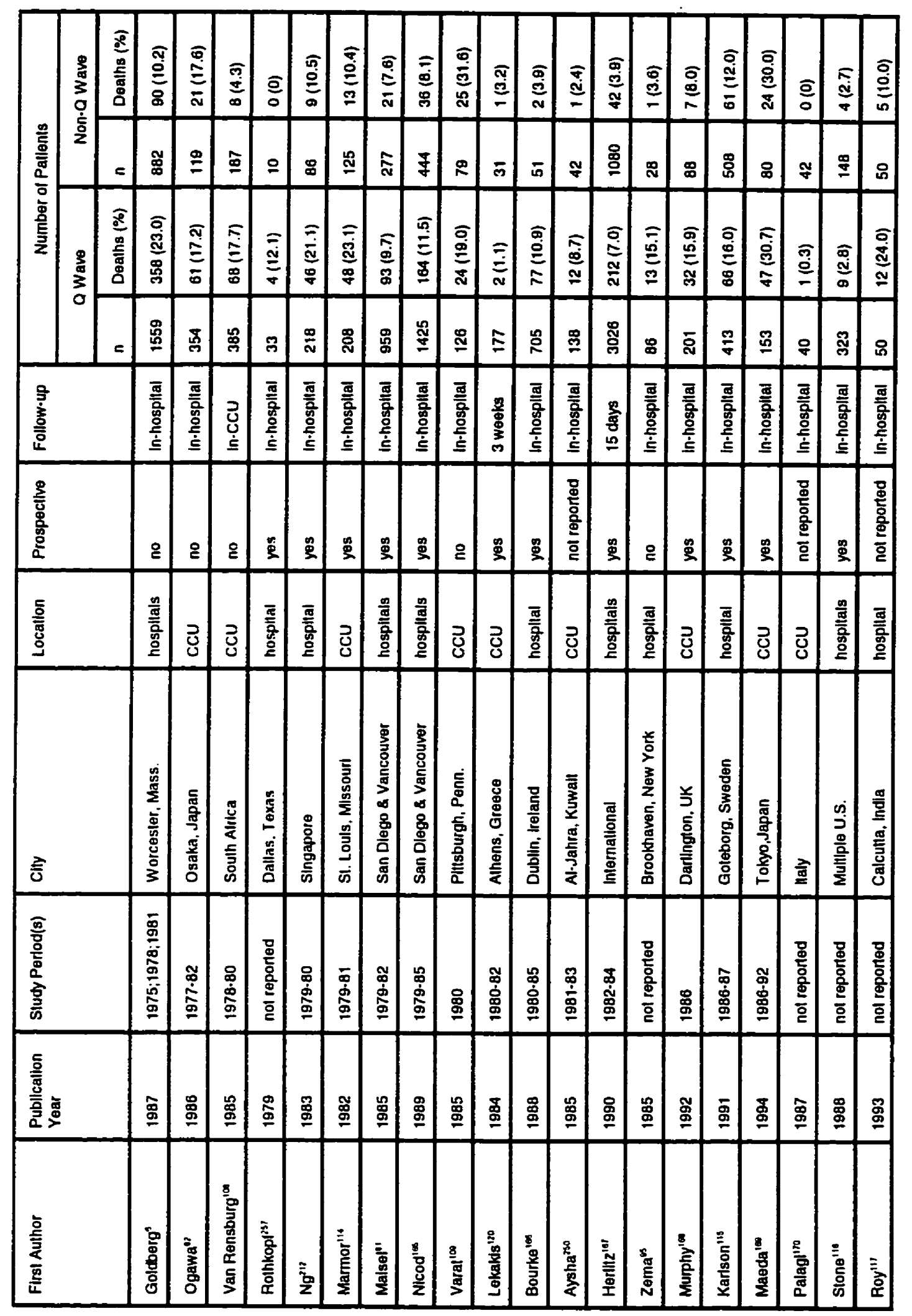


TABLE 4 - Short Term Reinfarction

\begin{tabular}{|c|c|c|c|c|c|c|c|c|c|c|}
\hline \multirow[t]{3}{*}{ First Author } & \multirow{3}{*}{$\begin{array}{l}\text { Publication } \\
\text { Year }\end{array}$} & \multirow{3}{*}{$\begin{array}{l}\text { Study } \\
\text { Perlod }\end{array}$} & \multirow[t]{3}{*}{ Clity } & \multirow[t]{3}{*}{ Location } & \multirow[t]{3}{*}{ Prospective } & \multirow[t]{3}{*}{ Follow-up } & \multicolumn{4}{|c|}{ Number of Subjects } \\
\hline & & & & & & & \multicolumn{2}{|r|}{ Q Wave } & \multicolumn{2}{|c|}{ Non-Q Wave } \\
\hline & & & & & & & $n$ & Reinfarctions (\%) & $n$ & Reinfarctions (\%) \\
\hline L'Abbate ${ }^{23 t}$ & 1986 & $1969-85$ & Pisa, Italy & $\mathrm{CCU}$ & no & in-hospltal & 55 & $6(10.9)$ & 52 & $0(0)$ \\
\hline Lofmark ${ }^{235}$ & 1979 & $1972-76$ & Huddinge, Sweden & $\mathrm{ccu}$ & not reported & 3 months & 229 & $25(10.9)$ & 191 & $32(16.8)$ \\
\hline Boxal|"13 & 1980 & $1974-78$ & Melbourne, New Zealand & $\mathrm{ccu}$ & no & in-hospital & 259 & $3(1.2)$ & 70 & $5(7.1)$ \\
\hline Rothkopf ${ }^{257}$ & 1979 & not reported & Dallas, Texas & hospital & yes & in-hospital & 33 & $8(24.2)$ & 10 & $2(20.0)$ \\
\hline Marmor 114 & 1982 & 1979.81 & St. Louls, Missouri & $\mathrm{CCU}$ & yes & in-hospltal & 208 & $21(10.1)$ & 125 & $43(34.4)$ \\
\hline Malsel|" & 1985 & $1979-82$ & San Diego \& Vancouver & hospitals & yes & in-hospital & 959 & $58(6.0)$ & 277 & $23(8.3)$ \\
\hline Nicod' ${ }^{10 s}$ & 1989 & 1979.85 & San Dlego \& Vancouver & hospitals & yes & In-hospltal & 1425 & $86(6.0)$ & 444 & $31(7.0)$ \\
\hline Lekakis ${ }^{120}$ & 1984 & 1980-82 & Athens, Greece & $\mathrm{CCU}$ & yes & 3 weoks & 177 & $4(2.3)$ & 31 & $6(19.4)$ \\
\hline Bosch"1" & 1987 & $1982-84$ & Montreal, Quebec & $\mathrm{ccu}$ & yes & In-hospital & 291 & $12(4.1)$ & 158 & $19(12.0)$ \\
\hline Herlitz' & 1990 & $1982-84$ & International & hospitals & yes & 15 days & 3026 & $127(4.2)$ & 1080 & $69(8.4)$ \\
\hline Palagi|10 & 1987 & not reported & Italy & $\mathrm{CCU}$ & nol reported & in-hospital & 40 & $1(2.5)$ & 42 & $2(4.8)$ \\
\hline Roy"l' & 1993 & not reported & Calcutta, India & hospltal & not reported & in-hospital & 50 & $12(24.0)$ & 50 & $16(32.0)$ \\
\hline
\end{tabular}




\begin{tabular}{|c|c|c|c|c|c|c|c|c|c|c|c|c|c|c|c|c|}
\hline & 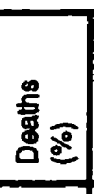 & 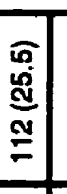 & & & & & & 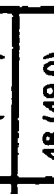 & 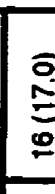 & & & & & & & 离 \\
\hline$\frac{\dot{c}}{\frac{c}{5}}$ & $c$ & $\frac{9}{9}$ & 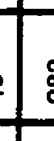 & 曲 & 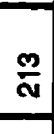 & 4 & $\overbrace{}^{2}$ & 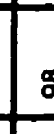 & $\Phi$ & $\underline{\mathscr{E}}$ & 하 & 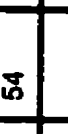 & B & 2 & 9 & $\Phi$ \\
\hline & 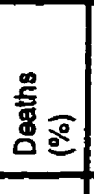 & 瓷 & 9 & 离 & $\underline{\underline{y}}$ & 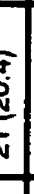 & 豙 & aَ & $\frac{\square}{\circ}$ & 高 & 戀 & $\stackrel{8}{0}$ & $\frac{8}{3}$ & & & 章 \\
\hline & $=$ & ఏ) & $:$ & $\frac{\Omega}{2}$ & $\frac{\infty}{7}$ & 3 & 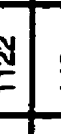 & 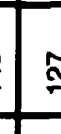 & $\stackrel{9}{9}$ & $\frac{8}{9}$ & ฐ & 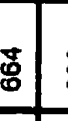 & $=$ & $g_{g}^{g}$ & $\equiv$ & 高 \\
\hline 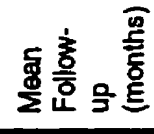 & & & 8 & : & @ & 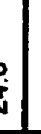 & 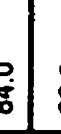 & 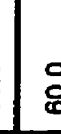 & $\stackrel{\circ}{\circ}$ & ঃ & 苞 & 范 & 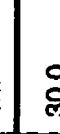 & & :๊ & 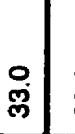 \\
\hline & & & & & & & & & $\stackrel{2}{2}$ & & 의 & & 5 & & 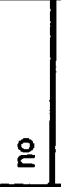 & 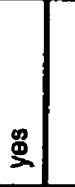 \\
\hline & & & & & & & & & נֶ. & 己े & : & $\bar{Z}$ & $\overline{0}$ & & & : \\
\hline 흘 & & & 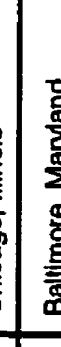 & & & & $\frac{1}{2}$ & 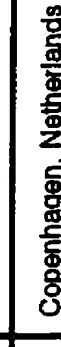 & 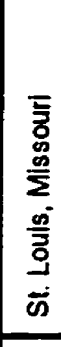 & 言| & & $\frac{\text { E }}{5}$ & 齒 & & & \\
\hline & & & & & & & 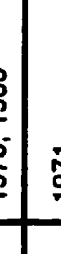 & $\mid \begin{array}{l}3 \\
\text { 音 }\end{array}$ & to & פ & 盯 & & $\Phi$ & & & \\
\hline 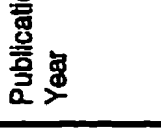 & & & $\frac{\sigma}{\sigma}$ & I兑 & 总 & & 1 & 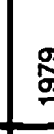 & 盢 & 总 & 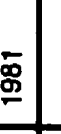 & & \begin{tabular}{|l}
$\frac{\mathscr{g}}{2}$ \\
\end{tabular} & & $\Phi$ & $\stackrel{\stackrel{\circ}{\circ}}{\square}$ \\
\hline & & & & & & & & & & & & & & & & \\
\hline
\end{tabular}


요

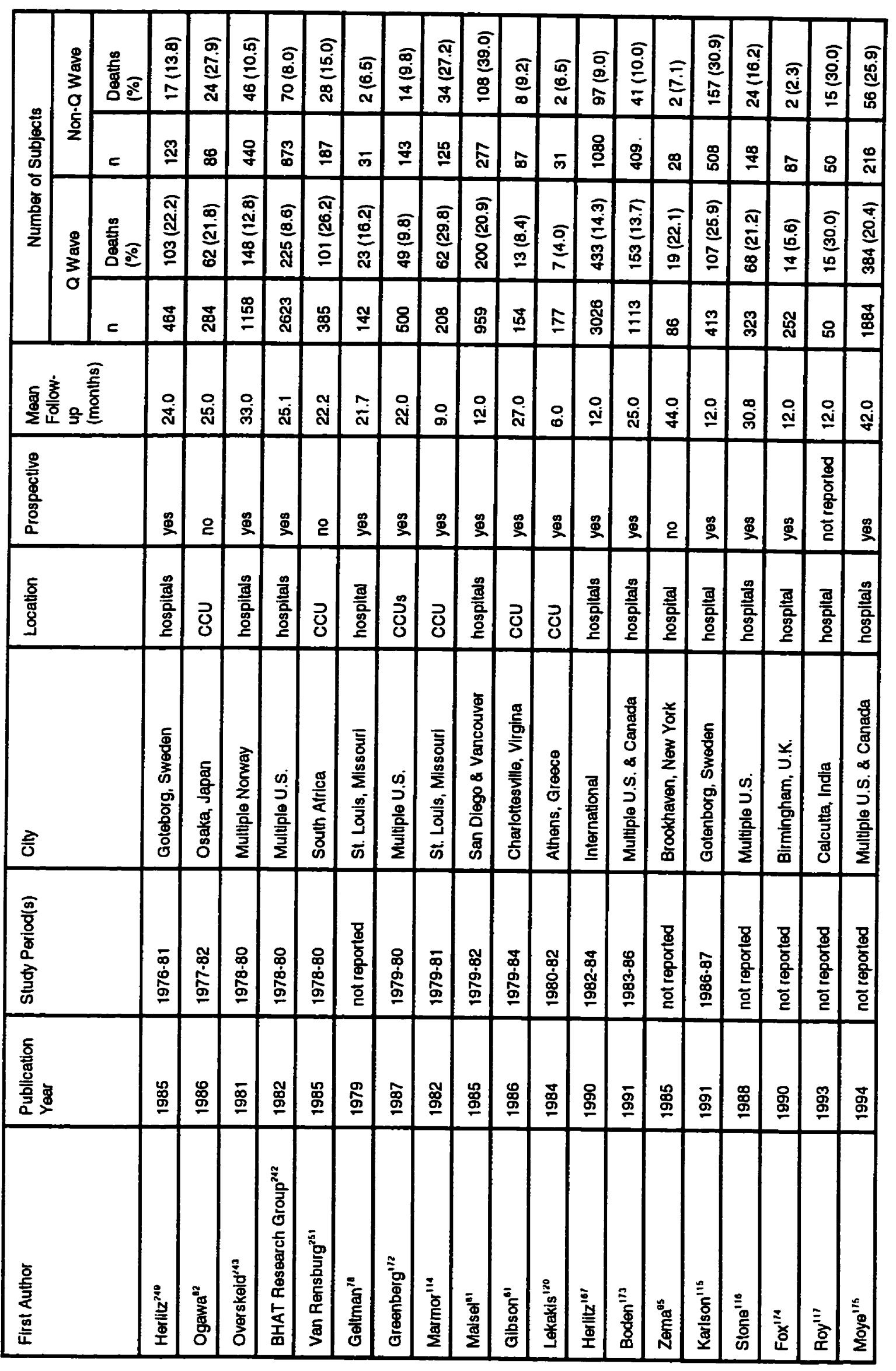


TABLE 6 - Long Term Reinfarction

\begin{tabular}{|c|c|c|c|c|c|c|c|c|c|c|}
\hline \multirow[t]{3}{*}{ First Author } & \multirow{3}{*}{$\begin{array}{l}\text { Publication } \\
\text { Year }\end{array}$} & \multirow{3}{*}{$\begin{array}{l}\text { Study } \\
\text { Period }\end{array}$} & \multirow[t]{3}{*}{ City } & \multirow[t]{3}{*}{ Location } & \multirow[t]{3}{*}{ Prospective } & \multirow{3}{*}{$\begin{array}{l}\text { Mean } \\
\text { Follow- } \\
\text { up } \\
\text { (years) }\end{array}$} & \multicolumn{4}{|c|}{ Number of Subjects } \\
\hline & & & & & & & \multicolumn{2}{|r|}{ Q Wave } & \multicolumn{2}{|c|}{ Non-Q Wave } \\
\hline & & & & & & & $n$ & Reinfarctions (\%) & n & Reinfarctions (\%) \\
\hline Berger ${ }^{\prime \prime \prime}$ & 1992 & 1968-87 & Framingham, Mass. & population & yes & 60.0 & 278 & $57(20.5)$ & 85 & $27(31.8)$ \\
\hline Cannom ${ }^{7 s}$ & 1976 & 1971 & New Haven, Connecticut & hospital & no & 36.0 & 148 & $10(6.8)$ & 40 & $5(12.5)$ \\
\hline Fabricius-Bjerre $\theta^{238}$ & 1979 & $1971-72$ & Copenhagen, Netherlands & hospital & no & 60.0 & 127 & $15(11.8)$ & 98 & $13(13.3)$ \\
\hline Krone $\theta^{23 r}$ & 1983 & $1971-75$ & St. Louis, Missouri & ccus & yes & 36.0 & 499 & $56(11.2)$ & 94 & $14(14.9)$ \\
\hline Hutter $^{112}$ & 1981 & $1971-77$ & Boston, Mass. & $\mathrm{ccU}$ & no & 28.6 & 129 & $3(2.3)$ & 67 & $38(56.7)$ \\
\hline Yukse/ $\left.\right|^{239}$ & 1994 & $1972-80$ & Istanbul, Turkey & $\mathrm{Ccu}$ & no & 57.6 & 664 & $90(13.6)$ & 54 & $5(9.3)$ \\
\hline Taylor ${ }^{211}$ & 1980 & $1974-76$ & Baltimore, Maryland & $\mathrm{cCU}$ & yes & 30.0 & 64 & $8(12.5)$ & 42 & $4(9.5)$ \\
\hline Boxall ${ }^{113}$ & 1980 & $1974-78$ & Melbourne, New Zealand & $\mathrm{ccu}$ & no & 31.0 & 259 & $29(11.2)$ & 70 & $10(14.3)$ \\
\hline Coll ${ }^{\circ 0}$ & 1983 & $1975-81$ & Barcelona, Spain & $\mathrm{CCU}$ & yes & 33.0 & 430 & $20(4.7)$ & 28 & $0(0)$ \\
\hline Norris ${ }^{250}$ & 1984 & $1977 \cdot 82$ & Auckland, Now Zealand & hospitel & yes & 72.0 & 236 & $24(10.2)$ & 88 & $14(15.9)$ \\
\hline Ogawa"2 & 1986 & $1977-82$ & Osaka, Japan & $\mathrm{CCU}$ & no & 25.0 & 284 & $8(2.8)$ & 86 & $11(12.8)$ \\
\hline Overskeld ${ }^{243}$ & 1981 & $1978-80$ & Multiple, Norway & hospitals & yes & 33.0 & 1158 & $129(11.1)$ & 440 & $48(10.9)$ \\
\hline Van Rensburg ${ }^{231}$ & 1985 & $1978-80$ & Soulh Africa & $\mathrm{CCU}$ & no & 22.2 & 385 & $46(11.9)$ & 187 & $33(17.6)$ \\
\hline Gheorghlade'178 & 1991 & $1978-80$ & Multiple U.S. & hospitals & yes & 36.0 & 1186 & $65(5.5)$ & 258 & $19(7.4)$ \\
\hline Marmor 114 & 1982 & 1979-81 & St. Louis, Missouri & $\mathrm{CCU}$ & yes & 9.0 & 208 & $21(10.1)$ & 125 & $53(42,4)$ \\
\hline Gibson ${ }^{61}$ & 1986 & $1979-84$ & Charlottesville, Virgina & $\mathrm{CCU}$ & yes & 27.0 & 154 & $10(6.5)$ & 87 & $16(18.4)$ \\
\hline Lekakis $^{120}$ & 1984 & 1980-82 & Athens, Greece & $\mathrm{ccu}$ & yes & 6.0 & 177 & $7(4,0)$ & 31 & $10(32.3)$ \\
\hline Aysha ${ }^{250}$ & 1985 & $1981-83$ & Al-Jahra, Kuwait & $\mathrm{CCU}$ & nol reported & 14.8 & 138 & $8(5.8)$ & 42 & $2(4.8)$ \\
\hline Herlitiz' & 1990 & 1982.84 & International & hospitals & yes & 12.0 & 3026 & $248(8.2)$ & 1080 & $135(12.6)$ \\
\hline Boden 1,3 & 1991 & 1983.86 & Multiple, U.S. \& Canada & hospitals & yes & 25.0 & 1113 & $128(11.5)$ & 409 & $53(12.6)$ \\
\hline
\end{tabular}




\begin{tabular}{|c|c|c|c|c|c|c|c|c|c|c|}
\hline \multirow[t]{3}{*}{ First Author } & \multirow{3}{*}{$\begin{array}{l}\text { Publlcation } \\
\text { Yoar }\end{array}$} & \multirow{3}{*}{$\begin{array}{l}\text { Study } \\
\text { Period }\end{array}$} & \multirow[t]{3}{*}{ City } & \multirow[t]{3}{*}{ Localion } & \multirow[t]{3}{*}{ Prospective } & \multirow{3}{*}{$\begin{array}{l}\text { Mean } \\
\text { Follow- } \\
\text { up } \\
\text { (years) }\end{array}$} & \multicolumn{4}{|c|}{ Number of Subjects } \\
\hline & & & & & & & \multicolumn{2}{|r|}{ Q Wave } & \multicolumn{2}{|r|}{ Non-Q Wave } \\
\hline & & & & & & & $n$ & Reinfarctions (\%) & $n$ & Reinfarctions (\%) \\
\hline Zema"s & 1985 & not reported & Brookhaven, New York & hospital & no & 44.0 & 86 & $6(7.0)$ & 28 & $3(10.7)$ \\
\hline Karlson"s & 1991 & $1986-87$ & Golenborg, Sweden & hospital & yes & 12.0 & 413 & $50(12.1)$ & 508 & $101(20.0)$ \\
\hline Stone $\theta^{116}$ & 1988 & not reported & Multiple, U.S. & hospltals & yes & 30.8 & 323 & $45(13.9)$ & 148 & $24(16.2)$ \\
\hline Fox ${ }^{1 / 4}$ & 1990 & not reported & Birmingham, U.K. & hospital & yes & 12.0 & 252 & $23(9.1)$ & 87 & $7(8.0)$ \\
\hline Roy"' & 1993 & not reported & Calcutta, India & hospital & not reported & 12.0 & 50 & $12(24.0)$ & 50 & $25(50.0)$ \\
\hline
\end{tabular}




\section{Short Term Mortality}

Forty-three studies were included in the analysis of short term mortality. In 6 studies, no deaths occurred in the $Q^{256}$ and/or non- $Q^{80.106,170,254,256,257}$ wave groups; these studies are included in the pooled but not in the meta-analysis (since a relative risk cannot be calculated). Thirteen studies reported lower mortality rates in non- $Q$ wave MI patients, ${ }^{6.107 .108,110.113 .114 .123 .165 .167 .212 .244 .245 .255}$ and two studies showed a significantly higher death rate among non- $Q$ wave $M ! .^{109.125}$ One study demonstrated a trend toward a higher mortality rate among non-Q as compared to $Q$ wave $M I$ patients; ${ }^{124}$ all of the remaining 25 studies observed either similar or a trend for lower mortality among non- $Q$ wave MI patients..$^{70,74,75,79-82,95,106,111,112,115-117.120 .122 .166 .168-170,250,254,256,257,259}$ The overall nonQ-to-Q wave relative risk for short term death was 0.68 ( $95 \%$ confidence intervals $(\mathrm{Cl})$ $0.63,0.75)$ (see Figure 10). However, there was a significant degree $(p<0.000001)$ of heterogeneity across the studies. 


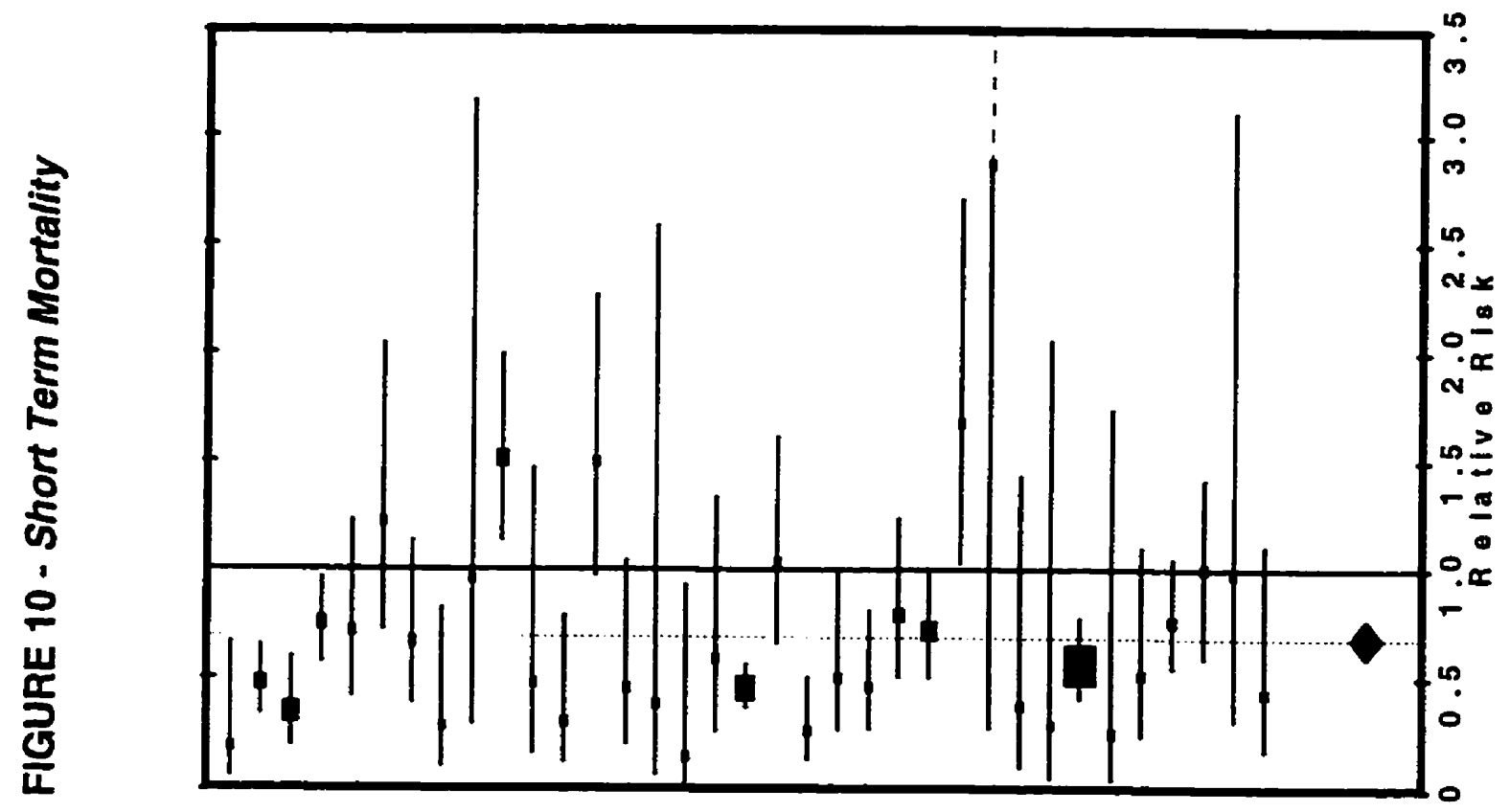

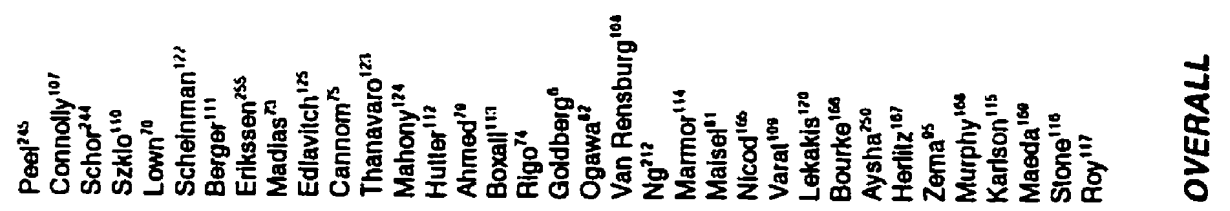




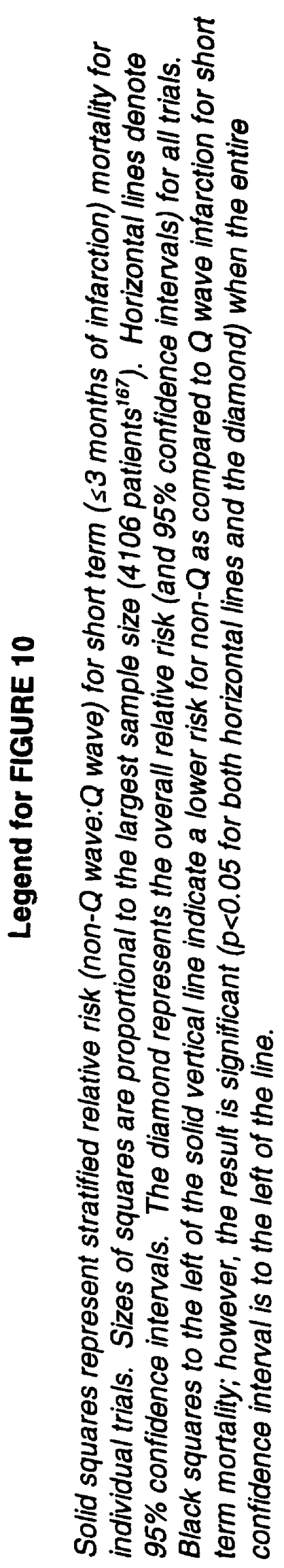


The meta-analysis was repeated stratifying the studies by those with $^{95,106,107,111,116,123,166,244,250}$ and without exclusion of patients with prior infarction. Short term mortality was lowest among non-Q wave Ml patients without prior infarction (42 of $588(7.1 \%$ ) vs. 179 of $1,230(14.6 \%$ ) Q wave without prior Ml; vs. 597 of 6,440 (9.3\%) non-Q vs. 2,716 of $17,967(15.1 \%) Q$ wave patients in studies that included patients with prior infarction). The non-Q-to- $Q$ wave relative risk for short term mortality was lower among patients in studies without prior infarction $(0.49 ; 95 \% \mathrm{Cl} 0.36,0.78$ vs. $0.65 ; 95 \% \mathrm{Cl} 0.60,0.71$ ).

Among the age-adjusted studies evaluating short term mortality, two studies ${ }^{6.107}$ demonstrated a significantly lower relative risk, one study ${ }^{111}$ found no difference in relative risk, and one study showed a significantly higher non-Q-to-Q relative risk. ${ }^{125}$

In the combined analysis of all patients in all short-term trials, 639 of 6,668 (9.6\%) non-Q and 2895 of 19,197 (15.1\%) Q wave MI patients died; the non-Q-to-Q wave relative risk for short term death was $0.64(95 \% \mathrm{Cl} 0.59,0.69)$ (see Figure 11).

When the meta-analysis was restricted to the select group of studies, ${ }^{75,81,82,110.113-115,123,124,168,169,212}$ the non-Q-to-Q wave relative risk for short term mortality was $0.77(95 \% \mathrm{Cl} 0.67,0.88)$. While less diversity was evident between studies in this analysis when compared to the unselected and combined analyses, the degree of heterogeneity remained statistically significant $(p=0.015)$. 


\section{FIGURE 11 - Combined Mortality}

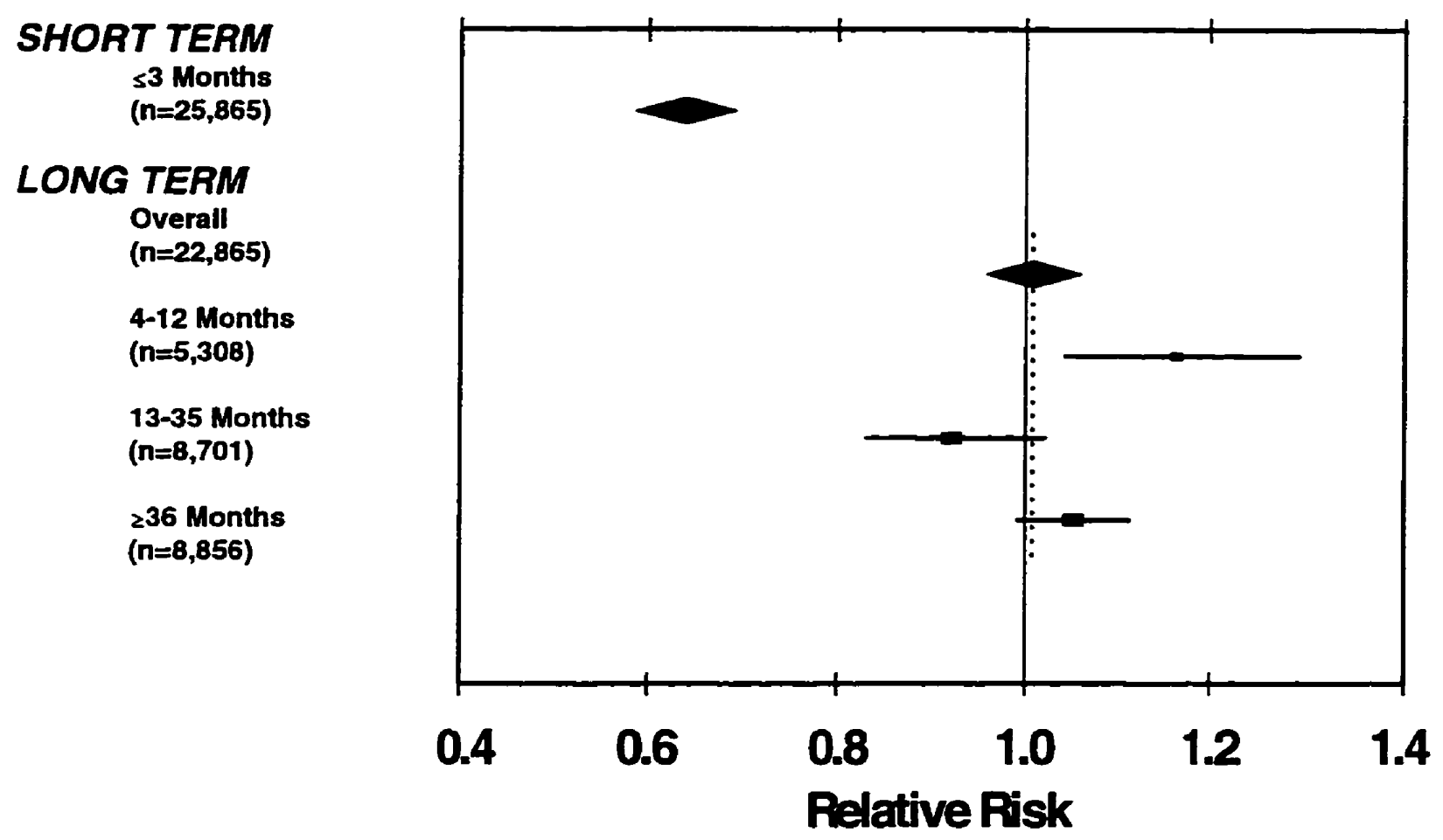

\section{Legend for FIGURE 11}

Solid diamonds represent the combined relative risk (non- $Q$ wave: $Q$ wave) and $95 \%$ confidence intervals for mortality among the short term ( $\leq 3$ months of follow-up postinfarction) and long term (overall) studies. Solid squares represent the combined relative risk for mortality among the long term studies (mean 4-12 months, 13-35 months, and $\geq 36$ months of follow-up). Sizes of squares are proportional to the combined long term sample size. Horizontal lines denote $95 \%$ confidence intervals. The diamond represents the overall relative risk for all trials. Diamond and solid squares to the left of the solid vertical line indicate a lower risk for non- $Q$ as compared to $Q$ wave infarction for short term mortality; however, the result is significant $(p<0.05$ for both horizontal lines and the diamond) when the entire confidence interval is to the left of the line. 


\section{Short Term Reinfarction}

Twelve studies were included in the analysis of short term reinfarction. Two series included only those patients who survived to hospital discharge. ${ }^{171.235}$ In 1 study, ${ }^{254}$ no reinfarctions occurred in the non- $Q$ wave group; this study was included in the pooled analysis but not the meta-analysis. In one study, ${ }^{235}$ reinfarction data was derived from a non- $Q$ wave patient cohort in which more than one recurrent $M I$ was counted as multiple events. Five studies reported higher reinfarction rates in non- $Q$ wave Ml patients; ${ }^{113,114,120.167,171}$ the remaining 6 studies observed either similar or a trend for higher reinfarction among non- $Q$ wave $M I$ patients. ${ }^{81,117,165,170,235,257}$ The overall non-Q-to-Q wave MI risk for short term reinfarction was $1.69(95 \% \mathrm{Cl} 1.44,1.99)$ (see Figure 12). However, there was a significant degree $(p<0.00006)$ of heterogeneity across the studies.

Only one study ${ }^{170}(n=82)$ excluded patients with prior infarction and the non-Qto- $Q$ wave relative risk for recurrent infarction was consistent with the results of the other studies $(1.90 ; 95 \% \mathrm{Cl} 0.18,20.20)$.

In the combined analysis, 248 of $2,530(9.8 \%)$ non-Q and 353 of $6,752(5.4 \%) Q$ wave $\mathrm{MI}$ patients had recurrent infarction; the non-Q-to-Q wave relative risk for short term reinfarction was $1.82(95 \% \mathrm{Cl} 1.56,2.13)$ (see Figure 13).

When the meta-analysis was restricted to the select group of studies, ${ }^{81.113 .114}$ the non-Q-to-Q wave relative risk for short term reinfarction was 2.27 (95\% Cl 1.64, 3.13; $p<0.000001)$. While less diversity was evident between studies in this analysis when compared to the unselected and combined analyses, the degree of heterogeneity remained statistically significant $(p=0.0024)$. 


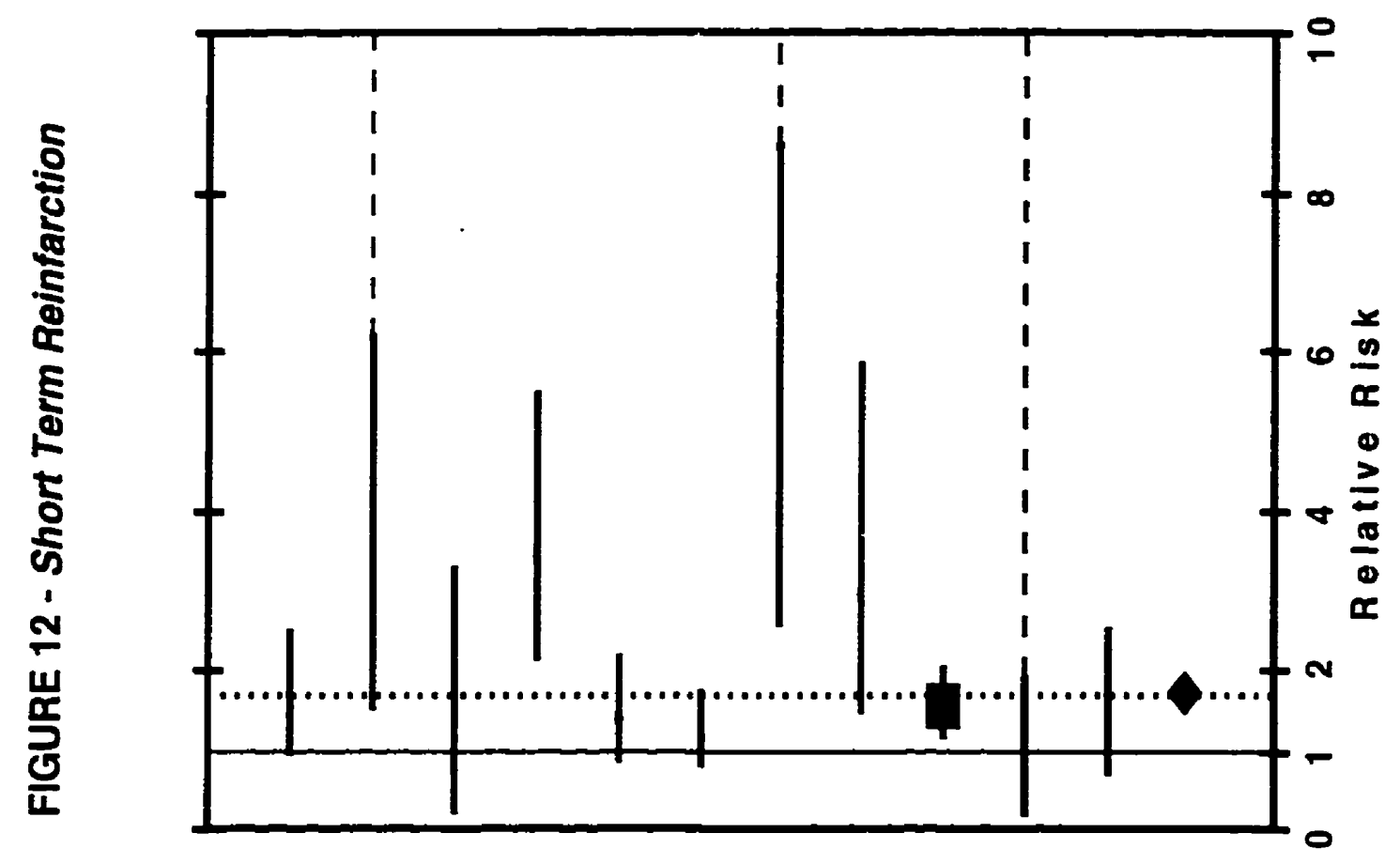

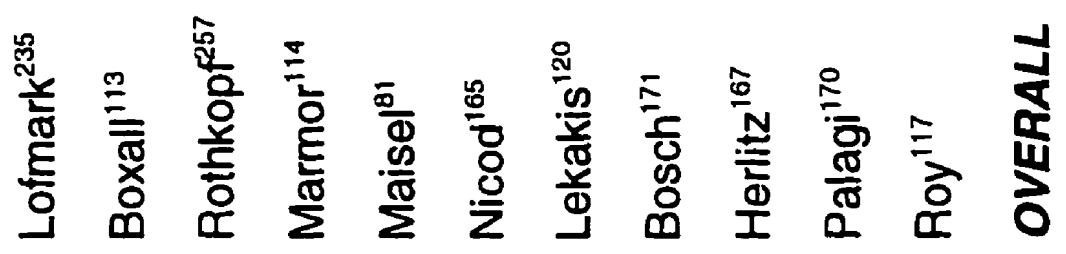




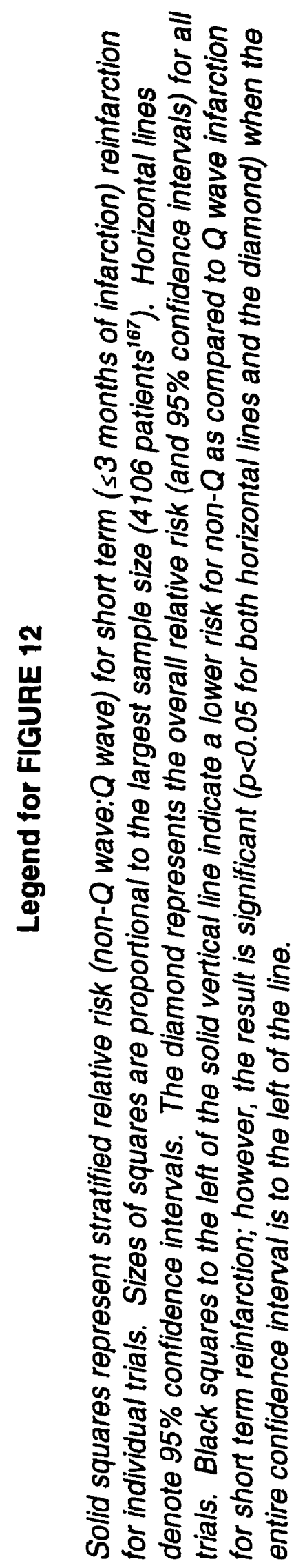


FIGURE 13 - Combined Reinfarction

\author{
SHORT TERM \\ s3 Months \\ ( $n=6,752$ ) \\ LONG TERM \\ Overall \\ $(n=11,787)$

\section{4-12 Months $(n=4,126)$} \\ 13-35 Months \\ $(n=4,437)$ \\ >36 Months \\ $(n=3,224)$
}

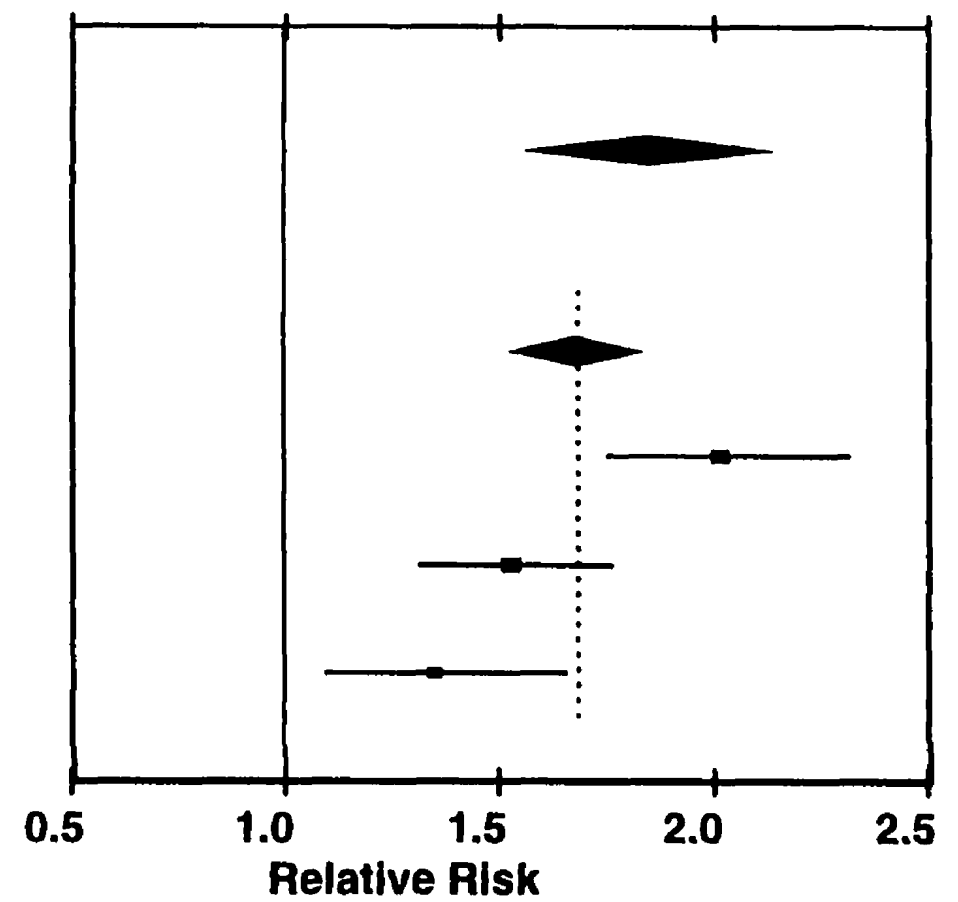

\title{
Legend for FIGURE 13
}

Solid diamonds represent the combined relative risk (non-Q wave: $Q$ wave) and $95 \%$ confidence intervals for mortality among the short term (s3 months of follow-up post-infarction) and long term (overall) studies. Solid squares represent the combined relative risk for mortality among the long term studies (mean 4-12 months, 13-35 months, and $z 36$ months of follow-up). Sizes of squares are proportional to the combined long term sample size. Horizontal lines denote $95 \%$ confidence intervals. The diamond represents the overall relative risk for all trials. Diamond and solid squares to the left of the solid vertical line indicate a lower risk for non- $Q$ as compared to $Q$ wave infarction for short term mortality; however, the result is significant $(p<0.05$ for both horizontal lines and the diamond) when the entire confidence interval is to the left of the line. 


\section{Long Term Mortality}

Thirty-eight studies with a mean follow-up range of 6-84 months were included in the analysis of long term mortality. Eleven series included only those patients who had survived to hospital discharge. ${ }^{172,174,175,236-243}$ Five studies reported lower long term mortality rates in non- $Q$ wave MI patients, ${ }^{107,167,238,249,251}$ and one study showed a significantly higher death rate among non- $Q$ wave $M 1{ }^{81}$ Four studies demonstrated a trend toward a higher long term mortality rate among non- $Q$ as compared to $Q$ wave $\mathrm{MI}$ patients; ${ }^{111,115,124.175}$ all of the remaining 28 studies observed similar or a trend for lower long term mortality among non- $\mathrm{Q}$ wave $\mathrm{MI}$

patients. $6,61,74,75,78,80,82,95,106,110,112-114,116,117,120,125,172-174,200,236,237,239-243$ The overall non-Q-to-Q wave relative risk for long term death was $0.98(95 \% \mathrm{Cl} 0.93,1.02)$ (see Figure 14). However, there was a significant degree $(p<0.000001)$ of heterogeneity across the studies.

The meta-analysis was repeated stratifying the studies by those with $^{80,95,106,107,111,116,172,173,237,239,249}$ and without exclusion of patients with prior infarction. Among those without prior Ml, 136 of 549 (24.8\%) non-Q and 400 of 830 (32.5\%) Q wave patients died during long term follow-up; among those studies that did not exclude prior MI, 1,760 of 7,480 (23.5\%) non-Q and 4,962 of $21,635(22.9 \%) Q$ wave patients died during long term follow-up. The non-Q-to-Q wave relative risk for long term mortality was lower among patients in studies without prior infarction $10.52 ; 95 \%$ $\mathrm{Cl} 0.40,0.68$ vs. $0.93 ; 95 \% \mathrm{Cl} 0.87,0.996)$.

In the combined analysis, 1,896 of $8,029(23.6 \%)$ non-Q and 5,362 of 22,865 (23.5\%) $Q$ wave $M l$ patients died during long term follow-up; the non-Q-to-Q wave relative risk for long term mortality was $1.01(95 \% \mathrm{Cl} 0.96,1.05)$ (see Figure 11). When the long term studies were stratified according to mean follow-up duration, the non-Qto- $Q$ wave relative risk (RR) for mortality was (1) in studies $\leq 12$ months follow-up (mean 10.9 \pm 2.2 months; 8 studies, 5,308 patients): 1.16 (95\% Cl 1.04, 1.29); (2) in studies with 13-35 months follow-up (mean 26.6 \pm 4.1 months; 17 studies; 8,701 patients): RR $0.92(95 \% \mathrm{Cl} 0.83,1.02)$; and, $(3)$ in studies with $\geq 36$ months follow-up (mean 
$52.0 \pm 14.2$ months; 13 studies; 8,856 patients): RR 1.05; (95\% Cl 0.99, 1.11).

When the meta-analysis was restricted to the select group of studies, ${ }^{75,81,82,110.113-115.124}$ the non-Q-to-Q wave relative risk for long term mortality was 1.20 ( $95 \% \mathrm{Cl} 1.11,1.31)$. The high degree of heterogeneity among these selected studies was similar to that seen in the unselected and combined analyses $(p=0.0001)$.

Among the age-adjusted studies evaluating long term mortality, one study ${ }^{107}$ demonstrated a significantly lower relative risk and one study ${ }^{111}$ showed a trend toward higher relative risk; two other studies showed no difference or a trend toward lower non- $Q$-to- $Q$ relative risk. ${ }^{6.125}$ 
Connolly ${ }^{107}$

Kaplan 253

Szklo 110

Berger'"

Pohjola'so

Lurla 240

Edlavitch ${ }^{125}$

Cannom ${ }^{\text {s }}$

Fabricius-Bjerre $\theta^{236}$

Krone ${ }^{237}$

Mahony'124

Hutter ${ }^{112}$

Yuksel 230

Bayley ${ }^{106}$

Taylor 241

Boxall1"

Boxall

Rigo"
Coll

Goldberg"

Herlitz $240^{\circ}$

Ogawa:

Ogawa

BHAT Research Group 242

Van Rensburg ${ }^{2 b 1}$

Geltman'

Greenberg"n

Marmor'14

Malsel"

Gibson ${ }^{61}$

Lekakis $^{120}$

Herlitz ${ }^{18 r}$

Boden's

Zema"s

Kerlson 115

Stone 116

Fox 114

Roy"11

Moye"s

OVERALL
FIGURE 14 - Long Term Mortality

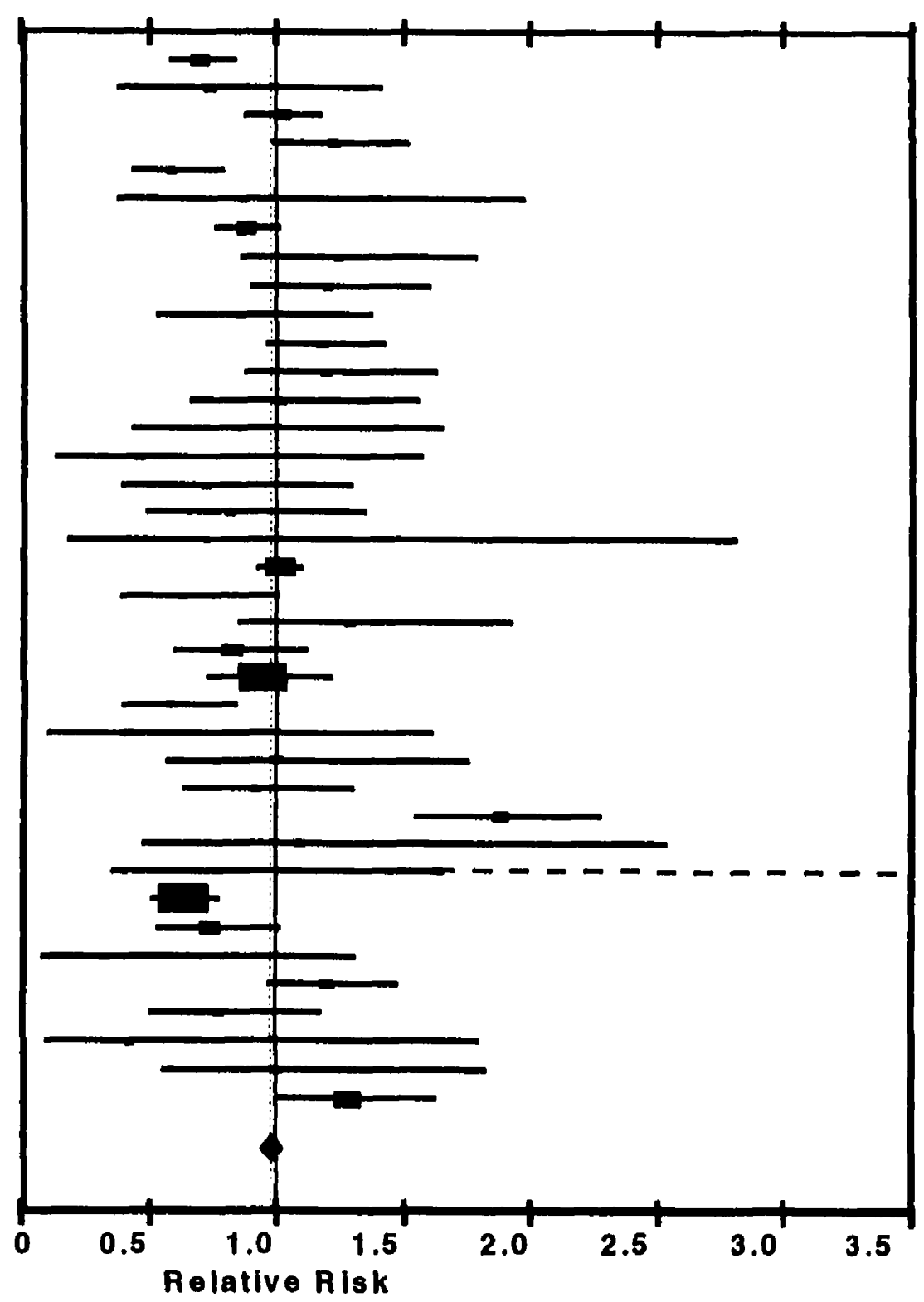




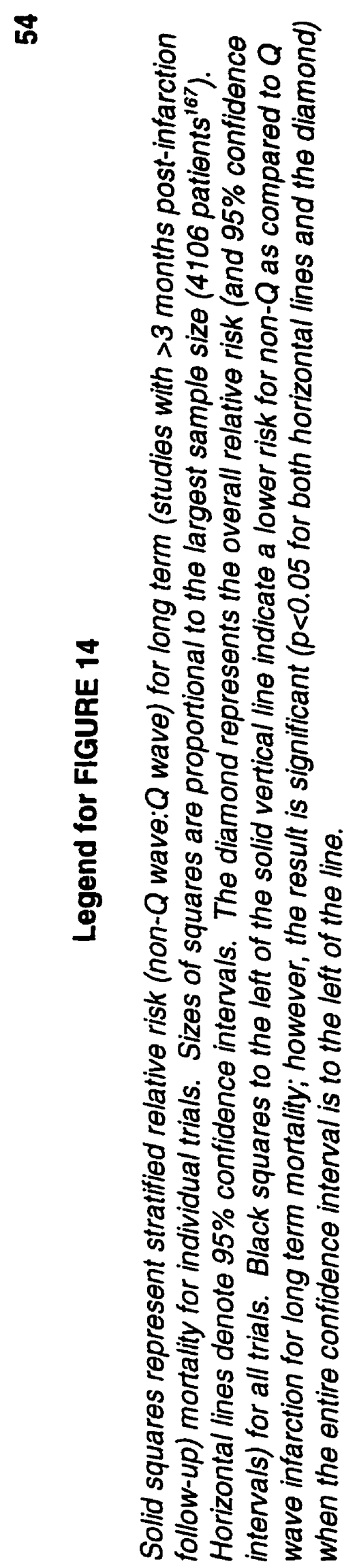




\section{Long Term Reinfarction}

Twenty-five studies with a mean follow-up range of 9-72 months were included in the analysis of long term reinfarction. Six series included only those patients who had survived to hospital discharge. ${ }^{174,236,237,239,241,243}$ In one study ${ }_{1}^{80}$ no reinfarctions occurred in the non- $Q$ wave group; this study was included in the pooled analysis but not the meta-analysis. Nine studies reported higher long term reinfarction rates in non- $Q$ wave MI patients; ${ }^{61,82,111,112,114,115,117.120 .167}$ all of the remaining 16 studies observed similar or a trend for lower long term reinfarction among non- $Q$ wave $\mathrm{MI}$ patients. ${ }^{75,80,95,113,116,173,174,176,236,237,239,241,243,250,251,258}$ The overall non-Q-to-Q wave relative risk for long term reinfarction was $1.52(95 \% \mathrm{Cl} 1.38,1.67 ; p<0.000001)$ (see Figure $15)$. However, there was a significant degree $(p<0.000001)$ of heterogeneity across the studies.

The meta-analysis was repeated stratifying the studies by those with $^{80,95,111,116,173,176,237,239,250}$ and without exclusion of patients with prior infarction. Among those without prior MI, 24 of 148 (16.2\%) non-Q and 45 of 323 (13.9\%) Q wave patients had recurrent infarction during long term follow-up; among those studies that did not exclude prior MI, 646 of 4,084 (15.8\%) non-Q and 1,073 of $11,464(9.4 \%) Q$ wave patients had recurrent infarction during long term follow-up. The non- $Q-$ to- $Q$ wave relative risk for reinfarction was somewhat lower among patients in studies

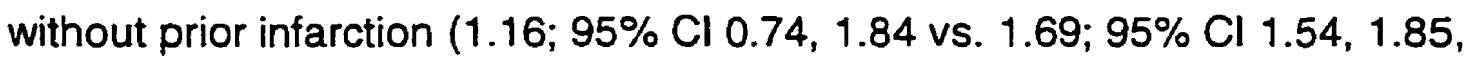
$\mathrm{p}=0.098$ )(see Figure 11).

In the combined analysis, 670 of $4,232(15.8 \%)$ non- $Q$ and 1,118 of 11,787 (9.5\%) Q wave $\mathrm{Ml}$ patients had recurrent infarction during long term follow-up; the non$Q$-to- $Q$ wave relative risk for long term reinfarction was 1.67 (95\% $\mathrm{Cl} 1.52,1.82)$ (see Figure 12). When the long term studies were stratified according to follow-up duration, the non-Q-to-Q wave relative risk (RR) for reinfarction was consistently increased (6 studies, 4,126 patients for $\leq 12$ (mean 10.5 \pm 2.5 ) months follow-up: RR 2.01 (95\% Cl $1.75,2.31$ ); 11 studies, 4,437 patients for $13-35$ (mean $27.3 \pm 5.4$ ) months follow-up: RR $1.52(95 \% \mathrm{Cl} 1.31,1.76)$; and, 8 studies, 3,224 patients for $\geq 36$ (mean $50.2 \pm 14.0$ ) 
months follow-up: RR 1.34; $95 \% \mathrm{Cl} 1.09,1.65)$.

When the meta-analysis was restricted to the select group of studies, ${ }^{75,81,82,113-115}$ the non- $Q-$ to- $Q$ wave relative risk for long term mortality was $2.16(95 \% \mathrm{Cl} 1.72,2.25)$. The high degree of heterogeneity among these selected studies was similar to that seen in the unselected and combined analyses ( $p=0.0002)$. 
ถิ
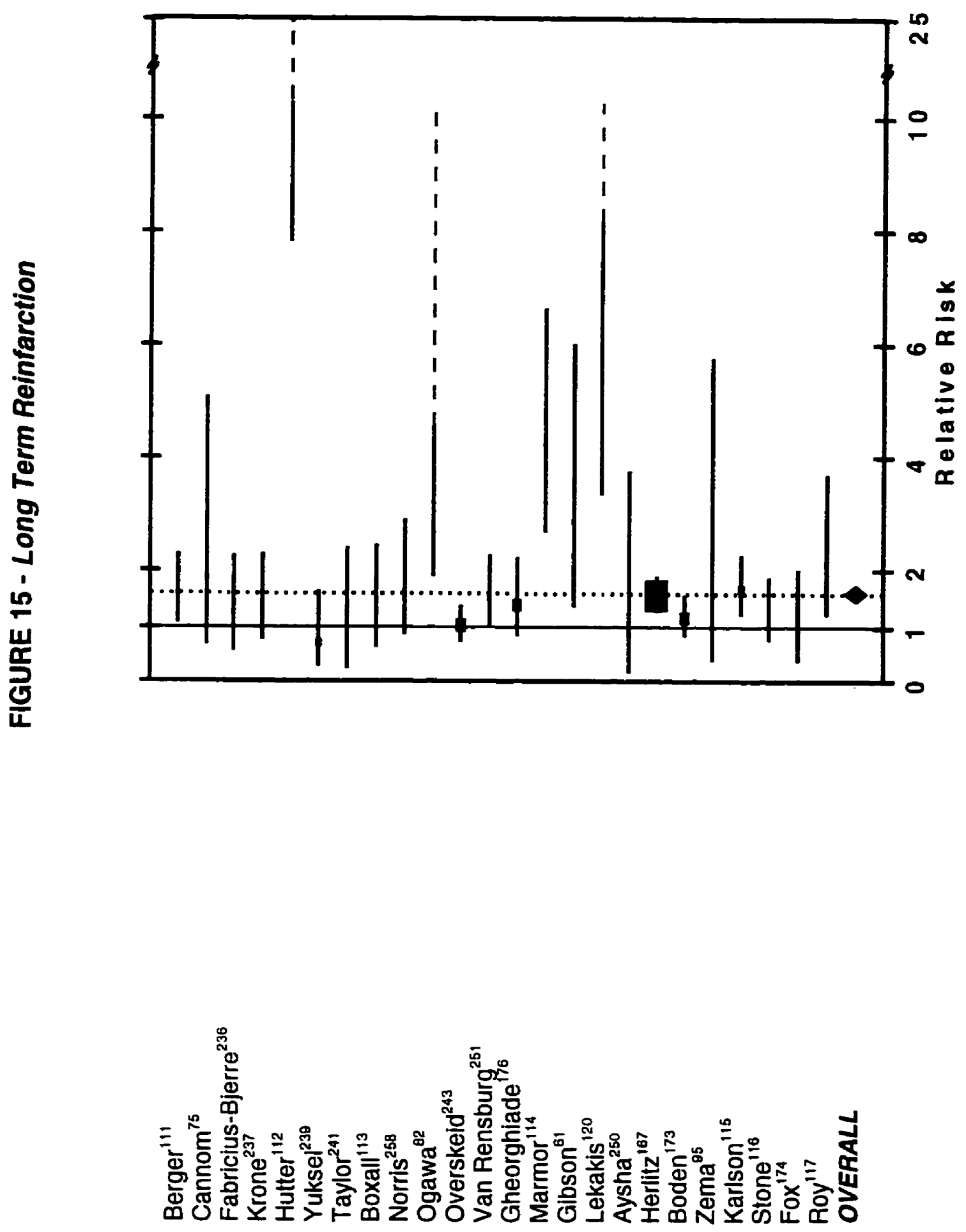


\section{Legend for FIGURE 15}

Solid squares represent stratified relative risk (non- $Q$ wave: $Q$ wave) for long term (mean $>3$ months follow-up postinfarction) reinfarction for individual trials. Sizes of squares are proportional to the largest sample size (4106 patients ${ }^{167}$ ). Horizontal lines denote $95 \%$ confidence intervals. The diamond represents the overall relative risk (and 95\% confidence intervals) for all trials. Black squares to the left of the solid vertical line indicate a lower risk for non- $Q$ as compared to $Q$ wave infarction for long term reinfarction; however, the result is significant $(p<0.05$ for both horizontal lines and the diamond) when the entire confidence interval is to the left of the line. 


\section{Discussion - Pre-Thrombolytic Era}

\section{Summary of the Results from the Current Analyses}

Over the past 30 years, more than 50 studies have provided data on differences in short and long term reinfarction and mortality in non-Q and $Q$ wave $M I$ patients. The main findings of these studies in the pre-thrombolytic era based on the current analyses are:

1. Short term (predominantly in-hospital) mortality was significantly lower among non- $Q$ as compared to $Q$ wave Ml patients;

2. Short term (predominantly in-hospital) reinfarction was significantly higher among non- $Q$ as compared to $Q$ wave $M I$ patients;

3. Mortality within the first 12 months was somewhat higher among non- $Q$ as compared to $Q$ wave $M l$ patients and was similar among the non- $Q$ and $Q$ wave $\mathrm{MI}$ groups beyond 12 months in the combined analyses; in the meta-analysis, long term mortality was similar among the non- $Q$ and $Q$ wave $M I$ groups;

4. The relative risk for reinfarction among non- $Q$ as compared with $Q$ wave patients is greatest during the first 12 months, but also remains greater beyond 12 months in the combined analyses; in the meta-analysis, the relative risk for long term reinfarction was significantly higher among non- $Q$ as compared to $Q$ wave MI patients;

5. A significant degree of heterogeneity was observed across studies within each analysis, even after restricting the analyses to those select studies with unambiguous clinical, electrocardiographic, and enzymatic criteria, and studies which attempted to adjust for differences in age and other covariates (e.g., history of prior Ml).

\section{Comparison with Previous Analyses}

The findings of lower short term mortality but higher short- and long-term reinfarction rates among non- $Q$ patients are consistent with three previous combined analyses. ${ }^{1-3}$ While mortality within the first 12 months of the index infarction was somewhat greater among non- $Q$ wave patients, the stratification of the studies by 
reported duration of follow-up is arbitrary; further, the magnitude of this apparent difference between $Q$ and non- $Q$ patients is small with the lower $95 \%$ confidence interval being close to 1 (RR 1.16; $95 \% \mathrm{Cl} 1.04,1.29$ ). In contrast to the previous findings of higher long term death rates among non- $Q$ as compared to $Q$ wave $M I$ patients, ${ }^{1,2}$ mortality beyond 12 months in the present analysis was similar among the two groups. This difference in longer term outcome may in part be explained by a major limitation of combining study results in a summary estimate (as was done in the three previous analyses. ${ }^{1-3}$ ) This combination approach assumes that the study populations and observed outcomes are similar, and simply averages the results. In contrast, the meta-analytic approach compares the different studies by taking into account both the direction and magnitude of the relative risk. The results of the metaanalysis suggest similar longer term outcome among the non- $Q$ and $Q$ wave $M I$ groups.

\section{Limitations of the Analyses}

Despite the current meta-analytic approach, there are many limitations to any attempt to combine the results of apparently heterogenous studies. The majority of studies were simple cohort studies from single institutions conducted over a relatively short period of time. Not surprisingly, the sample sizes for most studies were relatively small, with a range from as few as $43^{257}$ to as many as 5,006 patients (from a post-hoc analysis of a clinical drug trial). ${ }^{167}$ This may lead to reduced precision of the estimates and low power when testing for statistically significant differences in event rates. Follow-up also ranged widely, including those short term studies describing in-hospital outcomes; investigators rarely specified how long the mean hospital stay was. This unequal follow-up in both the short and long term studies was rarely accounted for in the analysis of event rates.

Another limitation of these studies relates to the lack of consistency in the point at which patients were enrolled. Many of the studies were retrospective ${ }^{6,70,74,75,79,82,95,107-110,112,113,124,125,236,239,240,244,251,254,260,261}$ or did not report whether or not patient recruitment was undertaken in a prospective manner. ${ }^{117,170,235,245,250}$ Even among the prospective studies, the consecutive nature of enrollment was not frequently 
commented upon. Some studies included only those patients who survived their coronary care unit or hospital stay or were secondary analyses of another study (e.g., non-invasive or invasive investigation, randomized clinical trial examining the use of medical therapy) with its own set of inclusion/exclusion criteria. This selection process may generate patient samples different from those found in the general post-MI population, thus resulting in "referral-filter" bias.

The timing of ECG classification was rarely reported. In addition, electrocardiographic criteria varied widely, with some studies failing to clearly define the duration, amplitude, and/or location of $Q$ wave abnormalities. Depending upon the study, poor $R$ wave progression and/or posterior infarction was inconsistently considered a non- $Q$ wave or $Q$ wave equivalent. The criteria used for a non- $Q$ wave $\mathrm{Ml}$ also varied from study to study. For example, some authors required a minimum duration of ST and/or T wave changes (e.g., persistent for at least 24-72 hours or throughout hospitalization). Others considered only initial ST segment depression as a marker for subsequent non- $Q$ wave evolution, excluding an important subgroup who present with ST segment elevation but do not develop subsequent $Q$ waves. Only a minority of studies did not require some ST-T wave change in the setting of typical chest pain and enzymatic confirmation of MI. While some studies specifically excluded those patients with ST-T wave changes in the same leads as those demonstrating preexisting $\mathrm{Q}$ waves (from previously documented $\mathrm{Ml}$ ), the majority of studies which included patients with prior $\mathrm{Ml}$ did not comment on the classification of this subgroup. While the majority of studies excluded patients with conduction abnormalities that preclude (e.g., left bundle branch block) or confound (e.g., left ventricular hypertrophy with secondary ST-T wave changes) a proper $Q$ or non- $Q$ wave diagnosis, others failed to comment upon or exclude these patients.

Enzymatic criteria for infarction was often not well defined (e.g., "above normal" or "serial changes") and did not consistently require specific myocardial necrosis markers such as CK-MB, particularly in some of the earlier reports. In a small minority of studies, patients with typical evolutionary ECG changes did not require a history of 
chest pain or cardiac enzyme support for the diagnosis of $Q$ wave $M I$.

Criteria for the diagnosis of recurrent infarction were rarely reported. In addition to a frequent lack of explicit reinfarction information, it was unclear whether this endpoint was classified in a consistent and blinded manner in the vast majority of studies. The clinician aware of the non- $Q$ or $Q$ wave status of their MI patient may have carried out more frequent or detailed searches (e.g., cardiac enzymes) for reinfarction; this frequent lack of a blinded outcome assessment may have introduced diagnostic-suspicion bias to many of the studies.

The issue of adjustment for other prognostic factors, apart from a non-Q or $Q$ wave diagnosis was also infrequently addressed. Many studies identified a higher prevalence of prior $\mathrm{Ml}$ and greater age--two important confounding factors impacting upon recurrent infarction and mortality--among patients with non- $Q$ as compared to $Q$ wave MI. Not surprisingly, when the studies were stratified according to whether or not a history of previous $\mathrm{MI}$ was an exclusion criterion, the non-Q-to-Q wave relative risks for short and long term mortality were lower among patients without prior Ml. This finding was most striking in the meta-analysis of long term mortality where the relative risk was significantly lower among non- $Q$ as compared to $Q$ wave patients without prior $\mathrm{Ml}$; in contrast, studies that did not exclude patients with prior $\mathrm{Ml}$ demonstrated a relative risk of 1.00 . Age-adjustment was undertaken in only 4 studies and again, the conclusions regarding relative risk were inconsistent.

Thus, the heterogeneity among the studies regarding patient selection and the timing of and criteria for diagnosis, makes comparisons of clinical outcomes between studies difficult, and likely accounts for the significant statistical heterogeneity seen in all of the attempted meta-analyses.

Finally, the present analyses were limited to published literature. Therefore, the results may be affected by "publication bias"; in other words, studies that demonstrated differences in outcomes between non- $Q$ and $Q$ wave $M I$ patients may have been more likely to be reported in the literature. This limitation applies to any review or metaanalysis; if publication bias is present, differences in reinfarction and mortality between 
non- $Q$ and $Q$ wave $M l$ patients may be less important than reported in the current literature.

A minority of the limitations listed above (e.g., initial ECG criteria and timing of $Q / n o n-Q$ classification) may actually bias the results in an unequal manner between the non- $Q$ and $Q$ wave groups. However, the majority of the abovementioned limitations would be expected to affect the distribution of non- $Q$ and $Q$ wave patients and their outcomes equally, and would therefore not distort the overall conclusions. However, the magnitude and generalizability of the observed differences between the non- $Q$ and $Q$ wave groups remain unclear. 


\section{CHAPTER FOUR}

\section{Outline of Chapter Four}

The purpose of this chapter is to:

1. Outline the rationale for review of non- $Q$ vs. $Q$ wave infarction in studies where thrombolytic therapy was administered;

2. Describe the methods for selection of studies of thrombolytic therapy;

3. Describe the results of the rate of development and subsequent prognosis of non- $Q$ wave infarction in studies of thrombolytic therapy;

4. . Discuss the limitations of the previous analyses.

\section{LITERATURE REVIEW}

\section{Rationale for Review of Non-Q and Q Wave Infarction in the Thrombolytic Era}

As discussed previously (in Chapter 2), early administration of thrombolytic agents may lead to reperfusion of an occluded coronary artery in the setting of acute MI. Further, it has been suggested that more widespread treatment of patients with thrombolysis may lead to more frequent development of non- $\mathrm{Q}$ wave $\mathrm{Ml}$, since the infarction has been "aborted" or "interrupted." In a similar process to that seen with spontaneous, endogenous thrombolysis, earlier recanalization of the infarct-related coronary artery with pharmacologic, exogenous thrombolysis may contribute to a smaller amount of myocardial necrosis, a potentially greater proportion of non- $Q$ wave infarctions (Thesis Hypothesis \#1), and a more favourable short-term outcome.

However, the patent but still stenotic infarct-related artery may lead to a greater number of subsequent cardiac events unless thrombolytic treatment can reduce the remaining thrombotic burden and contribute to healing and remodelling of the ruptured coronary artery plaque (Thesis Hypotheses \#2 and \#3). While the meta-analyses presented in 
Chapter Three and several previous reviews have addressed the development and subsequent prognosis of $Q$ and non- $Q$ wave myocardial infarction, ${ }^{1-3.162}$ no data following the administration of thrombolytic therapy have been systematically presented. Therefore, a systematic review and critical appraisal were undertaken.

\section{Thrombolytic Trials}

\section{Article Selection}

The English-language medical literature was searched for articles that described the results from studies of any thrombolytic agent used in the treatment of suspected MI. Articles were found through a MEDLINE search (from January 1966 through June 1995) by using as search terms the Medical Subject Headings (MeSH) "myocardial infarction," "thrombolysis," and "fibrinolysis." Another source of articles included the reference lists of all articles obtained to identify additional research not found in the computerized bibliographic database searching. In addition, the reference list of an overview of earlier (1959-84) randomized controlled trials of fibrinolytic therapy in acute $\mathrm{Ml}^{262}$ was used to identify additional studies. Articles were scanned to identify standardized electrocardiographic data (e.g., presence or absence of $Q$ waves on serial ECGs) and clinical outcome measures (e.g., reinfarction, mortality) obtained during each study.

\section{Results - Non-Q and $Q$ Wave Infarction in the Thrombolytic Era}

\section{Less $Q$ Wave Development and $R$ Wave Regression Following Thrombolysis}

Electrocardiographic evolution of $Q$ waves following thrombolysis has been documented in a small number of patients (see Table 7). Early studies evaluated the impact of thrombolytic administration on the depth and number of $Q$ waves and the amplitude of $R$ waves (with a significant loss of $R$ wave amplitude being considered a $Q$ wave equivalent in certain ECG leads). ${ }^{128-131}$

Anderson et $\mathrm{al}^{130}$ demonstrated a beneficial effect of intracoronary streptokinase 
on the preservation of $R$ wave amplitude and reduction in the development of $Q$ waves. The sum of $R$ waves in all leads demonstrating ST segment elevation on the admission ECG was similar among 24 patients randomized to receive streptokinase and 26 patients to standard (control) therapy within 3 hours of chest pain onset. While both groups had preserved only $50 \%$ of their initial R wave amplitude at 24 hours after therapy, no further $R$ wave loss was seen in the streptokinase-treated group from day 1 to 10; in contrast, the control group experienced additional loss beginning at day two $(p<0.05)$ with only $20 \%$ of initial $R$ wave amplitude preserved at day $10(p<0.001)$. The number of new $Q$ waves was also significantly lower among streptokinase-treated patients, noted first at 6 hours ( 1.4 vs. 2.4, p<0.05), and subsequently at days 1 ( 2.5 vs. $3.6, p<0.05)$ through 10 ( 2.0 vs. $3.8, p<0.01)$. These electrocardiographic changes were associated with a significantly shorter time to peak plasma cardiac enzyme concentration and greater echocardiographic wall-motion index improvement after streptokinase treatment $(p<0.01)$. Thus, smaller $Q$ wave development and less $R$ wave loss in the streptokinase group were consistent with a beneficial effect of thrombolytic therapy on the size of infarction.

Blanke et al ${ }^{131}$ compared the ECG outcome in 15 patients with left anterior descending artery occlusions successfully reperfused with intracoronary streptokinase with that of 22 historic controls who had undergone cardiac catheterization during the acute stage of infarction. Before angiography, no differences were found in the sum of $R$ waves ( 3.3 vs. $2.8 \mathrm{mV}$ ) or the number of $Q$ waves (1.7 vs. 1.9 ) in leads $V_{1.6}$. By 24 hours, the loss of $R$ wave amplitude (2.3 vs. $1.3, p<0.05)$ and the number of $Q$ waves ( 2.4 vs. $3.2, p<0.05$ ) was significantly less among the streptokinase-treated group, suggesting that jeopardized myocardium was salvaged by reperfusion therapy. The authors found a significant correlation between long-term ( $>3$ weeks) ECG findings with left ventricular ejection fraction and akinetic segment length, suggesting that $Q$ wave regression and increased $R$ wave amplitude after streptokinase treatment may represent salvage of jeopardized myocardium.

It should be noted from these and other studies listed in Table 7 that, although 
statistically significant differences between group mean values for $R$ and $Q$ wave amplitude may exist, the absolute magnitudes of these differences tend to be small and standard deviations are relatively large. This implies that the ability to recognize differing patterns of infarct evolution in an individual patient may be limited. Perhaps even more noteworthy is the failure of most of the abovementioned studies to provide a definition of a $Q$ wave; only Blanke et al $^{131}$ gave specific criteria regarding $Q$ wave classification in the precordial leads of the ECG. 


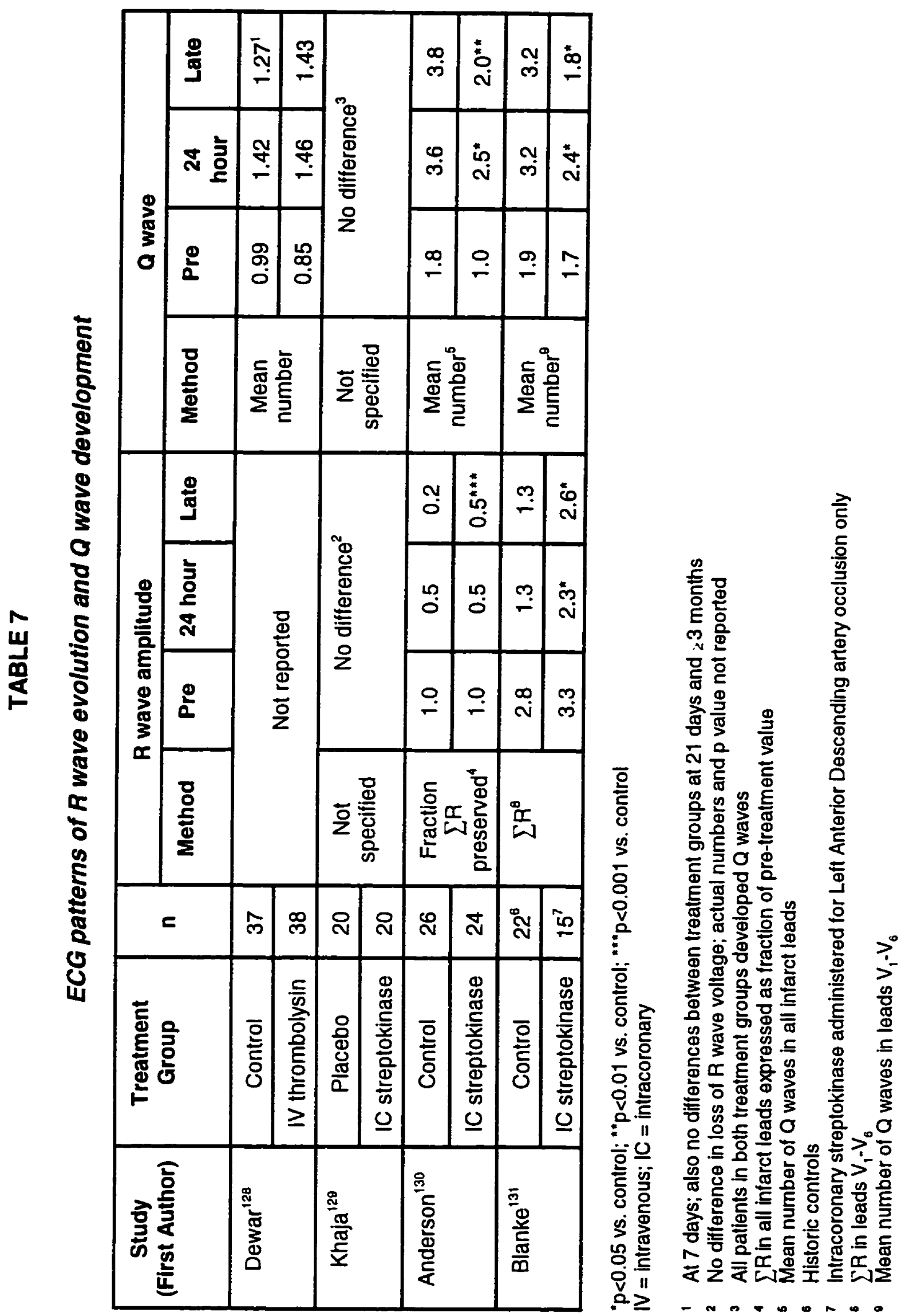




\section{Non-Q Wave Development Following Thrombolysis}

Studies reporting on the ECG classification of MI following thrombolytic therapy suggest that non-Q wave $\mathrm{Ml}$ occurs in $10.4 \%$ to $42 \%$ of patients (see Table 8 ) ) $^{4.5 .133-145}$, with the greatest occurrence in those patients who achieve early and sustained infarctrelated artery patency. ${ }^{58}$ The subsequent prognosis of non- $Q$ wave $M I$ patients following thrombolytic therapy remains uncertain with the majority of studies not reporting on clinical outcomes. ${ }^{4,5,128,133-137,139}$ Some studies suggest a similar outcome in non- $Q$ as compared with $Q$ wave $M l$ patients; ${ }^{140.141,144.146}$ however, other studies have demonstrated conflicting results suggesting either higher reinfarction ${ }^{142,145}$ and/or mortality ${ }^{142}$ or lower mortality ${ }^{143,145}$ rates among the non-Q wave group. ${ }^{142}$ The specific results of each study of thrombolysis trial are discussed briefly in an appendix (Appendix 1) at the end of the chapter. 


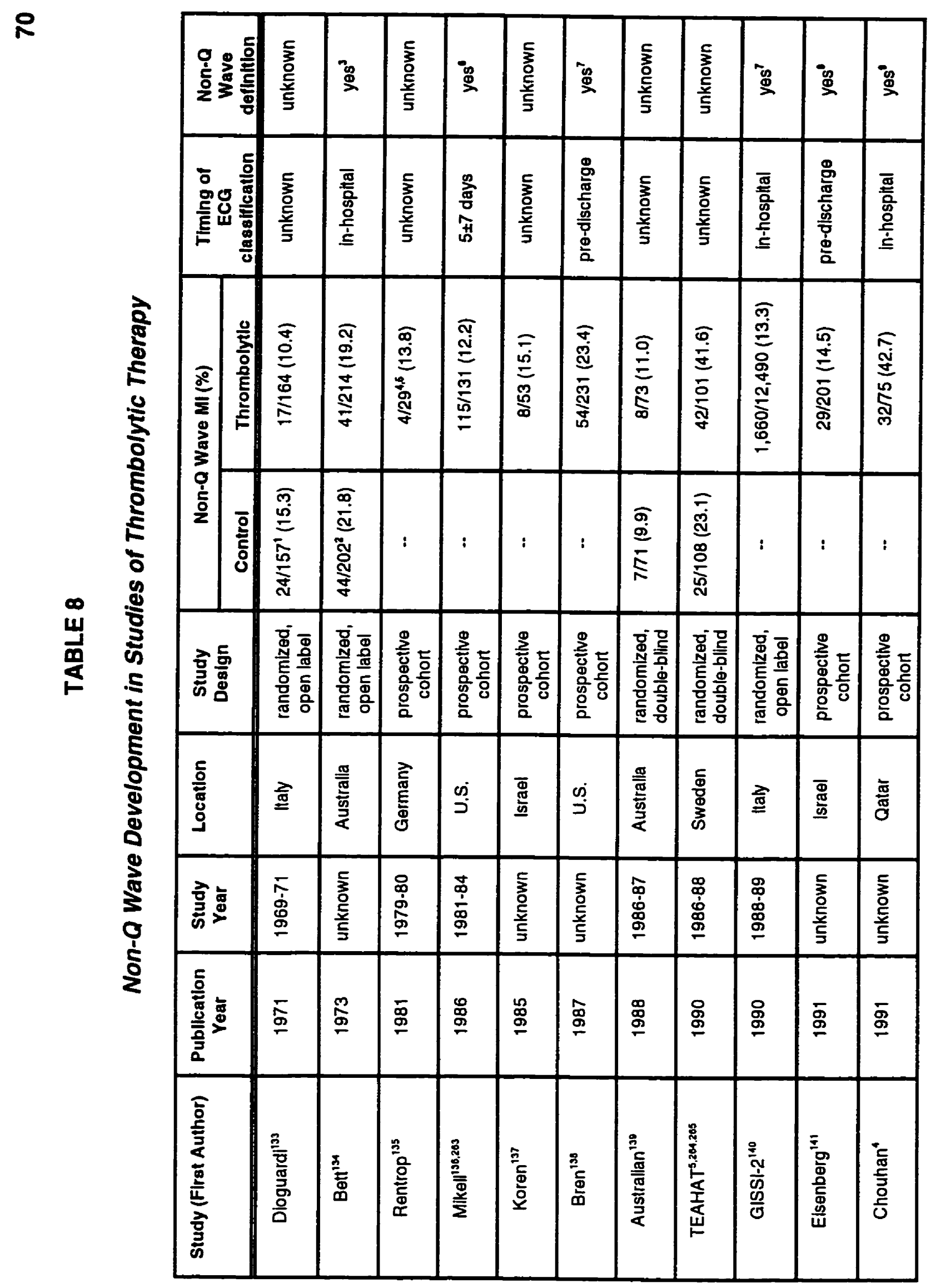




\begin{tabular}{|c|c|c|c|c|c|c|c|c|}
\hline Tajer 142 & 1993 & $1988-89$ & International & $\begin{array}{c}\text { randomized, } \\
\text { open label }\end{array}$ & .. & $1,444 / 7,605(20,6)$ & pre-discharge & yes ${ }^{10}$ \\
\hline Barbagelata ${ }^{143.260}$ & 1994 & $1990-93$ & Internatlonal & $\begin{array}{l}\text { randomized, } \\
\text { double-blind }\end{array}$ & -. & $4,601 / 21,570(21.3)$ & $>24 \mathrm{hr}$ & yes" \\
\hline Aguirre $\theta^{144}$ & 1995 & $1987-88$ & U.S. & $\begin{array}{l}\text { randomized, } \\
\text { double-blind }\end{array}$ & .. & $767 / 2,634(29.1)$ & day 2 & yes" \\
\hline \multirow[t]{2}{*}{ Matetzky ${ }^{145}$} & \multirow[t]{2}{*}{1995} & \multirow[t]{2}{*}{ unknown } & \multirow[t]{2}{*}{$\mid$ srael } & \multirow{2}{*}{$\begin{array}{l}\text { prospective } \\
\text { cohort }\end{array}$} & .. & $28 / 139(20.1)$ & $24 \mathrm{hr}$ & yes ${ }^{12}$ \\
\hline & & & & & .. & $39 / 139(28.1)$ & pre-dlscharge & yes ${ }^{13}$ \\
\hline
\end{tabular}

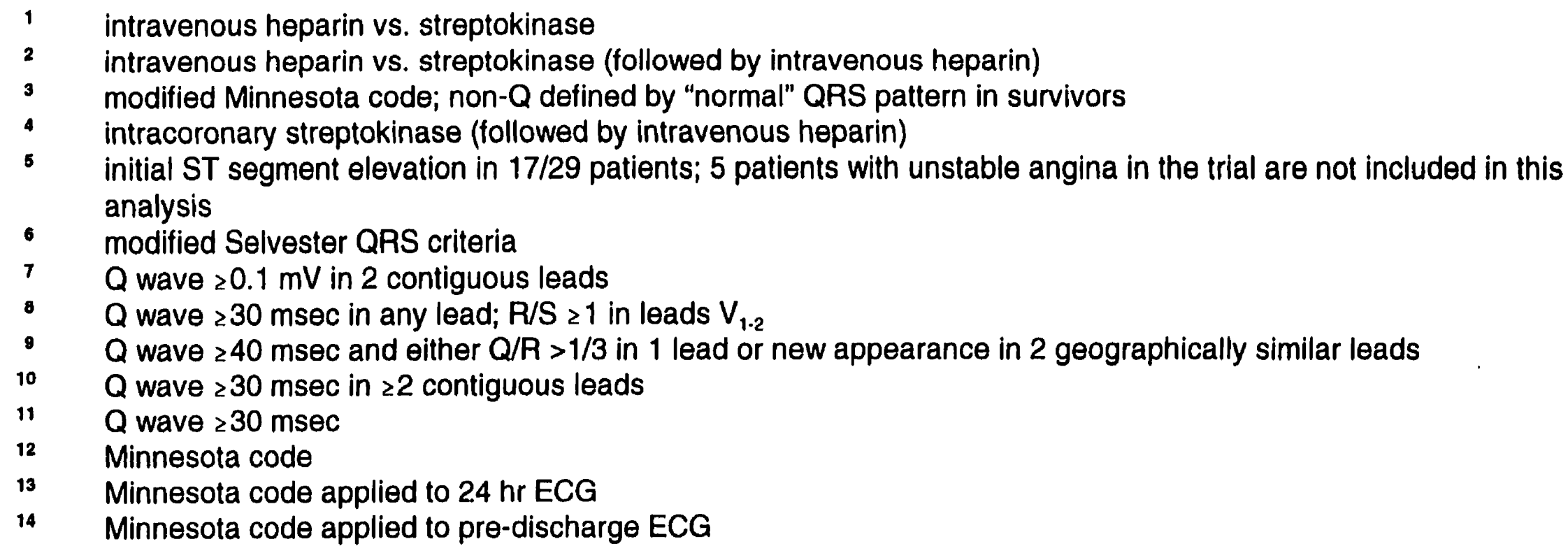




\section{Limitations of Previous Studies}

Unfortunately, evaluation of the impact of thrombolytic therapy on the rate of non- $Q$ wave $M I$ development and subsequent prognosis based on the abovementioned studies is limited by the lack of a control group in all but 4 studies (Table 7). . $^{5.133,134,139}$ All of these studies had relatively small sample sizes $(321,416,144$ and 207 patients, respectively) and failed to report on clinical outcomes. In addition, the timing and type (e.g., $Q$ wave definition) of ECG classification are reported in only 1 of these studies. ${ }^{134}$ Together with different thrombolytic dosages, duration and timing of thrombolytic administration, these factors may account (in part) for the observed inter-study differences in the rate of non- $Q$ wave $M l$ development (which ranges from $10.4 \%$ to $41.6 \%$ in the thrombolytic-treated groups). Particularly since non-Q wave $\mathrm{MI}$ in the prethrombolytic era has been reported in up to $23 \%$ of patients presenting with ST segment elevation, ${ }^{63}$ it is difficult to interpret studies in the thrombolytic era without a control group for comparison. While the value of thrombolysis in patients with acute $\mathrm{MI}$ and ST segment elevation is well established, ${ }^{147}$ there is some concern that the interrupted or aborted non- $\mathrm{Q}$ wave $\mathrm{Ml}$ following thrombolytic administration may be analogous to the incomplete, "naturally occurring" non- $Q$ wave $M I$ that results from spontaneous thrombolysis. ${ }^{10.148}$ The conceptual link between the naturally occurring and pharmacologically reperfused non- $Q$ wave $M l$ suggests that the initial coronary reperfusion associated with myocardial salvage will contribute to a more favourable short-term prognosis as compared with $Q$ wave MI. However, unless pharmacologic thrombolysis can reduce the remaining thrombotic burden and contribute to the healing and remodelling of the ruptured coronary artery plaque, the patent but residually stenotic infarct-related artery may lead to recurrent ischemia, infarction, and death. Indeed, despite initial treatment with thrombolysis, aggressive use of antithrombotic therapy (e.g., heparin and aspirin) and revascularization (with coronary artery bypass surgery or percutaneous transluminal coronary angioplasty) post-infarction, recurrent non-fatal infarction or death occurs in $15 \%$ of patients during 1 year follow-up. ${ }^{149}$ Whether the patients with non- $Q$ wave $M l$ account for the majority of the subsequent 
cardiac events observed in the thrombolytic era remains uncertain. 


\section{APPENDIX 1}

Non-Q Wave Infarction in Early Thrombolytic Trials (Late 1960s to Early 1980s)

Dioguardi et al ${ }^{133}$ studied 321 patients with acute myocardial infarction of $<12$ hours' duration confirmed by cardiac enzymes. Although there were no specific ECG criteria at presentation required for study inclusion, subsequent non- $Q$ wave $M I$ development was similar between the heparin- and intravenous streptokinase-treated groups $(15.3 \%$ vs. $10.4 \%, p=$ n.s. $)$.

Bett et $a l^{134}$ reported on the use of intravenous streptokinase followed by heparin vs. heparin alone in 517 patients with enzyme confirmed $\mathrm{Ml}$ of $<24$ hours' duration. Again, no ECG criteria were required for inclusion in this study. Among survivors, a modified Minnesota QRS score was utilized to classify the in-hospital ECG; the rate of non-Q development was similar among the two treatment groups $(19.2 \%$ vs. $21.8 \%$, $p=n . s$.$) .$

Rentrop et al ${ }^{135}$ evaluated the impact of intracoronary streptokinase on the acute angiographic patency of 34 patients with acute Ml or unstable angina. Among the 29 patients with confirmed MI (17 of whom had ST segment elevation at presentation), 4 (13.8\%) failed to develop $Q$ waves during their hospital course.

Mikell et al ${ }^{136}$ evaluated the development of $Q$ waves $5 \pm 7$ days post $\mathrm{Ml}$ among 131 patients who received intracoronary or intravenous streptokinase for ST elevation: 115 patients $(12.2 \%)$ failed to develop a $Q$ wave.

Koren et $\mathrm{al}^{137}$ administered thrombolytic therapy to 53 patients with ST elevation an average of $1.7 \pm 0.8$ hours after chest pain onset and demonstrated the development of non-Q wave $\mathrm{MI}$ in 8 patients (15.1\%). Recognizing the potential importance of timing of thrombolytic administration, the authors noted that 6 of the 8 non-Q Mls occurred in patients treated within the first 1.5 hours. Overall, non-Q MI patients had significantly lower peak creatine kinase levels and higher ejection fractions than the 45 patients who developed $Q$ wave $M l$, indicating less myocardial necrosis and better residual left ventricular function. 


\section{Non-Q Wave Infarction in the Thrombolytic Era (Mid-1980s to Present)}

In the Thrombolysis in Myocardial Infarction (TIMI) phase I study, ${ }^{138} 241$ patients presenting with chest pain of at least 30 minutes duration and ST segment elevation received thrombolytic therapy. At the time of hospital discharge, 54 of 231 (23.4\%) survivors had sustained a non- $Q$ wave $M I$.

In the National Heart Foundation of Australia Coronary Thrombolysis study, ${ }^{139}$ 144 patients presenting within 4 hours of onset of MI with ST segment elevation were randomized to receive either r-tPA or placebo: $8(11 \%)$ patients receiving r-tPA and 7 (9.9\%) receiving placebo developed a non- $Q$ wave $\mathrm{MI}$.

The Thrombolysis Early in Acute Heart Attack Trial (TEAHAT) Study Group ${ }^{5,264,265}$ from two hospitals in Sweden randomized 352 patients with suspected MI within 165 minutes from the onset of chest pain to placebo or tissue-type plasminogen activator (rt-PA). Acute MI was diagnosed in only $59 \%$ of randomized patients; this low rate of confirmed MI was likely due to the fact that ECG criteria were not used to determine study eligibility. Among the 209 patients with documented MI (176 of whom had ST segment elevation on the admission ECG), ${ }^{265}$ the occurrence of $Q$ wave infarcts was lower among the rt-PA- as compared to the placebo-treated patients (59 patients vs. 83 patients, $p=0.01$ ). Conversely, the rate of non- $Q$ wave infarction was increased in the rt-PA group as compared with the placebo group (42 patients vs. 25 patients, $p=0.03) .5,264$ Subsequent cardiac events were not reported by infarct type.

In the second study (GISSI-2) from the Gruppo Italiano per lo Studio della Sopravvivenza nell'Infarto Miocardico investigators, ${ }^{140} 12,490$ patients with chest pain onset within 6 hours and ST segment elevation on the presenting ECG received thrombolytic therapy (streptokinase or IPA); non-Q wave MI developed in 1,660 (13.4\%) of patients. The primary combined endpoint of this study (in-hospital mortality, clinical congestive heart failure occurring more than 4 days after admission, or extensive left ventricular damage in the absence of clinical heart failure) was significantly higher among those patients classified as having $Q$ as compared with nonQ wave MI (25.1\% vs. $10.1 \%, p=0.001)$. Subsequent analysis of the determinants of 6 
month mortality among those patients surviving to hospital discharge excluded the variable concerning the type of infarction ( $Q$ vs. non- $Q$ wave) since preliminary screening did not reveal different survival probabilities between these two groups. ${ }^{146}$

Eisenberg et $\mathrm{al}^{141}$ evaluated the timing of $Q$ wave evolution and its prognostic significance in 201 patients with ST segment elevation who received thrombolytic therapy (streptokinase or TPA) within 6 hours (mean of $145 \pm 84$ minutes) of symptom onset for a first acute MI. Q waves were present in 103 patients $(51 \%)$ before initiation of thrombolysis; an additional $38(19 \%)$ and 28 (14\%) developed $Q$ waves during the 3 hours and 3-24 hours after treatment began, respectively (see Figure 16). Only 3 patients (1.5\%) developed $Q$ waves after 24 hours but before discharge, with 29 patients (14.5\%) defined as having non-Q wave MI. Non- $Q$ wave Ml patients had significantly lower peak creatine kinase values and higher discharge left ventricular ejection fractions. In-hospital reinfarction (10.3\% vs. 16.9\%) and in-hospital mortality ( $0 \%$ vs. $2.9 \%$ ) was less frequent (but not statistically different) among this small group of non- $Q$ as compared to $Q$ wave $M l$ patients. One year mortality was similar between the non- $Q$ and $Q$ wave groups (3.4\% vs. $3.5 \%$ ). 
FIGURE 16 - Timing of Q Wave Development Post-Thrombolysis

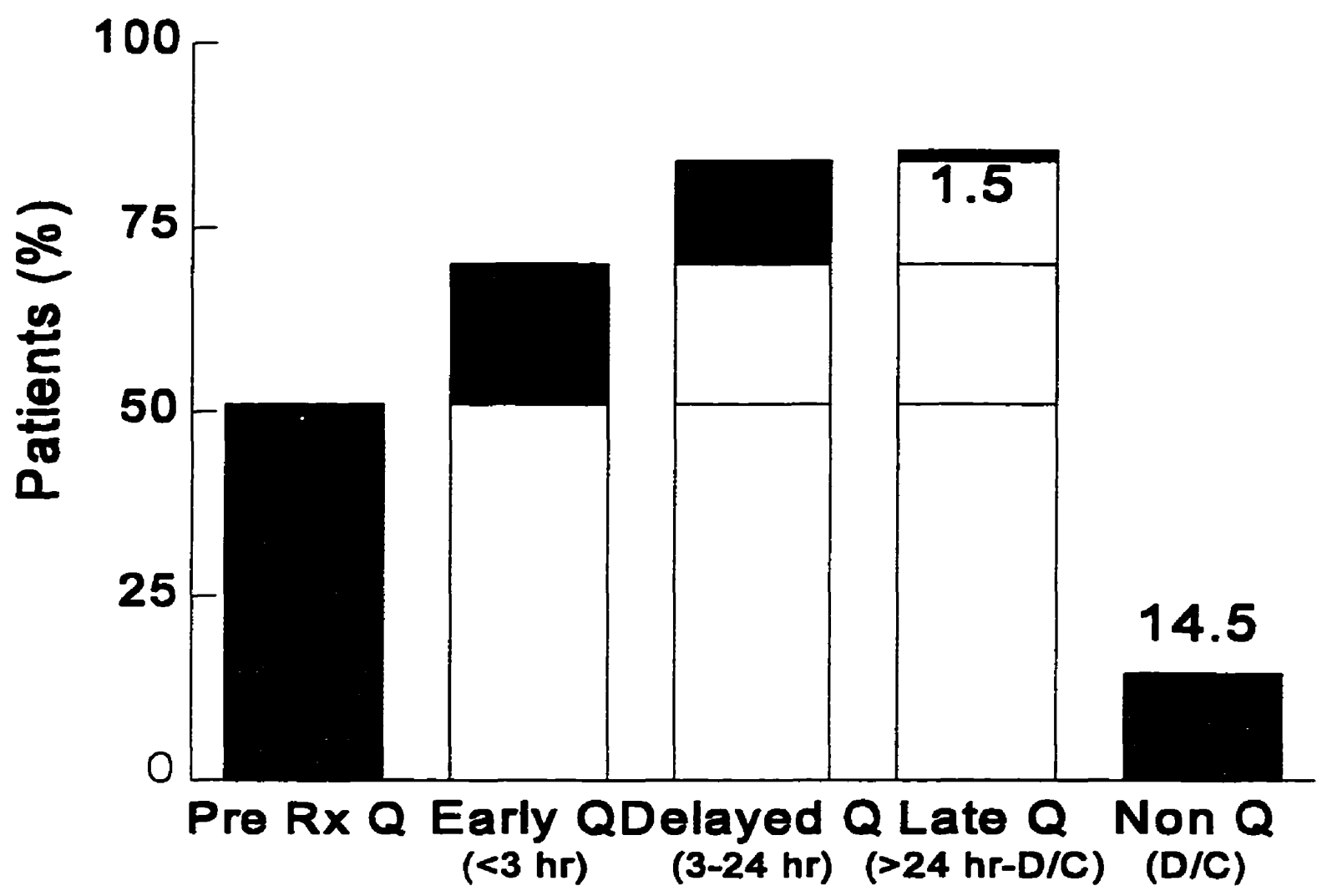

Timing of $Q$ wave evolution among 201 patients who received thrombolytic therapy for a first acute myocardial infarction. Fifty-one percent of patients had $Q$ waves prior to thrombolytic administration (first (hatched\} bar $=$ Pre $R \times Q$ ) and $70 \%$ had evolved $Q$ waves within 3 hours of treatment (second \{open\} bar $=$ Early $Q$ ). An additional 19\% evolved $Q$ waves from 3-24 hours post-thrombolysis (third \{open\} bar $=$ Delayed $Q$ ). Additional $Q$ wave development beyond 24 hours (up until the time of hospital discharge) was infrequent (1.5\%; fourth \{open\} bar = Late Q). Thus, $14.5 \%$ of patients sustained a non- $Q$ wave MI following thrombolytic therapy (last $\{$ hatched $\}$ bar $=$ Non- $Q$ ). Adapted from Eisenberg et al. ${ }^{141}$ 
Chouhan et $\mathrm{al}^{4}$ described the rate of non-Q MI development in 75 consecutive patients receiving thrombolysis (streptokinase) for anterior ST segment elevation within 6 hours (average 164 minutes) of symptom onset: $Q$ waves developed in $43(57 \%)$ and non-Q Ml occurred in 32 (43\%). Non-Q MI patients had significantly lower peak creatine kinase levels, and among those who went on to cardiac catheterization $5 \pm 3$ days later, this was associated with significantly better left ventricular function (left ventricular ejection fraction of $60 \pm 8 \%$ vs. $49 \pm 14 \%, p<0.001$ in $Q$ wave MI). No clinical outcomes were reported in this study.

A preliminary report (abstract) from Tajer et al ${ }^{142}$ described the 6-month prognosis of 7,605 patients $(1,444$ (20.6\%) of whom developed a non-Q wave MI) discharged alive in the International TPASK Mortality Trial. Reinfarction (6.2\% vs. $3.6 \%$; odds ratio $1.80,95 \%$ confidence intervals $(\mathrm{Cl}) 1.22,2.66)$ and death $(4.6 \%$ vs. $3.5 \%$; odds ratio $1.35,95 \% \mathrm{Cl} 1.01,1.81$ ) was higher among the non- $Q$ wave group.

In contrast, a post-hoc analysis by Barbagelata et al ${ }^{143,266}$ in 21,570 patients receiving thrombolysis (TPA, streptokinase, or the combination) for ST segment elevation MI within 6 hours of chest pain onset as part of the Global Utilization of Streptokinase and Tissue Plasminogen Activator for Occluded Coronary Arteries (GUSTO) trial demonstrated significantly better short- and long-term prognosis in non$Q$ as compared with $Q$ wave Ml patients. Among those patients surviving to 24 hours without prior ECG evidence of MI or specific ECG confounding factors, non-Q wave MI developed in 4,601 patients (21.3\%). Peak CK and CK-MB levels were significantly lower among non- $Q$ wave $M I$ patients $(997 \pm 1,201$ vs. $2,133 \pm 1,784, p=0.0001$; and $100 \pm 168$ vs. $192 \pm 204, p=0.0001$ ). The subsequent in-hospital mortality rate was significantly lower in the non- $Q$ as compared to $Q$ wave group $(0.9 \%$ vs. $1.8 \%$, $p=0.0001$ ); the enhanced survival among non- $Q$ Ml patients was also seen at 30 days $(0.9 \%$ vs. $1.8 \%, p=0.0001)$ and 1 year $(2.7 \%$ vs. $4.2 \%, p=0.0001)$.

A secondary analysis of 2,634 patients enrolled in the second Thrombolysis In Myocardial Infarction (TIMI II) trial with a first MI was performed to determine 6 week and 1 year cardiac event rates and identify angiographic differences among the 1,867 
patients $(70.9 \%)$ who evolved a Q wave and the 767 patients $(29.1 \%)$ who sustained a non-Q wave $\mathrm{Ml}$ after treatment with thrombolytic therapy. ${ }^{144}$ Infarct-related artery patency and complete reperfusion (restoration of normal flow through the recently occluded artery) were significantly greater among non- $Q$ wave patients. This was associated with a greater percentage of patients with a predischarge resting left ventricular ejection $>55 \%$ and less frequent development on in-hospital congestive heart failure as compared to the $Q$ wave group. Forty-two day and 1 year reinfarction and death rates were similar, regardless of infarct type. However, by study design, a substantial number of patients underwent cardiac catheterization (approximately $73 \%$ ) and subsequent revascularization (approximately $48 \%$ ) within 42 days of MI. In addition, exclusion of prior $\mathrm{Ml}$ (enhancing the ability to detect new $Q$ waves on the ECG) likely contributed to the very low 42 day (2.3\% in the $Q$ and $2.4 \%$ in the non- $Q$ wave group) and 1 year death rates observed ( $4.4 \%$ vs. $3.4 \%$ ). There was a trend $(p=0.07)$ toward slightly more frequent recurrent $M I$ in non- $Q$ wave compared with $Q$ wave patients during the year after study entry.

Matetzky et al ${ }^{145}$ studied the clinical outcome of 150 consecutive patients $<72$ years old who underwent thrombolysis (TPA) within 4 hours (mean 126 minutes) of symptom onset presenting with ST segment elevation. Based on a 24-hour ECG, 28 (20.1\%) patients developed non-Q wave $\mathrm{Ml}$; however, in-hospital reinfarction (14\% vs. $12 \%$ ), in-hospital mortality (0\% vs. $4.5 \%$ ), two year reinfarction ( $15 \%$ vs. $6 \%$ ), and two year mortality ( $4 \%$ vs. $6 \%$ ) rates were not significantly different when compared to those with $Q$ wave MI. The authors also evaluated a pre-discharge ECG and determined that $39(28.1 \%$ ) of patients had a non- $Q$ wave $\mathrm{Ml}$ (due to regression of $\mathrm{Q}$ waves in 18 patients and subsequent development of $Q$ waves in 7 patients whose 24hour ECG was classified as non-Q wave). This pre-discharge ECG dichotomization also identified patients in the non- $Q$ wave group as having similar in-hospital reinfarction ( $13 \%$ vs. $12 \%, p=1.0$ ) and mortality ( $0 \%$ vs. $5 \%, p=0.4)$, and two year reinfarction ( $14 \%$ vs. $6 \%, p=0.2$ ) rates as those in the $Q$ wave group. In contrast, there was a trend toward a lower 2 -year mortality rate $(0 \%$ vs. $7 \%, p=0.08)$ in the non- $Q$ wave 
group. 


\section{CHAPTER FIVE}

\section{Outline of Chapter Five}

The purpose of this chapter is to:

1. Outline the rationale for further analysis of the development and subsequent prognosis of non- $Q$ wave vs. $Q$ wave infarction from randomized controlled trials of thrombolytic therapy (Thesis Objective);

2. Describe the methods for obtaining electrocardiographic and clinical data from five trials of thrombolytic therapy;

3. Describe the methods for and results of the evaluation of the rate of transformation of ST segment elevation to $Q$ and non- $Q$ wave infarction following thrombolytic therapy (addressing Thesis Hypothesis \#1);

4. Describe the methods for and results of the evaluation of the prognosis of non- $Q$ and $Q$ wave infarction following thrombolytic therapy (addressing Thesis Hypothesis \#2 and \#3);

5. Discuss the strengths and limitations of these post-hoc analyses.

\section{THE DEVELOPMENT AND PROGNOSIS OF NON-Q WAVE MYOCARDIAL INFARCTION FOLLOWING THROMBOLYTIC THERAPY}

Rationale for Additional Analysis of Non-Q Wave Development and Prognosis in the Thrombolytic Era

Based on data from the pre-thrombolytic era, it appears that non-Q wave MI may occur spontaneously in over $20 \%$ of patients presenting with ST segment elevation. Thus, in the absence of a control group, it may be difficult to interpret the results of studies in the thrombolytic era suggesting a greater rate of non-Q MI. As discussed in the previous chapter, non-Q wave development following the administration of thrombolytic therapy has been evaluated in only a small number of patients from 4 randomized controlled studies. Further, while the short term outcome following thrombclysis may be better among non- $Q$ wave patients for the same reasons (greater infarct-related artery patency leading to less myocardial damage), it is unclear whether 
longer term prognosis will remain superior to that seen among $Q$ wave patients. Unfortunately, none of the randomized controlled thrombolytic trials evaluating non- $Q$ wave $\mathrm{MI}$ reported on clinical outcomes. Therefore, a retrospective evaluation of non- $Q$ wave development and prognosis was sought from five controlled studies of thrombolysis that had not previously addressed these issues.

\section{Thrombolytic Trial Selection}

Among the nine largest randomized controlled trials ( $>1000$ patients) of thrombolysis designed to evaluate the impact of treatment on mortality, ECGs that would allow for a diagnosis of non- $Q$ vs. $Q$ wave MI was not routinely collected in six studies (APSAC Intervention Mortality Study (AIMS), ${ }^{267}$ Anglo-Scandinavian Study of Early Thrombolysis (ASSET), ${ }^{268}$ Second International Study of Infarct Survival (ISIS2), ${ }^{269}$ Urochinasi per via Sistemica nell'Infarto Miocardico (USIM) Collaborative, ${ }^{270}$ Third International Study of Infarct Survival (ISIS-3), ${ }^{271}$ Estudio Miocardio Estreptoquinasa Republic Americas Sul (EMERAS) ${ }^{272}$ ). Personal communication with the investigators of the Gruppo Italian per lo Studio della Streptochinasi nell'Infarto Miocardio (GISSI)-I study $y^{273}$ during the initial data collection phase of this thesis revealed that all of the ECG information on 11,806 patients had been discarded approximately 6-12 months prior to contact. The remaining two large-scale trials (Intravenous Streptokinase in Acute Myocardial Infarction (ISAM) ${ }^{274-276}$ and Late Assessment of Thrombolytic Efficacy $\left(\right.$ LATE) ${ }^{2 \pi}$ ) are included in the thesis and the clinical and ECG databases were obtained from the principal investigators of the original studies (see Acknowledgements).

In addition, data was obtained from three smaller trials (designed to evaluate the impact of thrombolytic therapy on mortality and/or left ventricular function in acute $\mathrm{Ml}$ ) where ECG information was still available (Western Washington Randomized Intracoronary Streptokinase Trial (WWIC), ${ }^{278-280}$ Western Washington Intravenous Streptokinase in Acute Myocardial Infarction Randomized Trial (WWIV), ${ }^{281}$ and Tissue Plasminogen Activator: Toronto (TPAT) Placebo-Controlled Randomized Trial in Acute Myocardial Infarction; ${ }^{282}$ see Acknowledgements). An overview of the five trials included in the analyses was presented in Table 1, Chapter One. 


\section{Electrocardiographic Analysis}

In the WWIC, WWIV, and TPAT trials, ECGs were reviewed by experienced readers without the knowledge of patient treatment assignment or outcome using the modified Selvester criteria. ${ }^{283.284}$ The diagnosis of $Q$ or non- $Q$ wave MI was based upon a follow-up electrocardiogram performed at least 24 hours after (but prior to hospital discharge) the initiation of thrombolytic therapy. Intra- and inter-observer reliability for the electrocardiographic diagnosis of $Q$ wave $M I$ was evaluated in 115 patients in the TPAT study by the author (S.G.G.) and a Thesis Committee member (A.L.). The proportion of potential agreement beyond chance that was achieved ("kappa") was calculated according to the method described by Fleiss. ${ }^{285}$ In the ISAM study, the original ECGS were no longer available for review; however, the number of new $Q$ waves based on the Minnesota $\operatorname{code}^{286}$ (see Appendix 2) was determined by experienced readers without knowledge of treatment assignment or outcome at a core laboratory. ${ }^{276}$ An electrocardiographic classification was derived from this database where patients with one or more new $Q$ waves on the 24-hour ECG were designated as $Q$ wave Mls and those with no new $Q$ waves as non- $Q$ wave Mls. In the LATE study, ECGs were not available for review; however, the local study investigator provided a $Q$ vs. non- $Q$ wave $\mathrm{Ml}$ designation based upon a pre-discharge tracing without knowledge of treatment assignment.

\section{Review of Thesis Objective and Hypotheses}

As outlined in Chapter One, the objective of these analyses is to determine whether the frequency of development and subsequent prognosis of non-Q wave $\mathrm{MI}$ among patients presenting with ST segment elevation and receiving thrombolytic therapy is different from those receiving standard medical therapy. The hypotheses are: (1) among patients presenting with $S T$ I, the incidence of non-Q MI (vs. Q wave MI) will be higher in those receiving thrombolytic therapy as compared with a placebo; (2) the one year mortality for patients presenting with ST $\uparrow$ receiving thrombolysis will be lower in those who develop a non- $Q$ as compared with a $Q$ wave $M l$; and, (3) the one year mortality among patients presenting with STI who develop non-Q MI will be lower 
in those receiving thrombolytic therapy as compared with a placebo.

\section{Statistical Analysis}

Comparisons between the rate of development of non- $Q$ wave $M l$ between control- and thrombolytic-treated patients in each study were performed using a chisquare test. The relative risk of non-Q (as compared to $Q$ ) wave development (with $95 \%$ confidence intervals) were calculated for each study. The method described by Greenland and Robins ${ }^{246}$ was used to test for homogeneity under the null hypothesis that the relative risks were consistent across studies. The corrected Mantel-Haenszel chi-square test ${ }^{247}$ ( 1 degree of freedom, two-tailed) was used to test whether the relative risks differed systematically from a value of 1 . In addition, the relative risk for non-Q wave MI development (with $95 \%$ confidence intervals) with thrombolytic therapy as compared to control treatment in each study were calculated and pooled with variance weighting to derive a pooled relative response rate. ${ }^{287}$ The DerSimonian-Laird method ${ }^{287}$ was also used to assess absolute differences between thrombolytic-treated and control patients. This random effects approach to combining data from several trials comparing similar treatments incorporates the heterogeneity of effects in the analysis of the overall treatment. Further stratification according to the time of treatment administration (e.g., early $=0-12$ hours vs. late $=12-24$ hours) was performed in the LATE study and in the meta-analysis of non- $Q$ wave development.

The prognosis analyses were performed in a similar manner, and included comparisons (1) between the $Q$ and non- $Q$ wave groups regardless of initial treatment assignment; and, (2) among the $Q$ and non- $Q$ wave groups stratified by whether or not they had received thrombolysis. In addition, logistic regression models were used to examine the separate and combined impact of thrombolytic therapy and non-Q wave MI development on 1 year mortality.

Based on the fact that 1 year reinfarction and mortality data was available in the majority of patients in each study, long term prognosis was arbitrarily limited (prior to initiation of analysis) to this time frame.

Backward, stepwise logistic multiple regression models ${ }^{288,289}$ were used to 
examine individual and joint relations between important (example, age, history of prior Mi, presenting blood pressure and heart rate ${ }^{290}$ ) baseline clinical characteristics, treatment (thrombolysis vs. control), time to treatment, and $\mathrm{Q}$ wave $\mathrm{MI}$ development, inhospital, and 1 year outcome in each study.

\section{Results - Non-Q and $Q$ Wave Infarction in Randomized Controlled Trials of Thrombolytic Therapy}

\section{Overview of the Trials}

The five trials included in the data set are described briefly below. A more detailed description of background, patient selection, study design and treatment, and follow-up of each study is provided in Appendix 3. The trials were conducted from 1981 to 1992 and were all multicentre (range 10 to 230 hospitals) studies. With the exception of the TPAT study, all trials were international (range two to four countries). Patient inclusion criteria were similar in each study and required symptoms of acute MI and ST segment elevation (the WWIC, ISAM, and LATE studies included patients with other ECG changes at presentation but these patients were excluded from the current analyses). However, patients in the WWIC study required cardiac catheterization before random assignment to ensure that coronary artery thrombosis was present. All studies utilized a randomized controlled design with a control group in the WWIC and WWIV studies and the remaining studies employing a placebo treatment. Thrombolytic therapy consisted of intracoronary streptokinase in the WWIC, intravenous streptokinase in the ISAM and WWIV, and intravenous tissue plasminogen activator in the TPAT and LATE studies; the dosages and duration of administration varied among the trials. Time to randomized treatment ranged from $\leq 3.75$ to 24 hours. Intravenous heparin was required in the WWIC, ISAM, and TPAT studies, in streptokinase-treated patients in the WWIV trial, and recommended in the LATE study. Initial and/or subsequent aspirin or oral anticoagulants were mandated in all trials with the exception of control patients in the WWIV study. Other concomitant medical therapy was left to the discretion of the local physician. Subsequent cardiac catheterization, coronary 
angioplasty, and/or coronary bypass surgery, was also decided upon by the treating physician, with the exception of the WWIC (pre-randomization angiography) and TPAT (revascularization within the first 10 days confined to unstable patients). Patient followup (mortality and reinfarction) was available at $\geq 1$ year in the vast majority of patients with the exception of ISAM (reinfarction data available only up to seven months postindex $\mathrm{MI}$ ) and the WWIC and WWIV (no reinfarction data available) studies.

\section{Western Washington Randomized Trial of Intracoronary Streptokinase}

The Western Washington Randomized Trial of Intracoronary Streptokinase in Acute Myocardial Infarction was initiated in $1981,{ }^{278}$ with the 30 day and 1 year outcome reported in $1983^{279}$ and $1985,{ }^{280}$ respectively. Kennedy et al demonstrated a significant reduction in 30 day mortality $(3.7 \%$ vs. $11.2 \%, p=0.02)$ and a trend toward an improved outcome at 12 months ( $8.2 \%$ vs. $14.7 \%, p=0.10)$ among streptokinase as compared to control patients. ${ }^{279.280}$

Patients presenting $\leq 12$ hours of acute $\mathrm{Ml}$ were eligible. Prior to randomization patients underwent coronary angiography; if total or subtotal thrombosis was present following a single dose of intracoronary nitroglycerin, the patient was randomly assigned to the treatment (intracoronary streptokinase: $286,000 \pm 77,800$ units over $72 \pm 24$ minutes) or control group. Two hundred and fifty patients were enrolled in the trial; 237 presented with ST segment elevation. One hundred and eighty-four patients had pre-discharge ECGs available for review by experienced readers at a core laboratory using the modified Selvester criteria for $Q$ wave MI (see Appendix 2). ${ }^{283,284}$ Intravenous Streptokinase in Acute Myocardial Infarction (ISAM) Study

The Intravenous Streptokinase in Acute Myocardial infarction (ISAM) study was started in March 1982. Twenty-one day and long-term (average 21 and 31-month) outcomes were reported in $19866^{274}$ and $1987,{ }^{275.276}$ respectively. The mortality rate was similar between streptokinase- and placebo-treated patients at 21 days (6.3\% vs. $7.1 \%$, $p=n . s.),{ }^{274}$ seven months $(10.9 \%$ vs. $11.1 \%, p=n . s),.{ }^{275}$ and 31 months $(17.6 \%$ vs. $18.6 \%)^{276}$

Patients were randomized within 6 hours of Ml onset to receive intravenous 
streptokinase (1.5 million IU) or placebo over 60 minutes in a double-blind manner. A total of 1,741 patients was entered into the study; 233 were excluded from the present analysis: 20 died within 3 hours after randomization or had cardiac arrest and died shortly thereafter, 122 had bundle branch block or ventricular rhythm (mostly pacing), 48 had no significant ST segment elevation on their pre-randomization ECG (sum of ST segment elevation $<2 \mathrm{~mm}$ ), and 45 patients had no available ECG at 24 hours. Therefore, 1,508 patients were included in the present analysis, with ECG classification of the amount of ST segment elevation and the number of new $Q$ waves (based on the Minnesota code ${ }^{286}$; see Appendix 2) performed by experienced readers without knowledge of treatment assignment or outcome at a core laboratory. ${ }^{276}$

Electrocardiographic classification was made from this database; patients with $\geq 1$ new $Q$ wave on the 24-hour ECG were designated as $Q$ wave $M l s$ and those with no new $Q$ waves as non- $Q$ wave Mls.

\section{Western Washington Randomized Trial of Intravenous Streptokinase}

The Western Washington Intravenous Streptokinase in Acute Myocardial Infarction Randomized trial began patient enrollment in September 1983. ${ }^{281}$ The study was stopped prior to enrollment of the planned sample size after Gruppo Italiano per lo Studio della Streptochinasi nell'Infarto Miocardico (GISSI)-1 reported a significant benefit of intravenous streptokinase as compared to placebo in the reduction of mortality. ${ }^{273}$ Fourteen day mortality rates in the WWIV trial after 368 patients were randomized were similar among the streptokinase-treated and control groups $(6.3 \%$ vs. $9.6 \%, p=0.23) .{ }^{281}$ The Western Washington Streptokinase in Myocardial Infarction Trials study group published results in 1992 after combining the intracoronary and intravenous studies together and demonstrated an improved 6-week survival in patients who received streptokinase as compared to the control group ( $6 \%$ vs. $12 \%, p=0.01$ ). Three year mortality rates were similar among the two groups (16\% vs. $18 \%$, $\mathrm{p}=0.16)$. $^{291}$

Patients in the WWIV study were randomly assigned within 6 hours of acute MI to receive streptokinase (intravenous 1.5 million units over 1 hour) or control therapy. 
Three hundred and thirty-nine patients were enrolled in the trial and 284 had predischarge ECGs available for review by experienced readers at a core laboratory using the modified Selvester criteria for $Q$ wave MI (see Appendix 2). ${ }^{283,284}$

\section{The Tissue Plasminogen Activator: Toronto (TPAT) Study}

The Tissue Plasminogen Activator: Toronto (TPAT) study took place in 1987 with the 90-day results published in $1989 .{ }^{282}$ Although the study was designed to evaluate global and left ventricular function nine days after MI the 90-day mortality was $5.1 \%$ for $\mathrm{rt}$-PA- and $12.5 \%$ for placebo-treated groups.

Patients were randomized to receive rt-PA (0.51-0.57 MU/kg over 7-11 hours) or matching placebo in a double-blind manner. Of the 118 patients randomized, 3 were subsequently ruled ineligible because they did not have a myocardial infarction. Predischarge ECGs (performed 224 hours post-thrombolysis; $n=115$ ) were reviewed independently by two experienced readers using the modified Selvester criteria for $Q$ wave Ml (see Appendix 2). ${ }^{283,284}$

\section{The Late Assessment of Thrombolytic Efficacy (LATE) Study}

While several large trials in acute MI had demonstrated that thrombolytic therapy improves survival, ${ }^{267-269.273}$ two of these trials limited patient entry to the first 5-6 hours after symptom onset ${ }^{267,268}$ and one trial randomizing patients up to 12 hours showed a striking decrease in benefit with time. ${ }^{273}$ Another trial permitted randomization up to 24 hours and revealed a persistently significant benefit to 12 hours together with some benefit which approached statistical significance in the 12-24 hour group. ${ }^{269}$ Therefore, as the value of late thrombolysis was uncertain, The Late Assessment of Thrombolytic Efficacy (LATE) study was undertaken in 1989 to evaluate the impact of thrombolytic therapy initiated 6 to 24 hours after chest pain onset in acute $\mathrm{MI}^{277}$ There was a trend toward a lower 35-day mortality among the IPA- as compared to placebo-treated group ( $8.86 \%$ vs. $10.31 \%, p=0.07$ ). Mortality was significantly lower among tPA-treated patients randomized $6-12$ hours from symptom onset ( $8.90 \%$ vs. $11.97 \%, p=0.02)$; patients randomized $>12-24$ hours after $\mathrm{Ml}$ onset derived no benefit from thrombolysis $(8.68 \%$ vs. $9.18 \%, p=0.6)$. 
Patients were randomized to receive intravenous r-tPA (100 mg over 3 hours) or matching placebo in a double-blind manner. Of the 5,711 eligible patients, 2,769 presented with ST segment elevation, had a confirmed MI based on cardiac enzyme levels raised to greater than twice normal, and had a post-treatment ECG that could be classified according to infarct type. A pre-discharge ECG classification of $Q$ or non-Q wave was undertaken by the local investigator.

The LATE study provided a unique opportunity to evaluate the impact of thrombolytic therapy on non- $Q$ wave development and prognosis when compared to the other 4 trials in the analysis because of the randomization time window. While the WWIC study allowed enrollment up to 12 hours after MI onset, ISAM, WWIV, and TPAT restricted entry to patients within 6 hours ( 3.75 hours in TPAT); in contrast LATE patients were randomized within both the 6-12 and >12-24 hour time frames.

\section{Intra- and Inter-Observer Reliability}

Intra- and inter-observer variability for the electrocardiographic diagnosis using the modified Selvester criteria for Q wave MI was evaluated in 115 patients in the TPAT

study by the author (S.G.G.) and a Thesis Committee member (A.L.). The proportion of potential agreement beyond chance that was achieved ("kappa") was calculated according to the method described by Fleiss. ${ }^{285}$ The intra-observer agreement for the diagnosis of $\mathrm{Q}$ wave $\mathrm{MI}$ was $100 \%$ (1 reader) and the inter-observer agreement (two readers) was $99.1 \%$ (kappa=0.96).

\section{Non-Q Wave Development}

Of the 4,860 patients presenting with ST segment elevation in the five randomized trials, non-Q wave MI developed in 667 (13.7\%). The rate of non-Q wave development, regardless of treatment, ranged from $8.7 \%$ in the WWIC study to $15.1 \%$ in the ISAM study (see Table 9).

Of the 4,860 patients, 2,439 received placebo or control and 2,421 received thrombolytic therapy. Non- $Q$ wave development was significantly greater among thrombolytic- as compared to control/placebo-treated patients in the WWIC, ISAM, and WWIV studies; non- $Q$ rates were similar among the two treatment groups in TPAT and 
LATE (see Table 9).

TABLE 9

Non-Q Wave MI Development

\begin{tabular}{|c|c|c|c|}
\hline \multirow{2}{*}{ Trial } & \multicolumn{3}{|c|}{ Non-Q Wave MI Development } \\
\cline { 2 - 4 } & Overall & Control/Placebo & Thrombolytic \\
\hline WWIC & $16 / 184(8.7)$ & $14 / 101(2.4)$ & $2 / 83(13.9)^{\star}$ \\
\hline ISAM & $228 / 1508(15.1)$ & $94 / 764(12.3)$ & $134 / 744(18.0)^{\star *}$ \\
\hline WWIV & $32 / 284(11.3)$ & $6 / 143(4.2)$ & $26 / 141(18.4)^{* * *}$ \\
\hline TPAT & $13 / 115(11.3)$ & $6 / 56(10.7)$ & $7 / 59(11.9)$ \\
\hline LATE & $378 / 2769(13.7)$ & $194 / 1393(13.9)$ & $184 / 1376(13.4)$ \\
\hline
\end{tabular}

Thrombolytic-vs. contro/placebo-treated non $Q: " p=0.006 ; " * p=0.002 ; * * * p<0.001$

The relative risk for non- $Q$ wave development ranged from $0.96(95 \% \mathrm{Cl} 0.80$, 1.16) in LATE to $5.75(95 \% \mathrm{Cl} 1.35,24.59)$ in WWIC (see Figure 17). The rate of non$Q$ wave development among patients receiving thrombolysis as compared with placebo was similar in those treated 6-12 and $>12-24$ hours. The pooled relative risk for non- $Q$ wave development following thrombolytic as compared to control/placebo therapy was $1.18(95 \% \mathrm{Cl} 1.03,1.37$; chi-square test for heterogeneity $=24.01, p=0.00008)$ (see Figure 16). The relative risk for non- $Q$ wave development following thrombolysis (and the heterogeneity between the studies) was similar even after excluding patients in the LATE study who were randomized to treatment $>12-24$ hours after symptom onset (RR $1.24 ; 95 \% \mathrm{Cl} 1.05,1.46$; chi-square test for heterogeneity $=22.36, p=0.0002$ )(see Figure 17). 
FIGURE 17 - Non-Q Wave Development

WWIC

ISAM

WWIV

TPAT

LATE (All Patients)

(6-12 hrs)

\section{OVERALL}

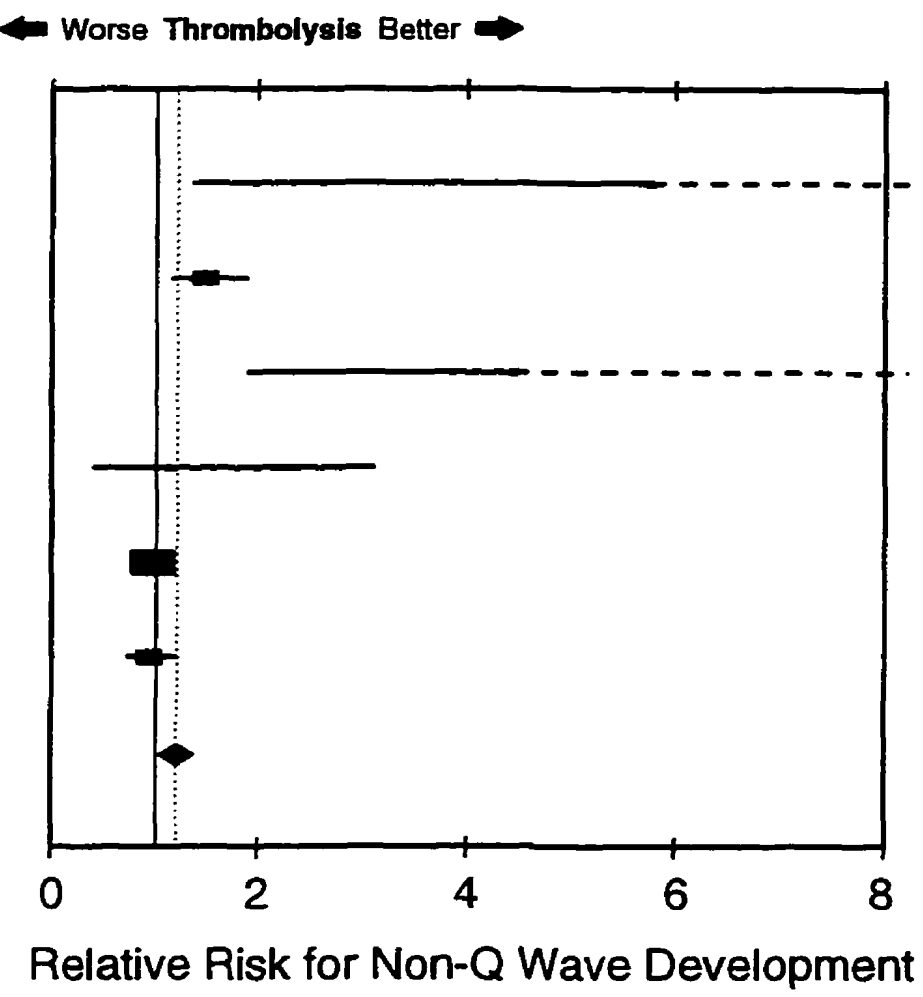

Solid squares represent stratified relative risk (thrombolytic:controlplacebo) for non- $Q$ wave development for individual trials. Sizes of squares are proportional to the overall sample size $(4,860$ patients from the five trials). Horizontal lines denote $95 \%$ confidence intervals. The diamond represents the overall relative risk (and 95\% confidence intervals) for all trials. Black squares to the right of the solid vertical line indicate a greater impact of thrombolysis (relative to controlplacebo) for non- $Q$ wave development in this pooled analysis; the result is significant $(p<0.05$ for both horizontal lines and the diamond) when the entire confidence interval is to the right of the line. 
Utilizing the DerSimonian and Laird ${ }^{287}$ technique of meta-analysis to incorporate the heterogeneity of effects in the analysis of the overall treatment effect, the (adjusted variance weighted) absolute difference in probability of response $\left(P_{\text {thromborytic }}\right.$ $\left.P_{\text {controuplacebo }}\right)$ was 0.031 ( $95 \% \mathrm{Cl} 0.012,0.050$; chi-square test of homogeneity of the treatment effect $=23.85 ; p<0.0001)$; in other words, thrombolytic treatment resulted in a $3.1 \%$ increase in non- $Q$ wave development. Repeat analysis excluding LATE patients randomized to treatment $>12$ hours after symptom onset demonstrated a similar absolute difference in probability of $0.041(95 \% \mathrm{Cl} 0.019,0.063$; test of homogeneity $\mathrm{Q}$ $=20.95 ; \mathrm{p}=0.0003$ ).

\section{Logistic Regression Analysis For Q Wave Development}

Prior to logistic regression analysis, data from the Western Washington Trials (WWIC and WWIV) were combined. As these two studies were coordinated by the same group of investigators, shared a common geographical location with respect to patient enrollment, and were undertaken in a sequential chronologic manner, the results were combined for the purposes of this analysis. Long-term (minimum of 3 and a mean of $4.9 \pm 2.3$ years) survival of the original 618 patients ( 250 from the intracoronary and 368 from the intravenous trials, respectively) was previously examined, ${ }^{291}$ and demonstrated that the control and streptokinase-treated groups were well matched for the majority of clinical characteristics on admission. The two trial patient subgroups in the current ECG analyses were also similar based on a comparison of the baseline characteristics (e.g., gender, coronary artery disease risk factors, prior history of myocardial infarction, etc.), the rate of non-Q wave development following the administration of streptokinase, and the in-hospital and 1 year mortality.

In models predicting the development of a $Q$ wave based on backward, stepwise logistic regression analyses and including predetermined variables known to impact on short-term clinical outcome following thrombolysis, ${ }^{290}$ the administration of thrombolytic therapy was an independent predictor in the Western Washington studies (odds ratio $(\mathrm{OR})=0.20 ; 95 \%$ confidence intervals $(\mathrm{Cl}) 0.09,0.45)$ and in ISAM (OR=0.62;95\% Cl $0.46,0.83$ )(see Table 10). In other words, thrombolytic therapy (as compared to 
placebo/control) was "protective" in that it was associated with less frequent development of $Q$ wave MI. A non-anterior or inferior location on the ECG and (lack of) history of prior MI were also independent predictors of $Q$ wave development in the Western Washington and LATE studies. One or more of the important clinical characteristics (e.g., male gender, greater than the study mean age, higher than the study mean baseline heart rate and systolic blood pressure) were independent predictors of $Q$ wave development in ISAM, TPAT, and LATE. Finally, while thrombolysis itself was not an independent predictor of $Q$ wave $M I$ in the LATE trial, a shorter time to thrombolytic administration was a modest independent predictor of $Q$ wave development (see Table 10).

Thus, in addition to important clinical characteristics, administration of thrombolytic therapy was a powerful (and favourable) predictor of non- $Q$ wave $\mathrm{MI}$ development in the Western Washington and ISAM trials. 
TABLE 10

Summary of the Results of Backward, Stepwise Logistic Regression Analyses by Trial

\begin{tabular}{|c|c|c|c|}
\hline \multirow[b]{2}{*}{ Study } & \multirow{2}{*}{$\begin{array}{l}\text { Variables in } \\
\text { the Model }\end{array}$} & \multicolumn{2}{|c|}{ Independent Predictors" (Odds Ratio; 95\% Confidence Intervals) of } \\
\hline & & Q Wave Development & 1 Year Mortality \\
\hline WW & $\begin{array}{l}\text { All except } \\
\text { DBP, HR }\end{array}$ & $\begin{array}{l}\text { Thrombolysis }(0.20 ; 0.09,0.51) \\
\text { Non-anterior location }(0.21 ; 0.08,0.51) \\
\text { Prior MI }(0.42 ; 0.17,1.02 ; p=0.054)^{*}\end{array}$ & $\begin{array}{l}\text { Control Group: } \\
\text { Greater age }(1.07 ; 1.02,1.19) \\
\text { Higher SBP }(0.98 ; 0.97,0.99) \\
\text { Thrombolytic Group: } \\
\text { Q Wave MI }(6.19 ; 0.8,47.99 ; p=0.081)^{*}\end{array}$ \\
\hline ISAM & All & $\begin{array}{l}\text { Thrombolysis }(0.62 ; 0.46,0.83) \\
\text { Greater age }(1.03 ; 1.01,1.04)\end{array}$ & $\begin{array}{l}\text { Control Group: } \\
\text { Greater age }(1.07 ; 1.04,1.11) \\
\text { Higher HA }(1.02 ; 1.01,1.04) \\
\text { Higher SBP }(0.98 ; 0.97,0.99) \\
\text { Thrombolytic Group: } \\
\text { Greater age }(1.10 ; 1.07,1.15) \\
\text { Higher HR }(1.02 ; 1.101,1.04) \\
\text { Q Wave MI }(6.42 ; 1.53,27.06)\end{array}$ \\
\hline TPAT & All & $\begin{array}{l}\text { Prior Ml }(0.14 ; 0.03,0.73) \\
\text { Male gender }(6.23 ; 1.58,24.54)\end{array}$ & $\begin{array}{l}\text { Greater age }(1.13 ; 1.02,1.25) \\
\text { Anterior location }(13.14 ; 1.52,113.52)\end{array}$ \\
\hline LATE & All & $\begin{array}{l}\text { Greater age }(1.01 ; 1.003,1.02) \\
\text { Higher SBP }(0.99 ; 0.98,0.995) \\
\text { Higher HR }(1.007 ; 1.00,1.01) \\
\text { Male gender }(1.33 ; 1.03,1.71) \\
\text { Prior Ml }(0.50 ; 0.38,0.66) \\
\text { Shorter time to treatment }(0.97 ; 0.95,0.99) \\
\text { Inferior location }(1.56 ; 1.21,2.00)\end{array}$ & $\begin{array}{l}\text { Greater age }(1.09 ; 1.07,1.10) \\
\text { Higher HR }(1.02 ; 1.01,1.03) \\
\text { Higher SBP }(0.98 ; 0.97,0.99) \\
\text { Q Wave MI }(1.55 ; 1.07,2.24)\end{array}$ \\
\hline
\end{tabular}

- Predictors of borderline statistical significance $(0.05<p<0.09)$ are included in the table with the $p$ value indicated after the $95 \%$ Cls. DBP $=$ diastolic blood pressure; SBP = systolic blood pressure; $\mathrm{HR}=$ heart rate; $\mathrm{MI}=$ myocardial infarction. Greater refers to greater than the study mean; location refers to ECG localization of infarct; shorter time to treatment refers to shorter than the study mean time to thrombolytic administration. 


\section{Non-Q vs. $Q$ Wave Infarction - Outcome by Infarct Type}

In-Hospital Mortality

Regardless of treatment, the in-hospital mortality rate was significantly lower among patients with non- $Q$ as compared to $Q$ wave patients in the LATE study (RR $0.58 ; 95 \% \mathrm{Cl} 0.39,0.86$ ). In-hospital mortality rates were also lower in the non- $Q$ wave groups in the WWIC, ISAM, WWIV, and TPAT studies, but these differences were not statistically significant. The overall pooled relative risk for in-hospital death was 0.62 $(95 \% \mathrm{Cl} 0.44,0.87$; chi-square test for heterogeneity $=0.67 ; p=0.7)$ among non- $Q$ relative to $Q$ wave $M l$ patients.

In the meta-analysis, the (adjusted variance weighted) absolute difference in probability of in-hospital mortality $\left(P_{\text {nor-Q wave }}-P_{Q_{\text {wave }}}\right)$ was $-0.045(95 \% \mathrm{Cl}-0.073$, 0.016; chi-square test of homogeneity $=11.31 ; p=0.023$ ); in other words, the non- $Q$ wave group experienced a $4.5 \%$ absolute lower in-hospital mortality rate as compared to the $Q$ wave group (see Figure 18). 
FIGURE 18 - Non-Q vs. Q Wave MI In-hospital and 1 Year Mortality and Reinfarction - Stratified Meta-Analysis

\section{Mortality}

In-Hospital

1 Year

Reinfarction

In-Hospital

1 Year

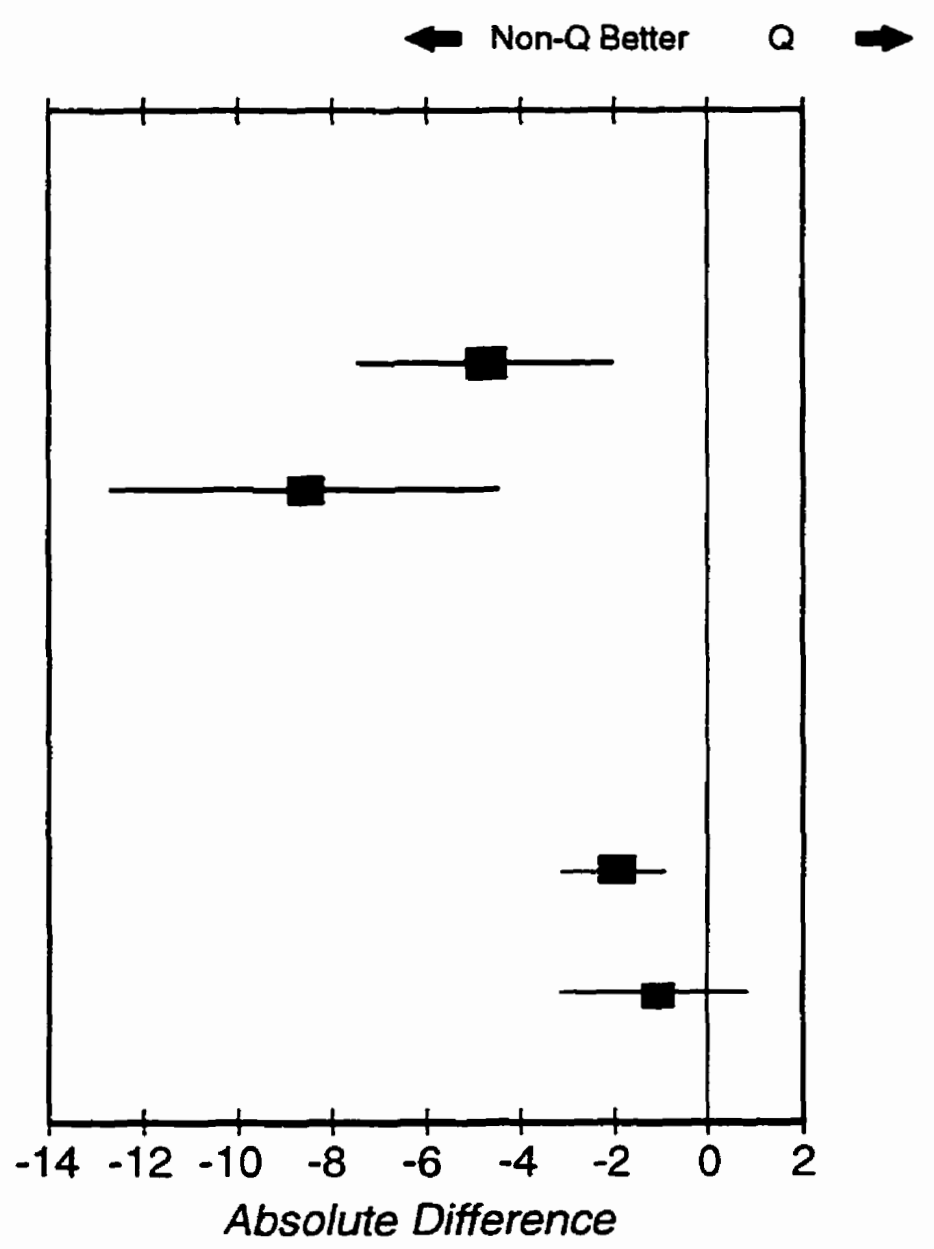

Solid squares represent the (adjusted variance weighted) absolute difference in probability of in-hospital and 1 year mortality and reinfarction $\left(P_{\text {Non-a wave }}-P_{\text {Q wave }}\right)$ for the five randomized trials (reinfarction data not available in the WWIC and WWIV trials). Sizes of squares are proportional to the overall sample size $(4,860$ patients from the five trials). Horizontal lines denote $95 \%$ confidence intervals. Black squares to the left of the solid vertical line indicate a lower absolute event rate among non- $Q$ as compared to $Q$ wave patients; the result is significant ( $p<0.05$ for horizontal lines) when the entire confidence interval is to the left of the line. 
In-Hospital Reinfarction

Regardless of treatment, the in-hospital reinfarction rates tended to be lower among patients with non- $Q$ as compared to $Q$ wave patients in the 3 studies (ISAM, TPAT, and LATE) where this data was available. However, the number of events was small in each study with broad confidence intervals were broad and these differences were not statistically significant. The overall pooled relative risk for in-hospital reinfarction was $0.59(95 \% \mathrm{Cl} 0.33,1.05$; chi-square test for heterogeneity $=0.21$; $p=0.7$ ) among non- $Q$ relative to $Q$ wave $M l$ patients.

In the meta-analysis, the absolute difference in probability of in-hospital reinfarction ( $\left.P_{\text {non-a wave }}-P_{\text {Q wave }}\right)$ was -0.017 (95\% Cl $-0.028,-0.006$; test of homogeneity $Q=3.52 ; p=0.17)$; in other words, the non- $Q$ wave group experienced a significant $1.7 \%$ absolute lower in-hospital reinfarction rate as compared to the $Q$ wave group (see Figure 18).

One Year Mortality

Regardless of treatment, the 1 year mortality rate was significantly lower among patients with non-Q as compared to $Q$ wave patients in the ISAM (RR $0.55 ; 95 \% \mathrm{Cl}$ $0.31,0.98$ ) and LATE studies (RR $0.68 ; 95 \% \mathrm{Cl} 0.51,0.91$ ). The 1 year mortality rates were also lower in the non- $Q$ wave groups in the WWIC, WWIV, and TPAT studies, but these differences were not statistically significant. The overall pooled relative risk for 1 year death was $0.65(95 \% \mathrm{Cl} 0.51,0.84$; chi-square test for heterogeneity $=0.14$; $p=0.9$ ) among non- $Q$ relative to $Q$ wave $M l$ patients.

In the meta-analysis, the absolute difference in probability of 1 year mortality $\left(P_{\text {non-Q wave }}-P_{\text {Qwave }}\right)$ was $-0.086(95 \% \mathrm{Cl}-0.128,-0.045$; chi-square test of homogeneity $=11.24 ; \mathrm{p}=0.024) ;$ in other words, the non- $\mathrm{Q}$ wave group experienced a $4.5 \%$ absolute lower in-hospital mortality rate as compared to the $Q$ wave group (see Figure 18). One Year Reinfarction

Regardless of treatment, the 1 year reinfarction rates were similar among patients with non- $Q$ as compared to $Q$ wave patients in the 3 studies (ISAM, TPAT, and LATE) where this data was available. The overall pooled relative risk for in-hospital 
reinfarction was 0.97 ( $95 \% \mathrm{Cl} 0.69,1.36$; chi-square test for heterogeneity $=0.33$; $p=0.6$ ) among non- $Q$ relative to $Q$ wave $M l$ patients.

In the meta-analysis, the absolute difference in the probability of 1 year reinfarction $\left(P_{\text {non-O wave }}-P_{Q \text { wave }}\right)$ was $-0.010(95 \% \mathrm{Cl}-0.030,0.009$; chi-square test of homogeneity $=1.34 ; p=0.51$ ); in other words, the non- $Q$ wave group experienced a non-significant $1.0 \%$ absolute lower 1 year reinfarction rate as compared to the $Q$ wave group (see Figure 18).

\section{Non- $Q$ vs. $Q$ Wave Infarction - Outcome by Treatment} In-Hospital Mortality

The in-hospital mortality rate was consistently lower among thrombolytic-treated patients who developed a non- $Q$ as compared to $Q$ wave $M l$ in all studies; this difference achieved statistical significance in the largest trial (the LATE study: $4.9 \%$ vs. $10.7 \%, p=0.02$ )(see Table 11). In the meta-analysis, the absolute difference in probability of in-hospital mortality among patients who received thrombolysis and developed a non- $Q$ as compared to a $Q$ wave $M I\left(P_{\text {non- } Q \text { wave thrombolytic }}-P_{Q \text { wave thrombolytic }}\right)$ was $-0.038(95 \% \mathrm{Cl}-0.052,-0.024$; chi-square test of homogeneity $=3.98 ; p=0.41)$; in other words, the thrombolytic-treated group who developed a non- $Q$ wave experienced a significant 3.8\% absolute lower in-hospital mortality rate as compared to those patients who developed a $Q$ wave $\mathrm{Ml}$ (see Figure 19). In contrast, the absolute difference in the probability of in-hospital mortality among patients who received control/placebo and developed a non- $Q$ as compared to a $Q$ wave $M I$ ( $\left.P_{\text {non- }-Q \text { wave controlplacebo }}-P_{Q \text { wave controlplacebo }}\right)$ was $0.046(95 \% \mathrm{Cl}-0.013,0.104$; chi-square test of homogeneity $=13.40 ; p=0.009)$ and was not statistically significant.

Comparison of thrombolytic- and placebo-treated patients who developed a non$Q$ wave $M I$ revealed a significantly lower in-hospital mortality $(0.8 \%$ vs. $6.4 \%, p=0.02)$ in the ISAM study. In the meta-analysis, the absolute difference in the probability of inhospital mortality among patients who developed a non-Q wave $\mathrm{MI}\left(\mathrm{P}_{\text {non-Q wave thrombolytic }}\right.$ $\left.P_{\text {non-Q wave controvplacebo }}\right)$ was $-0.046(95 \% \mathrm{Cl}-0.011,-0.082$; chi-square test of homogeneity $=1.37 ; p=0.85) ;$ in other words, the thrombolytic-treated group who developed a non- $Q$ 
wave experienced a significant $4.6 \%$ absolute lower in-hospital mortality rate as compared to the non- $Q$ wave patients who had received control/placebo (see Figure 20). In contrast, the absolute difference in the probability of in-hospital mortality among patients who developed a $Q$ wave $\mathrm{MI}\left(\mathrm{P}_{\mathrm{Q} \text { wave thrombolytic }}-\mathrm{P}_{\mathrm{Q} \text { wave controuplacebo }}\right)$ was only -0.016 $(95 \% \mathrm{Cl}-0.039,0.007$; chi-square test of homogeneity $=6.16 ; p=0.19)$ and was not statistically significant. 
FIGURE 19 - $Q$ vs. Non-Q Wave In-Hospital and 1 Year Mortality and Reinfarction Stratified According to Thrombolytic vs. Control/Placebo Treatment

\author{
IN-HOSPITAL \\ Mortality \\ Control/Placebo \\ Thrombolysis \\ Reinfarction \\ Control/Placebo \\ Thrombolysis \\ 1 YEAR \\ Mortality \\ Control/Placebo \\ Thrombolysis

\section{Reinfarction \\ Control/Placebo \\ Thrombolysis}

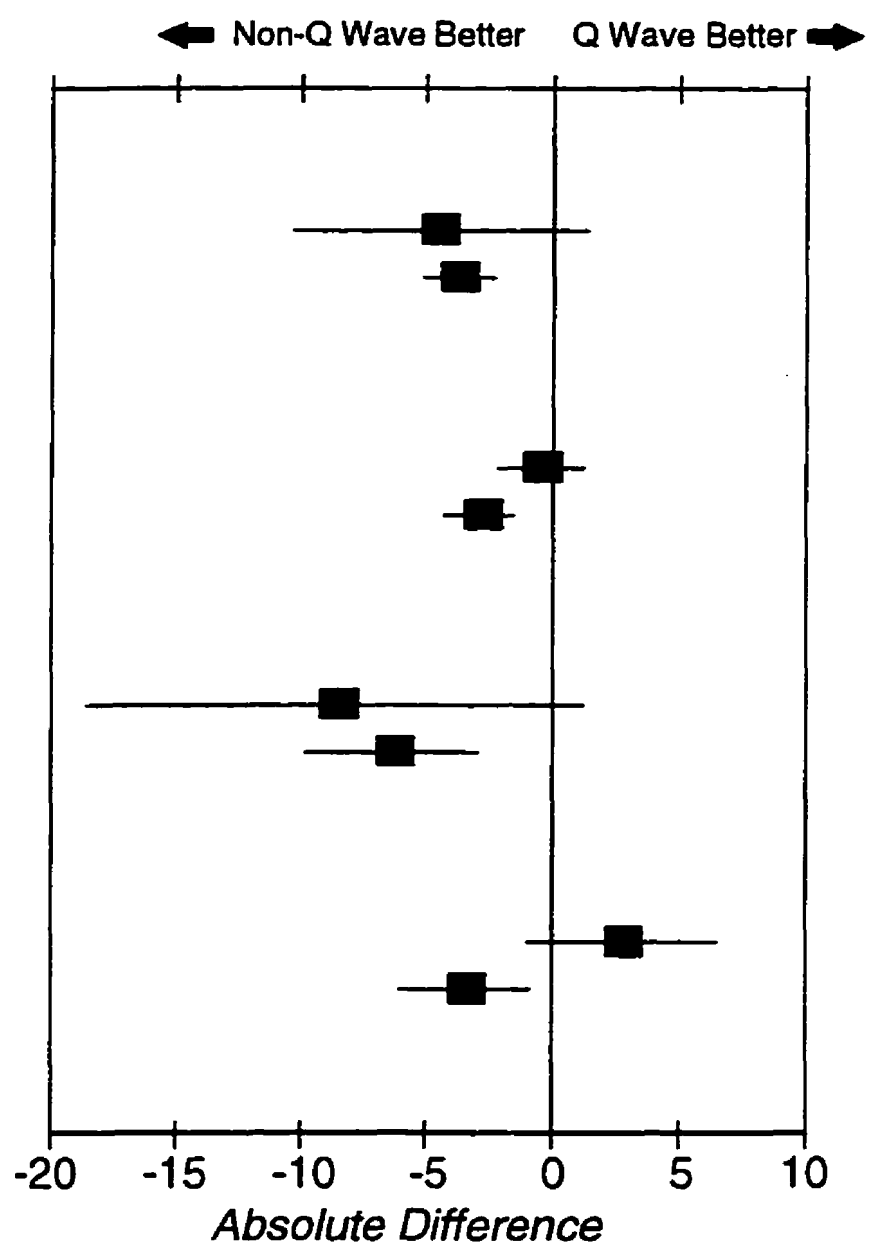

Solid squares represent the (adjusted variance weighted) absolute difference in probability of in-hospital and 1 year mortality and reinfarction ( $\left.P_{\text {non-a wave }}-P_{\text {a wave }}\right)$ between the controlplacebo and thrombolytic treatment groups for the five randomized trials (reinfarction did not occur in the non- $Q$ wave group in TPAT and reinfarction data were not available in the WWIC and WWIV trials). Sizes of squares are proportional to the overall sample size (4,860 patients from the five trials). Horizontal lines denote $95 \%$ confidence intervals. Black squares to the left of the solid vertical line indicate a lower absolute event rate among non- $Q$ as compared to $Q$ wave patients; the result is significant ( $p<0.05$ for horizontal lines) when the entire confidence interval is to the left of the line. 


\section{In-Hospital Reinfarction}

The in-hospital reinfarction rates were low in the 3 studies (ISAM, TPAT, and LATE) where this data was available. Among thrombolytic-treated patients, those who developed a non-Q as compared to a $Q$ wave $\mathrm{Ml}$ had a significantly lower in-hospital reinfarction rate in the LATE study $(1.1 \%$ vs. $4.1 \%, p=0.04)$, but similar reinfarction rates in the ISAM and TPAT trials.

In the meta-analysis, the absolute difference in probability of in-hospital reinfarction among patients who received thrombolysis and developed a non- $Q$ as compared to a $Q$ wave $\mathrm{MI}\left(\mathrm{P}_{\text {non-Q wave thrombolyic }}-\mathrm{P}_{\mathrm{Q} \text { wave thrombolytic }}\right)$ was $-0.029(95 \% \mathrm{Cl}$ $0.043,-0.016$; chi-square test of homogeneity $=0.93 ; p=0.63$ ); in other words, the thrombolytic-treated group who developed a non- $Q$ wave experienced a significant $2.9 \%$ absolute lower in-hospital reinfarction rate as compared to those patients who developed a $Q$ wave $\mathrm{Ml}$ (see Figure 19). In contrast, the absolute difference in the probability of in-hospital mortality among patients who received control/placebo and developed a non- $Q$ as compared to a $Q$ wave $M I$ ( $\left.P_{\text {non-Q wave controuplacebo }}-P_{\text {Q wave controlplacebo }}\right)$ was $-0.005(95 \% \mathrm{Cl}-0.027,0.012 ;$ chi-square test of homogeneity $=2.84 ; p=0.24)$ and was not statistically significant.

In the meta-analysis, the absolute difference in probability of in-hospital reinfarction among the non- $Q$ wave group $\left(P_{\text {non-Q wave thrombolyic }}-P_{\text {non-Q }}\right.$ wave placebo $)$ was -0.014 $(95 \% \mathrm{Cl}-0.034,0.006$; chi-square test of homogeneity $=1.72 ; p=0.42)$. Similarly, the absolute difference in the $Q$ wave group $\left(P_{Q \text { wave thromboytic }}-P_{Q \text { wave placebo }}\right)$ was $0.009(95 \%$ $\mathrm{Cl}-0.002,0.021$; chi-square test of homogeneity $=3.69 ; \mathrm{p}=0.16$ ). In other words, the thrombolytic- as compared to placebo-treated patients who developed a non- $Q$ wave $\mathrm{MI}$ experienced a non-significant $1.4 \%$ absolute lower in-hospital reinfarction rate and the thrombolytic-treated patients who developed a $Q$ wave experienced a non-significant $0.9 \%$ absolute higher rate of in-hospital reinfarction (see Figure 20 ). 


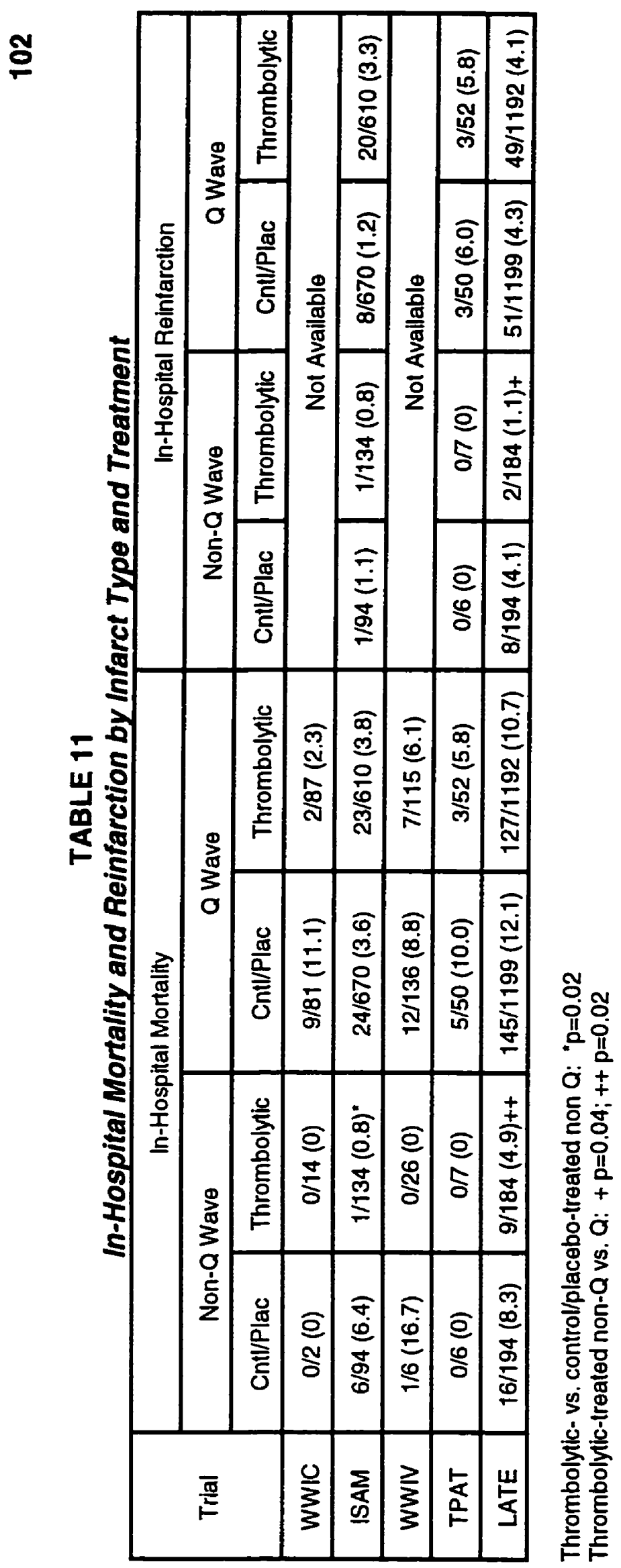


FIGURE 20 - Thrombolytic vs. Control/Placebo Treatment Between $Q$ and Non- $Q$ Wave MI Patients - In-hospital and 1 Year Mortality and Reinfarction

\author{
IN-HOSPITAL \\ Mortality \\ $Q$ Wave \\ Non-Q Wave \\ Reinfarction \\ $Q$ Wave \\ Non-Q Wave \\ 1 YEAR \\ Mortality \\ $Q$ Wave \\ Non-Q Wave \\ Reinfarction \\ $Q$ Wave \\ Non-Q Wave
}

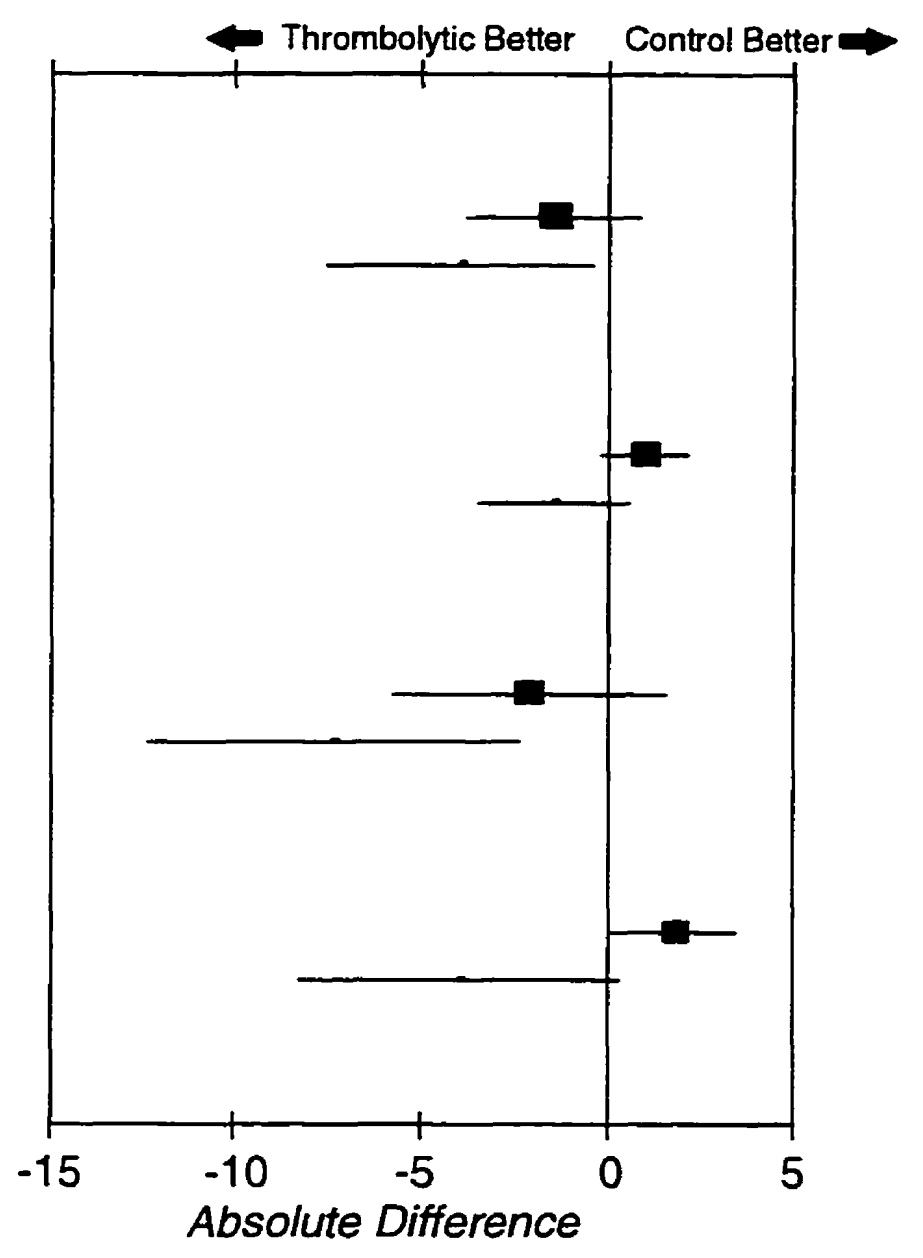

Solid squares represent the (adjusted variance weighted) absolute difference in probability of in-hospital and 1 year mortality and reinfarction ( $P_{\text {thrombontic }}-P_{\text {Controuplacebo }}$ ) between the $Q$ and non- $Q$ wave groups for the five randomized trials (reinfarction did not occur in the non- $Q$ wave group in TPAT and reinfarction data were not available in the WWIC and WWIV trials). Sizes of squares are proportional to the overall sample size $(4,860$ patients from the five trials). Horizontal lines denote $95 \%$ confidence intervals. Black squares to the left of the solid vertical line indicate a lower absolute event rate among thrombolytic- as compared to control/placebo-treated patients; the result is significant ( $p<0.05$ for horizontal lines) when the entire confidence interval is to the left of the line. 


\section{One Year Mortality}

The 1 year mortality rate was consistently lower among thrombolytic-treated patients who developed a non- $Q$ as compared to $Q$ wave $M l$ in all studies; this difference achieved statistical significance in the largest trial (the LATE study: $12.9 \%$ vs. $16.8 \%, p=0.02$ ) (see Table 12). In the meta-analysis, the absolute difference in probability of 1 year mortality among patients who received thrombolysis and developed a non- $Q$ as compared to a $Q$ wave $M I\left(P_{\text {non- } Q \text { wave thromboytic }}-P_{Q \text { wave thrombolytic }}\right)$ was $-0.064(95 \% \mathrm{Cl}-0.099,-0.030$; chi-square test of homogeneity $=7.64 ; \mathrm{p}=0.11)$; in other words, the thrombolytic-treated group who developed a non- $Q$ wave experienced a significant $6.4 \%$ absolute lower 1 year mortality rate as compared to those patients who developed a $Q$ wave MI (see Figure 19). In contrast, the absolute difference in the probability of 1 year mortality among patients who received control/placebo and developed a non- $Q$ as compared to a $Q$ wave $M I$ ( $\left.P_{\text {non- } Q \text { wave controuplacebo }}-P_{Q \text { wave controuplacebo }}\right)$ was 0.089 (95\% Cl $-0.186,0.012$; chi-square test of homogeneity $=19.74 ; p=0.0006$ ) and was not statistically significant.

Comparison of thrombolytic- and placebo-treated patients who developed a non$Q$ wave $M I$ revealed a significantly lower 1 year mortality ( $1.5 \%$ vs. $10.6 \%, p=0.004$ ) in the ISAM study. In the meta-analysis, the absolute difference in the probability of 1 year mortality among patients who developed a non-Q wave $M I\left(P_{\text {non-Q wave thrombolytic }}-P_{\text {non- }}\right.$ o wave controuplacebo $)$ was $-0.075(95 \% \mathrm{Cl}-0.12,-0.025$; chi-square test of homogeneity $=$ 2.55; $p=0.64)$; in other words, the thrombolytic-treated group who developed a non- $Q$ wave experienced a significant $7.5 \%$ absolute decrease in the 1 year mortality rate as compared to the non- $Q$ wave patients who had received control/placebo (see Figure 20). In contrast, the absolute difference in the probability of 1 year mortality among patients who developed a $Q$ wave $M I\left(P_{Q \text { wave thrombolylic }}-P_{Q \text { wave controuplacebo }}\right)$ was -0.021 ( $95 \%$ $\mathrm{Cl}-0.057,0.016$; chi-square test of homogeneity $=7.02 ; p=0.13$ ) and was not statistically significant. 
TABLE 12

1 Year Mortality and Reinfarction by Infarct Type and Treatment

\begin{tabular}{|c|c|c|c|c|c|c|c|c|}
\hline \multirow{3}{*}{ Trial } & \multicolumn{4}{|c|}{ 1 Year Mortality } & \multicolumn{4}{c|}{ Year Reinfarction } \\
\cline { 2 - 9 } & \multicolumn{2}{|c|}{ Non-Q Wave } & \multicolumn{2}{c|}{ Q Wave } & \multicolumn{3}{c|}{ Non-Q Wave } & Q Wave \\
\cline { 2 - 9 } & Cnt//Plac & Thrombolytic & Cntt/Plac & Thrombolytic & Cntt/Plac & Thrombolytic & Cnil/Plac & Thrombolytic \\
\hline WWIC & $0 / 2(0)$ & $0 / 14(0)$ & $16 / 81(19.8)$ & $7 / 87(8.0)$ & & \multicolumn{3}{|c|}{ Not Available } \\
\hline ISAM & $10 / 94(10.6)$ & $2 / 134(1.5)^{*}$ & $63 / 670(9.4)$ & $59 / 610(9.7)$ & $6 / 94(6.4)$ & $5 / 134(3.7)$ & $30 / 670(4.5)$ & $44 / 610(7.2)$ \\
\hline WWIV & $2 / 6(33.3)$ & $1 / 26(3.9)$ & $21 / 133(15.8)$ & $18 / 113(15.9)$ & & \multicolumn{3}{|c|}{ Not Available } \\
\hline TPAT & $0 / 5(0)$ & $0 / 6(0)$ & $7 / 35(20.0)$ & $3 / 42(7.1)$ & $0 / 5(0)$ & $0 / 6(0)$ & $0 / 35(0)$ & $2 / 42(4.8)$ \\
\hline LATE & $25 / 149(16.8)$ & $18 / 140(12.9)+$ & $216 / 968(22.3)$ & $206 / 966(21.3)$ & $17 / 149(11.4)$ & $8 / 140(5.7)$ & $78 / 968(8.1)$ & $83 / 966(8.6)$ \\
\hline
\end{tabular}

Thrombolytic- vs, control/placebo-treated non $Q$ : " $p=0.004$

Thrombolytic-Ireated non- $Q$ vs. $Q:+p=0.02$ 
Logistic Regression Analyses For 1 Year Mortality

In simple logistic regression models predicting 1 year mortality, the independent (predictor) variables non- $\mathrm{Q}$ (vs. $\mathrm{Q}$ ) wave $\mathrm{Ml}$ and thrombolytic (vs. control/placebo) therapy were each associated with improved outcome (odds ratio (OR) $0.11 ; 95 \% \mathrm{Cl}$ $0.08,0.15$; and $0.15 ; 95 \% \mathrm{Cl} 0.13,0.17$, respectively). In a similar model containing both variables, non- $Q$ wave $\mathrm{MI}$ and thrombolytic therapy were still associated with improved 1 year survival (OR 0.22; 95\% $\mathrm{Cl} 0.16,0.29$; and $0.17 ; 95 \% \mathrm{Cl} 0.15,0.19$, respectively). Finally, a model containing both variables and an interaction term (non$Q$ wave MI*thrombolytic therapy), confirmed a significant interaction ( $p=0.0034)$. This suggests that the impact of the ECG MI classification type (non-Q vs. Q wave) on 1 year mortality is different depending upon whether or not the patient received antecedent thrombolytic treatment. This interaction is displayed graphically in Figure 21: while the mortality is higher within each ECG subgroup of patients who received control/placebo as compared with thrombolysis ( $14.5 \%$ vs. $6.3 \%$ in the non- $Q$ and $17.1 \%$ vs. $14.1 \%$ in the $Q$ wave groups, respectively), the impact of thrombolysis is significantly greater among the non- $Q$ wave as compared to the $Q$ wave group (absolute difference of $8.2 \%$ vs. $3.0 \%$ ). 
FIGURE 21 - Pooled One Year Mortality According to Treatment and ECG Group

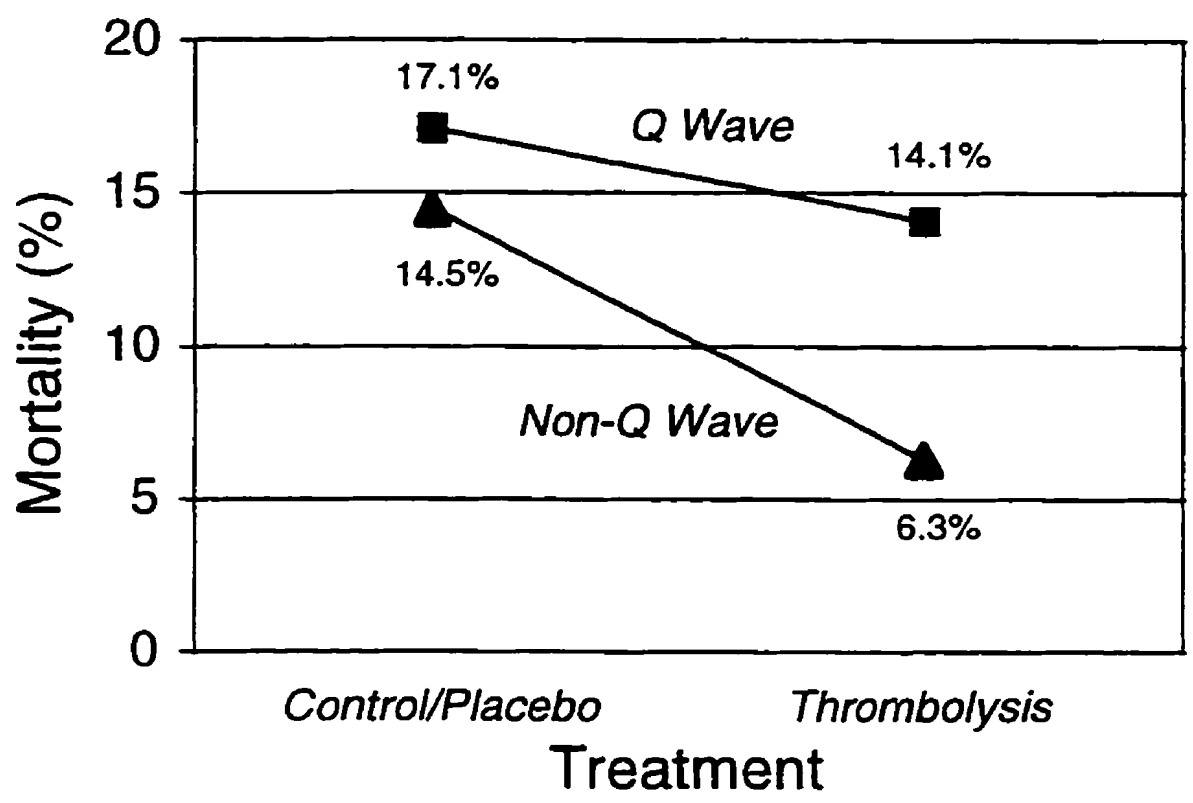

Graphic representation of pooled one year mortality demonstrating the significance of the ECG subgroup ( $Q$ or non- $Q$ wave $M I$ ) * treatment (control/placebo or thrombolytic therapy) interaction. The differences in outcomes among the $Q$ and non- $Q$ wave groups suggests that thrombolysis modifies the effect of ECG myocardial infarction type on mortality (and vice versa). 
In models predicting 1 year mortality based on backward, stepwise logistic regression analyses and including predetermined variables known to impact on shortterm clinical outcome following thrombolysis, ${ }^{290}$ the administration of thrombolytic therapy was strongly associated with $Q$ wave development (based on an interaction variable $Q$ wave $M l^{*}$ thrombolysis, $p<0.1$ ) in the Western Washington studies and in ISAM ( $p=0.099$ and $p=0.006$, respectively). Therefore, 1 year mortality models were performed separately in these studies for the control/placebo- and streptokinasetreated groups (see Table 10). One or more of the important clinical characteristics (e.g., greater than the study mean age, higher than the study mean baseline heart rate and systolic blood pressure) were independent predictors of 1 year mortality in the Western Washington, ISAM and LATE studies. In addition, development of a $Q$ wave MI was an important predictor of 1 year mortality in the thrombolytic- but not the placebo-treated group in ISAM (OR $=6.42 ; 95 \% \mathrm{Cl} 1.53,27.06)$ and in the LATE study $(O R=1.55 ; 95 \% \mathrm{Cl} 1.07,2.24)$. There was a trend toward independent predictive value of a $Q$ wave $M I$ in the thrombolytic-treated group in the Western Washington studies (OR $=6.19 ; 95 \% \mathrm{Cl} 0.8,47.99$ ). Thus, in addition to important clinical characteristics, development of a non- $Q$ as compared to $Q$ wave $M l$ following administration of thrombolytic therapy was an independent predictor of lower 1 year mortality.

\section{One Year Reinfarction}

The 1 year reinfarction rates were consistently lower among thrombolytic- as compared to placebo-treated non-Q wave patients but these differences were not significant (see Table 12). In the meta-analysis, the absolute difference in probability of 1 year reinfarction among patients who received thrombolysis and developed a non$Q$ as compared to a $Q$ wave $\mathrm{MI}\left(\mathrm{P}_{\text {non-O wave thrombolytic }}-\mathrm{P}_{\text {Q wave thrombolytic }}\right)$ was $-0.0354(95 \% \mathrm{Cl}$ $-0.061,-0.009$; chi-square test of homogeneity $=0.23 ; p=0.89$ ); in other words, the thrombolytic-treated group who developed a non- $Q$ wave experienced a significant $3.5 \%$ absolute lower 1 year reinfarction rate as compared to those patients who developed a $Q$ wave $\mathrm{Ml}$ (see Figure 19). In contrast, the absolute difference in the 
probability of 1 year reinfarction among patients who received control/placebo and developed a non- $Q$ as compared to a $Q$ wave $M I$ ( $\left.P_{\text {non-Q wave controuplacebo }}-P_{\text {Q wave controuplacebo }}\right)$ was 0.027 ( $95 \% \mathrm{Cl}-0.010,0.064$; chi-square test of homogeneity $=0.33 ; p=0.99$ ) and was not statistically significant.

In the meta-analysis, the absolute difference in probability of 1 year reinfarction among the non- $Q$ wave group $\left(P_{\text {non-Q wave thrombolytic }}-P_{\text {non-Q wave placebo }}\right)$ was $-0.040(95 \% \mathrm{Cl}$ $0.083,0.003$; chi-square test of homogeneity $=0.49 ; p=0.78$ ). In contrast, the absolute difference in the $Q$ wave group $\left(P_{Q \text { thrombolytic }}-P_{Q \text { placebo }}\right.$ ) was not statistically significant $(0.014 ; 95 \% \mathrm{Cl}-0.003,0.031$; chi-square test of homogeneity $=1.90 ; p=0.39)$. In other words, the thrombolytic- as compared to placebo-treated patients who developed a non- $Q$ wave $\mathrm{Ml}$ experienced a non-significant $4.0 \%$ absolute lower 1 year reinfarction rate and the thrombolytic-treated patients who developed a $Q$ wave experienced a nonsignificant $1.4 \%$ absolute higher rate of in-hospital reinfarction (see Figure 20 ). 
Revascularization

Information regarding coronary revascularization (angioplasty or bypass surgery) was available in four of the five studies (see Table 13). One year rates varied widely between studies (12.1\% in LATE, $30.4 \%$ in TPAT, and $46 \%$ in the Western Washington studies). In-hospital revascularization rates were similar between control/placebo- and thrombolytic-treated non- $Q$ and $Q$ wave groups. In the LATE study, 1 year revascularization rates were significantly lower among the non- $Q \mathrm{MI}$ group who received thrombolysis when compared with the placebo-treated non- $Q$ group. 


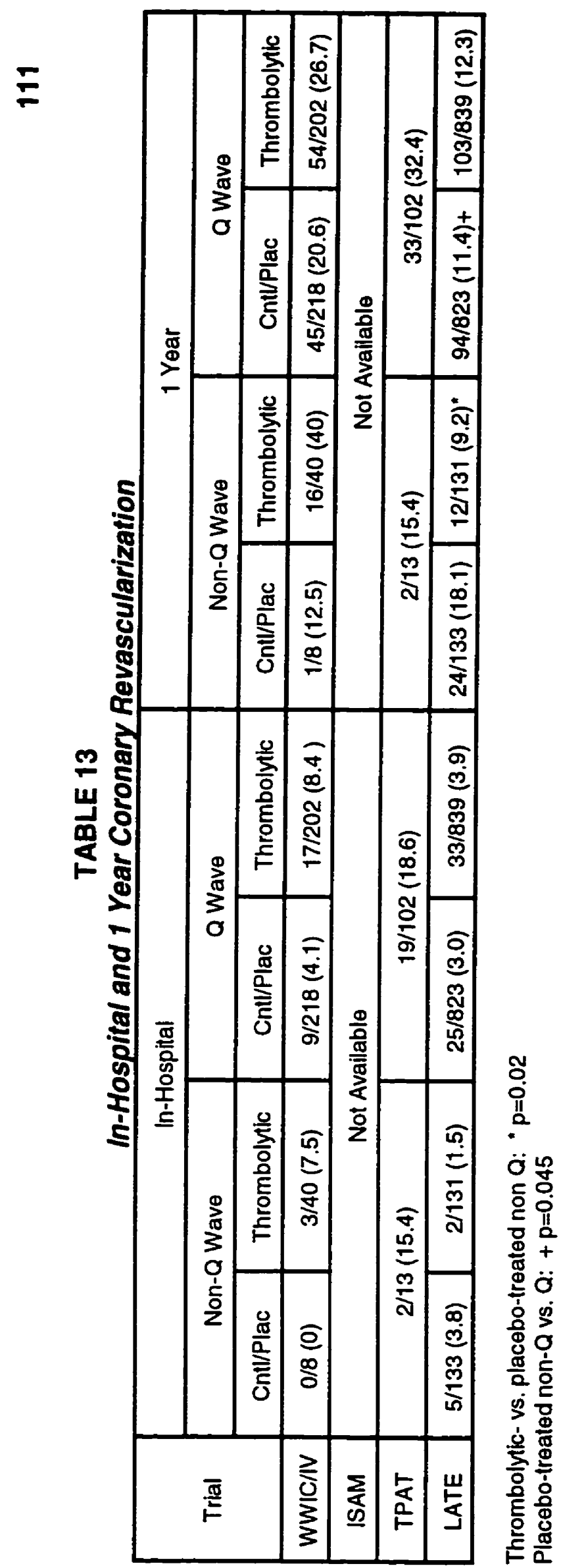




\section{Medical Therapy}

Data regarding post-MI medical treatment was only available in the LATE study. Use of conventional therapy (e.g., aspirin or warfarin and beta-blockers) proven to reduce subsequent morbidity and mortality was similar between the non-Q and $Q \mathrm{MI}$ groups. In contrast, calcium channel-blocker use (of unproven efficacy for secondary prevention) was greater among non- $Q$ as compared to $Q$ wave patients (see Table 14).

\section{TABLE 14}

Treatment at Discharge in the LATE Study'

\begin{tabular}{|l|c|c|}
\hline & Non-Q Wave & Q Wave \\
\hline Number of patients & 289 & 1934 \\
\hline Aspirin (\%) & $59(20)$ & $402(21)$ \\
\hline Dipyridamole (\%) & $2(1)$ & $23(1)$ \\
\hline Warfarin (\%) & $10(4)$ & $127(7)$ \\
\hline Beta blockers (\%) & $118(41)$ & $735(38)$ \\
\hline Calcium blockers (\%) & $77(27)$ & $344(18)$ \\
\hline Diuretics (\%) & $59(20)$ & $402(21)$ \\
\hline ACE inhibitors (\%) & $31(11)$ & $278(14)$ \\
\hline Other hypotensives (\%) & $5(2)$ & $17(1)$ \\
\hline Nitrates (\%) & $180(62)$ & $1073(55)$ \\
\hline Antiarrhythmics (\%) & $11(4)$ & $73(4)$ \\
\hline
\end{tabular}

ACE=Angiotensin Converting Enzyme

${ }^{1}$ For patients who died during the initial hospitalization, medications prior to death were included. 


\section{Summary of Results}

The main findings of these analyses of the five randomized, controlled trials are:

1. Among patients with acute myocardial infarction presenting with ST segment elevation, the incidence of non- $Q$ wave $\mathrm{Ml}$ was higher following thrombolytic as compared to placebo/control therapy.

2. In contrast to the pre-thrombolytic era, in-hospital reinfarction was lower among non- $Q$ as compared to $Q$ wave $M I$ patients. Further, the 1 year rates of reinfarction were similar between the non- $Q$ and $Q$ wave $M l$ groups.

3. As in the pre-thrombolytic era, the in-hospital mortality was lower among non- $Q$ as compared to $Q$ wave $M l$ patients. However, in contrast to the prethrombolytic era, subsequent 1 year mortality remained significantly lower among the non- $\mathrm{Q}$ wave $\mathrm{Ml}$ group.

4. Patients who received thrombolytic therapy and developed a non- $Q$ wave $M I$ had the lowest in-hospital and 1 year mortality rates; these rates were significantly lower than those seen among patients who received thrombolysis and developed a $Q$ wave MI, and among control/placebo-treated patients who developed non- $Q$ wave MI.

5. In-hospital and 1 year reinfarction rates were lowest among thrombolytic-treated patients who developed a non- $Q$ wave $M l$; these rates were significantly lower than those seen among thrombolytic-treated patients who developed a $Q$ wave MI.

Thus, consistent with the Thesis Hypothesis \#1, the incidence of non-Q wave MI was higher among thrombolytic-treated patients. Consistent with Thesis Hypothesis \#2, thrombolytic-treated patients who developed a non- $Q$ as compared with a $Q$ wave MI had significantly lower 1 year mortality rates. Finally, consistent with Hypothesis \#3, 1 year mortality was significantly lower among thrombolytic- as compared to control/placebo-treated patients who developed a non-Q wave MI. 


\section{Discussion}

While the rate of development of non- $Q$ wave $\mathrm{Ml}$ following thrombolysis was significantly greater than that seen with standard medical therapy, the absolute difference (3.1\%) was quite modest. However, logistic regression analysis confirmed the independent importance of thrombolytic administration in the subsequent evolution of non- $Q$ wave $M I$ in the Western Washington and ISAM studies. Previous studies reporting on the ECG classification of Ml following thrombolytic therapy suggest that non- $Q$ wave $\mathrm{Ml}$ occurs in $10.4 \%$ to $42 \%$ of patients (see Table 8 , Chapter 4 ) $4.5,133-145$, with the greatest occurrence in those patients who achieve early and sustained infarctrelated artery patency..$^{58}$ The apparent differences in rate of non- $Q$ wave development between studies is, in part, due to different timing of ECG classification post-MI and/or ECG criteria. This is also a limitation of the current analysis; while identical criteria were used at a similar point in time (pre-discharge) in 3 of the studies (the 2 Western Washington and Toronto trials), classification in the LATE study was made by the local investigator (pre-discharge) and the ECGs were not adjudicated in a uniform manner at a core laboratory. In the ISAM analysis $\geq 1 Q$ wave (by the Minnesota code) at 24 hours was considered a $Q$ wave $M l$; while the rate of non- $Q$ wave development was highest in this study (15.1\%), it is possible that a later time of classification (e.g., predischarge) would have resulted in a different rate. While Eisenberg et al ${ }^{141}$ found that only $1.5 \%$ of patients developed $Q$ waves from 24 hours to the time of discharge, Matetzky et $\mathrm{al}^{145}$ described some degree of "crossover" (from non-Q to $Q$ wave and vice versa) during this same time period and actually reported an increase (from $20.1 \%$ to $28.1 \%$ ) in the number of patients with non-Q wave MI by discharge. While the ECG criteria in these two studies differed somewhat, it is unlikely that classification criteria alone can account for what remains an unresolved issue. ${ }^{292}$

Time from symptom onset to initiation of thrombolysis has been clearly identified as a prognostic factor in the thrombolytic era, with approximately 2 lives lost per 1000 patients treated for each additional hour of delay. ${ }^{147}$ Rapid time to treatment $(<2.75$ hours in all patients) in the TEAHAT ${ }^{5}$ and Chouhan et al ${ }^{4}$ studies may in part account 
for the very high rate of non-Q wave $\mathrm{MI}$ development $(41.6 \%$ and $42.7 \%$, respectively) in these trials. The TEAHAT study is the only report prior to the current analysis that demonstrated a higher rate of non- $Q$ wave $\mathrm{Ml}$ development among thrombolytic- as compared to placebo-treated patients; two other studies with a control group may have failed to detect such a difference despite larger sample sizes ${ }^{133,134}$ since treatment was initiated later (up to 12 and 24 hours, respectively).

The duration of administration of thrombolytic therapy also varied between previous studies and those trials included in the current analysis. Both streptokinase and IPA are administered in a more rapid fashion in the current era, in part based on the demonstration of a superior effect on infarct related artery patency, left ventricular function, and mortality in the GUSTO study. ${ }^{293,294}$ The earlier studies of Dioguardi ${ }^{133}$ and Bett $^{134}$ administered intravenous streptokinase over many hours (12.5 and 17.5, respectively) and utilized a relatively small initial bolus (250,000 IU over 30 minutes) by more recent standards. In the current analysis, slower duration of administration may have also led to lower rates of non- $Q$ wave development. Despite an early time of symptom onset to thrombolytic treatment frame in TPAT ( $<3.75$ hours), tPA was given over 7-8 hours and only $11.9 \%$ of patients evolved a non-Q wave MI. In the LATE study, not only was time to treatment later in the course of Ml onset (6-24 hours), but tPA was administered over 3 hours with $13.4 \%$ of patients developing a non- $Q$ wave MI. In contrast, among patients presenting within 6 hours of chest pain onset, accelerated tPA administration over 1.5 hours in the GUSTO study ${ }^{294}$ led to a $21 \%$ rate of non-Q wave MI. $^{143}$

In the remaining 3 studies in the current analysis that demonstrated a significantly greater rate of non- $Q$ wave development in thrombolytic-versus control/placebo-treated patients, the dose and duration of streptokinase (e.g., 1.5 million units over 1 hour in the Western Washington intravenous and ISAM trials) was comparable to that utilized in current practice.

Despite the lack of placebo controlled comparisons in the more recent studies, 20-30\% of patients appear destined to develop non- $\mathrm{Q}$ wave $\mathrm{Ml}$ following thrombolytic 
therapy; the somewhat lower rate (17.8\% overall) observed in the five studies in the current analysis is most likely due to a combination of treatment factors including later time to treatment, lower thrombolytic dose, and slower administration of therapy.

However, in spite of the $<20 \%$ rate and modest treatment differences observed in the development of non-Q wave $\mathrm{Ml}$ in the current analysis, the impact upon mortality is striking. Using a conservative meta-analytic technique that generates wider confidence intervals around the pooled treatment effects in the setting of more heterogeneity in results among the individual studies, the absolute difference in inhospital mortality (thrombolytic - control/placebo) among non- $Q$ wave patients was $4.6 \%$. The absolute difference in 1 year mortality between the thrombolytic- and control/placebo-treated patients who developed a non-Q wave MI was even greater at 7.5\%. In-hospital reinfarction was lower (absolute difference of $1.4 \%$ ) among thrombolytic- as compared to placebo-treated patients who developed non- $Q$ wave $\mathrm{MI}$ but this did not achieve statistical significance. Similarly, there was a trend towards a lower 1 year reinfarction difference between thrombolytic- and placebo-treated non- $Q$ wave patients $(4 \%)$. As compared to the mortality data, information on reinfarction was only available in a total of 519 (in-hospital) and 528 (1 year) patients from three of the five studies, respectively. This small sample size provides very limited power to show a modest but potentially clinically important $(20-25 \%)$ difference in reinfarction rates.

Among thrombolytic-treated patients, those who develop a non- $Q$ as compared to a $Q$ wave $M I$ experience significantly lower rates of in-hospital (absolute difference $3.8 \%)$ and 1 year $(6.4 \%)$ mortality and reinfarction (2.9\% and $3.5 \%$, respectively). This suggests that non- $Q$ wave $\mathrm{Ml}$ development post-thrombolysis is a predictor for improved outcome as compared with $Q$ wave MI.

Thus in contrast to information from the pre-thrombolytic era, those who develop non- $Q$ wave $\mathrm{Ml}$ following thrombolysis have a distinct prognostic advantage when compared to either the placebo/control-treated non-Q or placebo/control- and thrombolytic-treated $Q$ wave subgroups. The excellent prognosis among the subgroup of patients who develop non- $Q$ as compared to $Q$ wave infarction after thrombolytic 
therapy is related to early, complete, and sustained infarct-related artery patency with resultant limitation of left ventricular infarction and dysfunction (as demonstrated in the TIMI II ${ }^{144}$ and GUSTO I angiographic analyses ${ }^{295.296}$ ). While the mechanism(s) underlying the benefit of thrombolysis as compared to standard medical treatment in patients who develop non- $Q$ wave $\mathrm{MI}$ are uncertain, it is hypothesized that long term improvement is mediated by a lower tendency to reocclusion. In addition to the myocardial salvage that occurs in patients with ST segment elevation who experience early recanalization of the occluded infarct related artery due to endogenous (placebo/control group) or administered (thrombolytic group) thrombolysis, the latter group may benefit from an accelerated and more complete remodelling of the site of coronary plaque rupture. The risk of reocclusion is directly related to the amount of residual thrombus bulk and inversely proportional to the minimal luminal diameter: reduced thrombus burden following thrombolytic therapy in non- $Q$ wave $M I$ may result in less subsequent incorporation of clot and inflammatory cells into the healing region of the culprit stenosis, in turn leading to a greater minimal luminal diameter. ${ }^{297}$

\section{Study Limitations}

In addition to classification of the baseline (detecting the presence of ST segment elevation) and pre-discharge (detecting a non-Q or $Q$ wave $\mathrm{MI}$ ) ECG, determination of reinfarction was also left to the discretion of experienced principal investigators at participating centres in LATE; in the absence of uniform surveillance and criteria for reinfarction, it is possible that the overall frequency of some findings in this study may have been influenced by this bias. However, the ECG comparison of $Q$ and non- $Q$ wave $\mathrm{Ml}$ was never an intended part of the overall study and given the double-blind design of the trial, it is unlikely that the local investigators would have influenced the distribution of non- $Q$ wave $M I$ between the thrombolytic and placebo groups. If a measurement bias did exist (i.e., physicians followed their non- $Q$ wave patients more closely for evidence of recurrent ischemia or reinfarction), it would result in an underestimation of these events in the $Q$ wave group and therefore further minimize the differences between $Q$ and non- $Q$ wave MI. Total mortality was 
specifically chosen as the primary endpoint in the current analysis so as to avoid any inconsistency or bias inherent in a type of death classification scheme.

It is possible that either the overall non- $Q$ wave cohort or more specifically those thrombolytic-treated patients who developed a non- $Q$ were more carefully evaluated for recurrent ischemia or treated more aggressively post MI. In the Western Washington studies, the rates of revascularization (bypass surgery and angioplasty) in-hospital and by 1 year were similar between the non- $Q$ and $Q$ wave groups. Thrombolytic-treated patients who developed non- $Q$ had the highest rate of revascularization by 1 year; however, this was in a small group of patients and did not achieve statistical significance. No significant differences in revascularization rates were seen in a small number of patients in the TPAT study. In contrast, one year revascularization rates were lowest among the thrombolytic-treated patients who developed a non- $Q$ wave $M I$, and were significantly lower when compared with the placebo-treated non- $Q$ group.

Although overall rates of revascularization varied widely between studies, there was no difference between non- $Q$ and $Q$ wave patients (16.9\% vs. $14.8 \%$ ) nor between placebo/control- and thrombolytic-treated non-Q wave patients (17.7\% vs. $16.3 \%)$. Therefore, it is unlikely that revascularization could account for the improved outcome observed in the non- $Q$ as compared to the $Q$ wave or the thrombolytic-treated as compared to the placebo/control-treated non- $Q$ wave groups.

Use of conventional post-Ml therapy (e.g., aspirin or warfarin and beta-blockers) proven to reduce subsequent morbidity and mortality was similar between the non- $Q$ and Q MI groups in the LATE study. In contrast, calcium channel-blocker use (of unproven efficacy for secondary prevention) was greater among non- $Q$ as compared to $Q$ wave patients. Predischarge therapy was not available for comparison from the other studies. Based on the LATE data, one might expect that the use of more proven therapy in the $Q$ wave group would lead to a bias against the non- $Q$ wave group by minimizing the differences in prognosis already demonstrated.

Among thrombolytic-treated patients, the subsequent development of non- $Q$ as compared to $Q$ wave $\mathrm{MI}$ was an important factor in predicting improved 1 year survival. 
A trend for independent predictive value was seen in the Western Washington studies, with significance noted in the ISAM and LATE trials. This is consistent with more recent data from a subgroup analysis of 21,570 GUSTO-I patients (all of whom received thrombolytic therapy for ST segment elevation $\leq 6$ hours of chest pain onset) without prior $\mathrm{MI} .{ }^{143}$ In addition to other factors (such as age) previously shown to be independent predictors of 30 day mortality in 41,021 patients in GUSTO-I in a multivariate analysis, ${ }^{290}$ development of non-Q wave $\mathrm{Ml}$ post-thrombolysis was also identified as an independent predictor in this model. Further, among 2,046 patients in the GUSTO-I angiographic substudy population, even after adjustment for differences in baseline characteristics and other prognostic determinants of survival (for example, time to thrombolytic treatment, thrombolytic strategy) in a multivariable model, non-Qwave infarction was a significant predictor of lower 2-year mortality (odds ratio 0.61 , $95 \%$ confidence intervals $0.38,0.97 ; P=0.044) .{ }^{295.296}$

While the ECG is widely available, relatively easy to interpret, and provides a simple, inexpensive, and noninvasive method of classifying infarction, the semantic dichotomy it provides is relatively crude. Non- $Q$ wave $\mathrm{Ml}$ encompasses a heterogeneous population; although some patients will have an "incomplete" infarction and exhibit residual ischemia, others will not. Patients presenting with ST segment elevation or depression who subsequently evolve a non- $\mathrm{Q}$ wave $\mathrm{Ml}$ appear to have higher morbidity and mortality rates when compared to patients presenting with ECG changes confined to the $T$ wave or those lacking any significant abnormalities..$^{38,62,70,95,183,298}$ These different patient subgroups may have unique clinical and pathophysiologic characteristics that, apart from the lack of a $Q$ wave on their ECG, actually represent extremes in the spectrum of infarct severity and prognosis. ${ }^{299}$ Perhaps there is greater benefit in the assessment of in-hospital morbidity and mortality through the analysis of variables from the presenting ECG (e.g., ST segment deviation vs. isolated $T$ wave changes vs. no significant abnormalities); in contrast, long term prognosis may be predicted best by the pre-discharge ECG (e.g., $Q$ vs. non- $Q$ wave). To date, however, information on the ideal timing and ECG classification scheme in the 
prediction of such outcomes is lacking.

It should be noted that several other methods of risk stratification, including clinical characteristics (e.g., age and history of prior MI) and non-invasive (e.g., stress testing and echocardiography) and invasive (e.g., coronary and left ventricular angiography) testing have been clearly established as important factors in the prediction of short- and long-term outcomes. Whether ECG characteristics (including the development of non- $Q$ wave $\mathrm{MI}$ ) provide additional or independent value in the overall post-MI population remains unclear. However, there is some evidence to suggest that non- $Q$ wave development post-thrombolysis (among patients presenting with ST segment elevation $\mathrm{MI}$ ) is an independent predictor of 1 year mortality even after adjusting for clinical characteristics also known to impact upon prognosis. ${ }^{143}$

It is important to recognize that an isolated 12 lead ECG analysis performed at an arbitrary moment following $\mathrm{Ml}$ provides only a brief snapshot in time during the recovery phase. Thus, it is not surprising that both the phenomena of transient $Q$ wave appearance ${ }^{300,301}$ and $Q$ wave regression ${ }^{130,302,303}$ have been described in patients post $\mathrm{MI}$; this could significantly influence the rates and subsequent estimation of prognosis depending on the evolution of an individual patient's ECG.

The current analysis provides the strongest confirmatory evidence to date that the rate of non-Q wave $\mathrm{MI}$ development is greater among thrombolytic- as compared to placebo/control-treated patients and is associated with an improved short- and 1 year prognosis; however, it was restricted to those acute MI patients who presented with ST segment elevation. In contrast, the majority of patients who develop non-Q-wave infarction do not present with ECG changes (e.g., ST-segment elevation or left bundle branch block) ${ }^{1}$ that would lead the physician at the bedside to administer thrombolytic therapy. Thus, patients with ST-segment elevation who evolve non-Q-wave infarction are an important subgroup but still represent $<50 \%$ of the overall non-Q-wave MI population. ${ }^{304}$

Since the majority of studies in the pre-thrombolytic era failed to report on initial ECG characteristics, it is difficult to estimate the proportion of patients who presented 
with ST segment elevation (up to $23 \%$ has been reported ${ }^{63}$ ). Similarly, the short-and long-term prognosis of the overall non- $Q$ wave $M I$ population reported in these studies may be different than the specific subgroup whose original ECG findings included ST elevation. These limitations notwithstanding, it is interesting to note that the in-hospital mortality rates were similar among control/placebo-treated patients in the current analysis (study years ranging from 1981-92) and those non- $Q$ and $Q$ wave groups managed without any thrombolytic treatment in 5 North American studies conducted during the same time period ${ }^{81,95,114,116,165}$ (previously included in the "pre-thrombolytic era" meta-analysis): non-Q: $7.6 \%$ vs. $7.3 \%$, and Q: $9.1 \%$ vs. $10.9 \%$. The 1 year mortality rates were also similar among the control/placebo-treated patients in the current analysis when compared to the pre-thrombolytic $Q$ wave group (in 5 studies conducted during the same time period and reporting on 1 year mortality $81,115,167,174,249$ ): $17.1 \%$ vs. $16.5 \%$. The 1 year mortality rate was somewhat lower among the control/placebo patients in the current analysis when compared to the pre-thrombolytic non-Q wave group: $14.5 \%$ vs. $17.9 \%$. Thus, apart from a slightly higher 1 year mortality in the pre-thrombolytic non-Q wave group, the in-hospital and 1 year outcomes are comparable among ECG subgroups in the current analysis and in studies that did not use thrombolytic therapy. This suggests that the control/placebo group in the current analysis is a representative sample of the larger group of MI patients during that era (circa 1980-1990) and that the findings of greater non- $Q$ wave development and improved prognosis post-thrombolysis derived from 5 randomized controlled studies may be generalized to the greater population of patients presenting with ST segment elevation MI.

While the current analysis represents a post hoc pooling of five trials with some differences in inclusion/exclusion criteria, type, dosage and administration duration of thrombolytic therapy, timing and method of ECG classification, this is a unique evaluation that will not likely be repeated. As it is no longer ethical to withhold thrombolytic therapy from patients presenting with ST segment elevation and acute MI, no prospective trials will be performed to further address the hypotheses raised in this 
thesis. Similarly, few additional previously published large scale, placebo controlled trials would be available for additional analysis, with the two largest such studies ${ }^{269,273}$ lacking ECG data that would allow for a Q/non-Q wave classification. Finally, it is unlikely that additional large scale, placebo controlled trials of thrombolytic therapy have not been published in the literature. 


\section{CONCLUSIONS}

Data from the pre-thrombolytic era suggests that short term mortality is significantly lower $(15.1 \%$ vs. $9.6 \%$; relative risk $(R R)=0.68 ; 95 \%$ confidence intervals (Cl) $0.63,0.75$ ) and long term mortality is similar (23.6\% vs. $23.5 \%$; RR $=1.01 ; 95 \% \mathrm{Cl}$ $0.96,1.05)$ among non- $Q$ as compared to $Q$ wave $M I$ patients. Short $(9.8 \%$ vs. $5.4 \%$; $\mathrm{RR}=1.82 ; 95 \% \mathrm{Cl} 1.56,2.13)$ and long term $(15.8 \%$ vs. $9.5 \%$; R $=1.67 ; 95 \% \mathrm{Cl} 1.52$, 1.82) reinfarction rates are higher among non- $Q$ wave $M I$ patients. However, there is a substantial degree of heterogeneity seen between studies in the published literature, even after restricting meta-analyses to those select studies with unambiguous clinical, electrocardiographic, and enzymatic criteria, and studies which attempted to adjust for differences in age and other covariates.

This thesis presents novel data from the thrombolytic era and confirms that administration of thrombolysis to patients with acute MI presenting with ST segment elevation results in a modest, but significantly greater subsequent development of non$Q$ as compared to $Q$ wave infarction (absolute difference of $3.1 \% ; 95 \% \mathrm{Cl} 1.2 \%, 5.0 \%$ ). Further, this thesis demonstrates that patients who receive thrombolytic therapy and develop a non- $Q$ wave $M I$ have a better prognosis than those who develop a $Q$ wave Ml following thrombolysis (lower in-hospital mortality: absolute difference of $-3.8 \% ; 95 \%$ $\mathrm{Cl}-5.2 \%,-2.4 \%$; lower in-hospital reinfarction: absolute difference of $-2.9 \% ; 95 \% \mathrm{Cl}$ $4.3 \%,-1.6 \%$; lower 1 year mortality: absolute difference of $-6.4 \% ; 95 \% \mathrm{Cl}-9.9 \%,-3.0 \%$; and lower 1 year reinfarction: absolute difference $-3.5 \% ; 95 \% \mathrm{Cl}-6.1 \%,-0.9 \%$ ). Finally, this thesis demonstrates that patients who receive thrombolytic therapy and develop a non- $Q$ wave $M I$ have a better prognosis than those who develop a non- $Q$ wave Ml following standard medical therapy (control/placebo) (lower in-hospital mortality: absolute difference of $-4.6 \% ; 95 \% \mathrm{Cl}-8.2 \%,-1.1 \%$; lower 1 year mortality: absolute difference of $-7.5 \% ; 95 \% \mathrm{Cl}-12.0 \%,-2.5 \%$; lower, but not statistically significant rate of in-hospital reinfarction: absolute difference of $-1.4 \% ; 95 \% \mathrm{Cl}-3.4 \%$, $0.6 \%$; and lower, but not statistically significant 1 year reinfarction rate: absolute difference $-4.0 \% ; 95 \% \mathrm{Cl}-8.3 \%, 0.3 \%$ ). 


\section{APPENDIX 2 \\ Modified Selvester Criteria for the Definition of $Q$ wave or $Q$ wave equivalent $M I$}

1. $Q$ wave $\geq 30 \mathrm{~ms}$ in lead aVF (inferior $\mathrm{MI}$ );

2. $Q$ wave $\geq 40 \mathrm{~ms}$ in leads I and aVL (lateral MI);

3. $Q$ wave $\geq 40 \mathrm{~ms}$ in at least 2 of leads $\mathrm{V}_{4}-\mathrm{V}_{6}$ (apical MI)

4. $\quad R$ wave $\geq 40 \mathrm{~ms}$ in lead $\mathrm{V}_{1}$ (posterior $\mathrm{Ml}$ );

5. Any $Q$ wave in $V_{2}$ or $R$ wave $\leq 0.1 \mathrm{mV}$ and $\leq 10 \mathrm{~ms}$ in lead $V_{2}$ (anterior $\mathrm{MI}$ ).

\section{Minnesota Q Wave Code Criteria}

Anterolateral Site (Leads $\mathrm{I}$, aVL, and $\mathrm{V}_{6}$ ):

1-1-1 $Q / R$ amplitude ratio $\geq 1 / 3$; plus $Q$ duration $\geq 0.03$ second in lead $I$ or $V_{6}$.

1-1-2 $Q$ duration $\geq 0.04$ second in lead $I$ or $V_{6}$.

1-1-3 $Q$ duration $\geq 0.04$ second, plus $R$ amplitude $\geq 3 \mathrm{~mm}$. in lead aVL.

1-2-1 $Q / R$ amplitude ratio $\geq 1 / 3$, plus $Q$-wave duration $\geq 0.02$ second and $<0.03$ second in lead $\mathrm{l}$ or $\mathrm{V}_{6}$.

1-2-2 $Q$ duration $\geq 0.03$ second and $<0.04$ second in lead $I$ or $V_{6}$.

1-2-3 QS pattern in lead I.

1-2-8 Initial $R$ amplitude decreasing to $2 \mathrm{~mm}$. or less in every beat between $V_{5}$ and $V_{6}$. (All beats in lead $V_{5}$ must have an initial $R>2 \mathrm{~mm}$.)

1-3-1 $Q / R$ amplitude ratio $\geq 1 / 5$ and $<1 / 3$, plus $Q$ duration $\geq 0.02$ second and $<0.03$ second in lead $\mathrm{I}$ or $\mathrm{V}_{6}$.

1-3-3 $Q$ duration $\geq 0.03$ second and $<0.04$ second, plus $R$ amplitude $\geq 3 \mathrm{~mm}$. in lead aVL.

Inferior Site (Leads II, III, and aVF):

1-1-1 Q/R amplitude ratio $\geq 1 / 3$, plus $Q$ duration $\geq 0.03$ second in lead II.

$1-1-2 Q$ duration $\geq 0.04$ second in lead II.

1-1-4 $Q$ duration $\geq 0.05$ second in lead III, plus a $Q$-wave amplitude $\geq 1.0 \mathrm{~mm}$ in the majority of beats in lead aVF.

1-1-5 $Q$ duration $\geq 0.05$ second in lead aVF.

1-2-1 $Q / R$ amplitude ratio $\geq 1 / 3$, plus $Q$ duration $\geq 0.02$ second and $<0.03$ second in lead II.

1-2-2 $Q$ duration $\geq 0.03$ second and $<0.04$ second in lead II.

1-2-3 QS pattern in lead II.

1-2-4 $Q$ duration $\geq 0.04$ second and $<0.05$ second in lead III, plus a $Q$-wave $\geq 1.0 \mathrm{~mm}$ amplitude in the majority of beats in aVF.

1-2-5 $Q$ duration $\geq 0.04$ second and $<0.03$ second in lead aVF.

1-2-6 $Q$ amplitude $\geq 5.0 \mathrm{~mm}$ in lead III or aVF.

1-3-1 $Q / R$ amplitude ratio $\geq 1 / 5$ and $<1 / 3$, plus $Q$ duration $\geq 0.02$ second and $<0.03$ 
second in lead II.

1-3-4 Q duration $\geq 0.03$ second and $<0.04$ second in lead III, plus a $Q$-wave $\geq 1.0 \mathrm{~mm}$ amplitude in the majority of beats in lead aVF.

1-3-5 $Q$ duration $\geq 0.03$ second and $<0.04$ second in lead aVF.

1-3-6 QS pattern in each of leads III and aVF.

Anterior Site (Leads $V_{1}, V_{2}, V_{3}, V_{4}$, and $V_{5}$ ):

1-1-1 $Q / R$ amplitude ratio $\geq 1 / 3$ plus $Q$ duration $\geq 0.03$ second in any of leads $V_{2}-V_{5}$.

1-1-2 $Q$ duration $\geq 0.04$ second in any of leads $V_{1}-V_{5}$.

1-1-6 QS pattern when initial $R$-wave is present in adjacent lead to the right on the chest, in any of leads $V_{2}-V_{6}$.

1-1-7 QS pattern in all of leads $V_{1}-V_{4}$ or $V_{1}-V_{5}$.

1-2-1 $Q / R$ amplitude ratio $\geq 1 / 3$, plus $Q$ duration $\geq 0.02$ second and $<0.03$ second, in any of leads $V_{2}-V_{5}$.

1-2-2 $Q$ duration $\geq 0.03$ second and $<0.04$ second in any of leads $V_{2}-V_{5}$.

1-2-7 QS pattern in all of leads $V_{1}-V_{3}$.

1-2-8 Initial $R$ amplitude decreasing to $2.0 \mathrm{~mm}$ or less in every beat between any of leads $V_{2}$ and $V_{3}, V_{3}$ and $V_{4}$, or $V_{4}$ and $V_{5}$. (All beats in the lead immediately to the right on the chest must have an initial $R>2 \mathrm{~mm}$.)

1-3-1 $Q / R$ amplitude ratio $\geq 1 / 5$ and $<1.3$ plus $Q$ duration $\geq 0.02$ second and $<0.03$ second in any of leads $V_{2}-V_{5}$.

1-3-2 QS pattern in lead $V_{1}$ and $V_{2}$. 


\section{APPENDIX 3}

\section{Western Washington Randomized Trial of Intracoronary Streptokinase Background}

Based on encouraging results from several non-randomized trials, ${ }^{135,305-307}$ the Western Washington Randomized Trial of Intracoronary Streptokinase in Acute Myocardial Infarction was conceived in late 1980 and developed during early $1981,{ }^{278}$ with the 30 day and 1 year outcome reported in $1983{ }^{279}$ and $1985,{ }^{280}$ respectively. Patients were enrolled beginning July 1,1981 , and the trial was carried out at 13 hospitals in western Washington and at 1 in Vancouver, British Columbia. Three of the institutions were university teaching hospitals, and 11 were community hospitals. The 14 hospitals contributed an average of 17.8 patients each, ranging from 2 to $45 ; 60$ enrolled patients were treated in teaching hospitals, and 190 were treated in community hospitals.

\section{Patient Selection}

Patients with symptoms and signs of acute myocardial infarction who were $\leq 75$ years of age and could be randomly assigned within 12 hours of symptom onset were eligible for enrollment. Electrocardiographic criteria required ST segment elevation ( $20.15 \mathrm{mV}$ in $V_{1-3}$ or $\geq 0.1 \mathrm{mV}$ in other leads) in $\geq 2$ leads measured $60 \mathrm{msec}$ beyond the $\mathrm{J}$ point, and $\geq 1$ lead with ST segment elevation without $Q$ waves ( $240 \mathrm{msec}$ ). A marked increase in the $T$ wave amplitude was acceptable in a patient with an otherwise typical presentation. Patients excluded from the trial included those with: (1) disease or conditions other than coronary disease involving a substantial increase in the risk of death or the ability to cooperate or give informed consent or both (e.g., cancer, severe liver or kidney disease, sepsis, coma, emotional illness); (2) prior exposure to streptokinase; (3) any contraindication to anticoagulation therapy, including recent surgery; and (4) any treatment for congestive heart failure before the onset of acute MI.

\section{Study Design and Treatment}

The design of the study required that all patients undergo cardiac catheterization before random assignment so that in all patients enrolled, coronary artery thrombosis 
would be documented. The coronary artery most likely to be occluded was usually studied last. If a partially or totally occluded vessel serving the region of the suspected infarct was identified, $0.2 \mathrm{mg}$ of intracoronary nitroglycerin was infused into the artery, followed by repeat angiography to detect coronary artery spasm. If total or subtotal thrombosis was still present, the patient was randomly assigned to the treatment or control group.

In each hospital, patients were randomly assigned to the treatment and control groups in approximately equal numbers in four subgroups: (1) those with anterior $\mathrm{MI}$ $<3$ hours duration, (2) those with anterior Ml of 3-12 hours duration, (3) those with inferior $\mathrm{Ml}<3$ hours duration, and (4) those with inferior $\mathrm{Ml}$ of 3-12 hours duration. Patients with posterior infarction were grouped with those who had inferior $\mathrm{Ml}$ and those with lateral MI were included with those who had anterior MI.

Patients assigned to the control group were returned to the coronary care unit. Those assigned to the therapy group received intracoronary streptokinase at a rate of 4000 units/minute, administered as a constant infusion into the coronary ostium for treatment of proximal occlusions; distal occlusions were treated with either intermittent bolus injections of streptokinase (1000 units every 15 seconds) or a constant infusion through a subselective 2.5 French intracoronary catheter. The infusion was continued until reperfusion occurred or a total of 250,000 to 350,000 units failed to reperfuse the vessel. If reperfusion occurred, streptokinase was continued for an additional 30 minutes or until all visible thrombi had lysed.

Both treatment and control patients were given a continuous infusion of intravenous heparin after cardiac catheterization until effective oral anticoagulation had been achieved with warfarin. It was recommended that anticoagulation be discontinued at the time of hospital discharge in control patients and in those in whom coronary reperfusion was unsuccessful. Patients who had successful reperfusion continued to receive oral anticoagulation treatment for 3 months. In addition to anticoagulation, patients received routine hospital care given after Ml, as prescribed by their physicians. 


\section{Follow-Up}

As follow-up at 6 months, a form was mailed to the patient's physician or a telephone call was made to the patient or family. Twelve-month follow-up was completed by telephone contact with physicians, patients, and families, determining the vital status of all patients. At 6 months, it was determined in all patients whether interim coronary bypass surgery or coronary angioplasty had been performed; at 12 months, this could be determined in all but five patients. Documentation regarding recurrent infarction was not undertaken in this trial.

\section{Intravenous Streptokinase in Acute Myocardial Infarction (ISAM) Study Background}

Based on a growing body of evidence that intravenous infusion of thrombolytic agents were beneficial in the reperfusion of occluded coronary arteries in acute myocardial infarction, ${ }^{308-310}$ a large, prospective, placebo-controlled, double-blind multicenter trial was started in 1982. The Intravenous Streptokinase in Acute Myocardial infarction (ISAM) study was designed to evaluate the risk-benefit ratio of high-dose short-term intravenous infusion of streptokinase, with the 21-day and long-

term (average 21 and 31 month) outcomes reported in $1986{ }^{274}$ and 1987, ${ }^{275.276}$ respectively. Patients were enrolled from 38 hospitals in West Germany, Switzerland, and Toronto, Canada, from March 1982, to March 1985.

\section{Patient Selection}

Patients of either sex were considered for randomization if they were $\leq 75$ years of age, were admitted to coronary care units of the participating hospitals, and could be treated with the study medication within 6 hours of the onset of symptoms of myocardial infarction. Evolving MI was diagnosed if typical symptoms were present and ST elevations of $\geq 1 \mathrm{~mm}$ in the limb leads or $\geq 2 \mathrm{~mm}$ in the chest leads were observed. A patient was excluded is s/he had: (1) a hemorrhagic diathesis; (2) received oral anticoagulant treatment; (3) received streptokinase $<9$ months before; (4) valvular heart disease and atrial fibrillation; (5) had peptic ulcer $\leq 6$ months, colitis, esophageal varices, aortic aneurysm, a history of severe therapy-resistant hypertension (systolic 
blood pressure despite therapy, $2200 \mathrm{~mm} \mathrm{Hg}$; diastolic pressure, 2120 ), resuscitation with external cardiac massage, puncture of the subclavian or internal jugular vein, trauma, surgery $<10$ days before, stroke, acute headache or visual disorders of unknown cause; (6) implantation of a permanent pacemaker; or (7) any severe disease that would exclude the patient in the opinion of the clinical investigator.

\section{Study Design and Treatment}

Immediately after randomization, $5000 \mathrm{IU}$ of heparin, $0.5 \mathrm{~g}$ of acetylsalicylic acid, and $250 \mathrm{mg}$ of methylprednisolone were administered intravenously. The study medication, 1.5 million IU of streptokinase or placebo, was infused within 60 minutes. Subsequently, a heparin infusion was started at a rate of 800-1000 IU/hour and continued for 72-96 hours. After approximately 12 hours, the heparin dose was adjusted to maintain the thrombin or partial thromboplastin time at 2-3 times control. Phenprocoumon (oral anticoagulant) treatment was initiated with $15 \mathrm{mg}$ on the first day and $12 \mathrm{mg}$ on the second day, and was continued for at least 3 weeks, during which the prothrombin time was kept in the range of $20-25 \%$. Additional treatment, at the discretion of the attending physician, was given if clinically indicated.

\section{Follow-Up}

During the first seven months after randomization, all critical events including reinfarction, were reviewed by an independent critical event committee. Follow-up $>7$ months concerned total mortality only, evaluated by inquiries based on the government's registry. At a cutoff date of August 31, 1986 (minimum follow-up of 17 months), no vital status could be obtained for six patients.

\section{Western Washington Randomized Trial of Intravenous Streptokinase Background}

By 1986, the short- and long-term mortality results of the Western Washington Randomized Trial of Intracoronary Streptokinase ${ }^{279,280}$ and the Interuniversity Cardiology Institute in the Netherlands study ${ }^{311,312}$ had clearly demonstrated the benefit of intracoronary thrombolytic administration in acute myocardial infarction. However, ongoing concerns regarding the feasibility of widespread use of emergency cardiac 
catheterization and the associated time delay in the onset of intracoronary treatment provided the rationale for further study of intravenous thrombolysis in the Western Washington Intravenous Streptokinase in Acute Myocardial Infarction Randomized trial. ${ }^{281}$

The trial was planned in the spring of 1982, funded in August 1983, and began patient enrollment in September 1983. The planned sample size was 660 patients; however, after 386 patients had been randomized after 3 years of recruitment and the results of Gruppo Italiano per lo Studio della Streptochinasi nell'Infarto Miocardico (GISSI)-1 became available, ${ }^{273}$ the Western Washington investigators and the Policy Advisory Board recommended discontinuation of the study on July 31, 1986.

The trial was carried out in 27 hospitals in Washington, Idaho, and Vancouver, British Columbia. Four of the institutions were university teaching hospitals, 4 were Veteran's Administration hospitals, and the remainder were community hospitals. The 27 hospitals contributed an average of 13.6 patients each, ranging from 1 to $64 ; 57 \%$ of the total enroliment originated in community hospitals and only $15 \%$ of patients were treated in teaching hospitals.

\section{Patient Selection}

Patients with symptoms and signs of acute myocardial infarction (including typical chest pain for $\geq 20$ minutes) who were $\leq 75$ years of age and could be randomly assigned within 6 hours of symptom onset were eligible for enrollment. Electrocardiographic criteria required ST segment elevation $\left(20.15 \mathrm{mV}\right.$ in $\mathrm{V}_{1-3}$ or $\geq 0.1$ $\mathrm{mV}$ in other leads) in $\geq 2$ leads measured $60 \mathrm{msec}$ beyond the $\mathrm{J}$ point, and $\geq 1$ lead with $S T$ segment elevation without $Q$ waves ( $>40 \mathrm{msec}$ ). Patients excluded from the trial included those with: (1) disease of organ systems likely to reduce longevity or ability to cooperate or give informed consent (e.g., cancer, severe liver or kidney disease, sepsis, coma, emotional illness); (2) prior streptokinase therapy; (3) any contraindication to anticoagulation therapy, including active peptic ulcer disease, diabetic retinopathy, and hypertension with diastolic blood pressure $>120 \mathrm{~mm} \mathrm{Hg}$; (4) recent major surgical procedure (two weeks) or neurosurgical procedure or history of a 
stroke (4 weeks); (5) trauma likely to result in bleeding; (6) presence of central venous lines placed in non-compressible entry sites such as subclavian or internal jugular veins; and (7) prior coronary artery bypass surgery.

\section{Study Design and Treatment}

Patients who met entry criteria and gave informed consent were randomly assigned to streptokinase or control therapy. In each hospital, patients were randomly assigned to the treatment and control groups within the following strata: (1) anterior MI $<3$ hours from symptom onset, (2) anterior Ml of 3-6 hours from symptom onset, (3) inferior $\mathrm{Ml}<3$ hours from symptom onset, and (4) inferior MI 3-6 hours from symptom onset.

The streptokinase group received $50 \mathrm{mg}$ benadryl and $100 \mathrm{mg}$ hydrocortisone intravenously, followed by 1.5 million IU of intravenous streptokinase over 1 hour. In addition, treated patients received intravenous heparin starting at $1000 \mathrm{U} / \mathrm{hour}$ beginning two hours after the completion of the streptokinase infusion and were continued on heparin until stabilized on oral anticoagulation with warfarin. Participating physicians were advised to continue oral anticoagulation when appropriate for 3 months after hospital discharge. Control patients received routine coronary care as defined by their physicians, which may or may not have included heparin or warfarin anticoagulation. At the discretion of their physicians, patients in both groups were encouraged to undergo left heart catheterization, coronary arteriography, and left ventriculography before hospital discharge or shortly thereafter.

\section{Follow-Up}

A 6 month and second follow-up carried out at 1 or more years were accomplished by mail and/or phone. Vital status and interim coronary bypass surgery and coronary angioplasty was ascertained in all patients. Documentation regarding recurrent infarction was not undertaken in this trial.

\section{The Tissue Plasminogen Activator: Toronto (TPAT) Study}

\section{Background}

The Tissue Plasminogen Activator: Toronto (TPAT) study ${ }^{282}$ was a randomized, 
double-blind, placebo-controlled trial examining the efficacy and safety of double-chain rt-PA (Burroughs Wellcome Co.) in the management of acute myocardial infarction.

\section{Patient Selection}

Patients aged 20 to 75 years with typical ischemic chest pain lasting at least 30 minutes, ST segment elevation of $20.1 \mathrm{mV}$ in two inferior leads or leads I and aVL or $\geq 0.15 \mathrm{mV}$ in at least two anterior precordial leads were considered for study admission. Patients were excluded if they presented $>3.75$ hours after the onset of chest pain or had cardiogenic shock, left bundle branch block, prior aortocoronary bypass surgery or recent ( $<1$ month) percutaneous transluminal coronary angioplasty, obvious contraindications to thrombolytic therapy or inability to provide informed consent.

Patients were recruited from 10 collaborating hospitals in Toronto, with randomization balanced within each hospital according to blocks of four.

\section{Study Design and Treatment}

Study treatment consisted of it-PA or matching placebo. The first 39 patients received the study drug at $0.4 \mathrm{MU} / \mathrm{kg}$ per hour intravenously for hour $1,0.14 \mathrm{MU} / \mathrm{kg}$ per hour for hour two, and $0.03 \mathrm{MU} / \mathrm{kg}$ per hour for the subsequent 8 hours. The final 79 patients received $0.4 \mathrm{MU} / \mathrm{kg}$ per hour intravenously for hour $1,0.08 \mathrm{MU} / \mathrm{kg}$ per hour for hour two, and $0.03 \mathrm{MU} / \mathrm{kg}$ per hour for the subsequent 4 hours. Ten percent of the hour 1 dose was given as a bolus injection initially. All patients received heparin, concomitant with the study drug, commencing with a bolus injection of 4,000 IU followed by an infusion of $1,000 \mathrm{lU} /$ hour. Heparin administration was continued for 96 hours and monitored by periodic partial thromboplastin times (PTTs) with the objective of maintaining the PTT between 1.5-2 times the control value. In all patients, 325 $\mathrm{mg} /$ day of enteric-coated aspirin was given orally before cessation of heparin therapy. All patients received prophylactic lidocaine therapy for the first 24 hours.

Enzymatic assessment of myocardial infarction was obtained by utilizing serum levels of CK and CK-MB determined at 4 hour intervals for the first 36 hours. Thereafter, CK activity was determined at 12 hour intervals throughout the hospital course. Reinfarction was defined as an increase of $250 \%$ in CK-MB activity over a 
previousiy established basal level.

Patients were systematically monitored for clinical and ECG evidence of recurrent ischemia. Coronary angioplasty and bypass surgery within the first 10 days were confined to those patients experiencing recurrent episodes of ischemic chest pain ( 22 during a 48-hour period despite maximal medical therapy or associated $>2 \mathrm{~mm}$ ST segment shift) or those who developed hemodynamic instability. Revascularization at and after day 10 was performed at the discretion of the attending cardiologist. There was no difference between the anti-ischemic and other medical therapy of placebo- and rt-PA-treated groups at day five or at hospital discharge.

The study plan was to randomize 150 patients per group on the basis of anticipated beneficial effect of rt-PA on global and regional (in the distribution of the qualifying $\mathrm{MI}$ ) left ventricular ejection fraction at nine days following the onset of symptoms. However, the study was terminated sooner when rt-PA became generally available and the steering committee believed it was no longer ethical to randomize patients to receive placebo.

\section{Follow-Up}

Clinical assessment of cardiac functional status was performed on admission and daily throughout the hospital course. Clinical follow-up study was undertaken after hospital discharge to assess morbidity (defined as recurrent ischemic events and need for revascularization) and mortality up to 90 days after randomization; however, additional follow-up was available at 1 year in 88 of $115(76.5 \%)$ of patients.

\section{The Late Assessment of Thrombolytic Efficacy (LATE) Study Background}

Several large trials in acute $\mathrm{Ml}$ have demonstrated that thrombolytic therapy improves survival. ${ }^{267-269,273}$ Two of these trials limited patient entry to the first 5-6 hours after symptom onset ${ }^{267.268}$ and one trial randomizing patients up to 12 hours showed a striking decrease in benefit with time. ${ }^{273}$ Another trial permitted randomization up to 24 hours and revealed a persistently significant benefit to 12 hours together with some 
benefit which approached statistical significance in the 12-24 hour group. ${ }^{269}$ Therefore, as the value of late thrombolysis was uncertain, a double-blind trial of thrombolytic therapy compared with placebo initiated 6 to 24 hours after chest pain onset in acute MI was undertaken from 1989 to 1992.

\section{Patient Selection}

The Late Assessment of Thrombolytic Efficacy (LATE) study ${ }^{27}$ was performed in 230 centres (Australia 35, Canada 21, Europe 146, United States 28) in 5,711 patients with symptoms and electrocardiographic criteria consistent with acute MI. Inclusion criteria were: (1) chest pain of suspected myocardial origin lasting for at least 30 minutes; (2) an ECG exhibiting at least one of (a) ST elevation $\geq 1 \mathrm{~mm}$ in $\geq 2$ limb leads or $\geq 2 \mathrm{~mm}$ in $\geq 2$ chest leads, (b) ST depression $\geq 2 \mathrm{~mm}$ in $\geq 2$ leads, (c) pathological $Q$ waves, (d) abnormal $T$ wave inversion in $>2$ leads, (e) old or equivocal ECG changes or bundle-branch block in the presence of raised cardiac enzymes; (3) the decision to start treatment 6-24 hours after chest pain onset. Exclusion criteria were: (1) a risk of serious bleeding (overt gastrointestinal or genitourinary bleeding within the previous 6 months, any history of stroke, history of transient ischemic attack in the previous 6 months, neurosurgery within the previous 6 months, major surgery or trauma within the previous month); (2) shock with systolic blood pressure $<80 \mathrm{~mm} \mathrm{Hg}$; (3) hypertension ( $>200 \mathrm{~mm} \mathrm{Hg}$ systolic or $>110 \mathrm{~mm} \mathrm{Hg}$ diastolic, not controlled within the 6-24 hour time window); and (4) other reasons (e.g., refused consent, participant in another trial, serious organic or psychiatric illness, or lived too far away for reliable follow-up). Of note, an initial upper age limit of 75 years was removed after 14 months of patient recruitment.

\section{Study Design and Treatment}

Patients were randomized to receive intravenous r-tPA (10 mg bolus, $50 \mathrm{mg}$ infusion over 1 hour followed by $40 \mathrm{mg}$ over two hours) or matching placebo. In addition, they received aspirin (75-360 $\mathrm{mg}$ according to local practice) for the duration of follow-up. Intravenous heparin was strongly recommended after 14 months of recruitment; previously, heparin had been used according to local practice. Oral beta- 
blockers were also strongly recommended; all other drug and interventional therapies were at the discretion of the participating physicians.

\section{Follow-Up}

Recruitment and follow-up spanned 41 months; there was little loss to follow-up with $99.6 \%$ of 1 -month and $96.6 \%$ of 1 -year mortality data available for analysis. 


\section{REFERENCES}

1. Gibson RS. Non-Q wave myocardial infarction: prognosis, changing incidence, and management, in Current Topics in Cardiology. New York, Elsevier, 1991, pp 284-307.

2. Gibson RS. Non-Q-wave myocardial infarction: diagnosis, prognosis, and management. Current Problems in Cardiology. 1988;13:1-72.

3. Gibson RS. Non-Q-wave myocardial infarction: pathophysiology, prognosis, and therapeutic strategy. Annual Review of Medicine. 1989;40:395-410.

4. Chouhan L, Hajar HA, George T, Pomposiello JC. Non-Q- and Q-wave infarction after thrombolytic therapy with intravenous streptokinase for chest pain and anterior ST-segment elevation. American Joumal of Cardiology. 1991;68:446-450.

5. The Thrombolysis Early in Acute Heart Attack Trial Study Group. Very early thrombolytic therapy in suspected acute myocardial infarction. American Journal of Cardiology. 1990;65:401-407.

6. Goldberg RJ, Gore JM, Alpert JS, Dalen JE. Non-Q wave myocardial infarction: recent changes in occurrence and prognosis--a community-wide perspective. American Heart Journal. 1987;113:273-279.

7. Yarzebski J, Col N, Pagley P, Savageau J, Gore J, Goldberg R. Gender differences and factors associated with the receipt of thrombolytic therapy in patients with acute myocardial infarction: a community-wide perspective. American Heart Journal. 1996;131:43-50.

8. Wellford L, Ashcom TL, Whitney EJ, Rubal BJ, Wellford LA, Moody JM, Jr. Changing presentation of coronary heart disease in an inpatient population within the U.S. military health care system. Military Medicine. 1993;158:598-603.

9. Anonymous. Non-Q-wave myocardial infarction. Lancet. 1989;2:899-900.

10. Boden WE. Electrocardiographic correlates of reperfusion status after thrombolysis: is the "incomplete" or "interrupted" infarction a non-Q-wave infarction? American Journal of Cardiology. 1991;68:520-524.

11. Borzak S, Rosman HS. Non-Q wave myocardial infarction. Henry Ford Hospital Medical Journal. 1991;39:256-262.

12. Davies MJ, Thomas AC. Plaque fissuring--the cause of acute myocardial infarction, sudden ischaemic death, and crescendo angina. British Heart Journal. 1985;53:363-373. 
13. Fuster V, Badimon L, Badimon JJ, Chesebro JH. The pathogenesis of coronary artery disease and the acute coronary syndromes. Part I. New England Journal of Medicine. 1992;326:212-250.

14. Cheitlin MD. Non-Q-wave infarction: diagnosis, prognosis, and treatment. Advances in Internal Medicine. 1988;33:267-294.

15. Prinzmetal H, Shaw CMJ, Maxwell MH, Flamm EJ, Goldman A, Kimura N, Rakita L, Borduas J, Rothman S, Kennamer R. Studies on the mechanisms of ventricular activity. VI. The depolarization complex in pure subendocardial infarction; role of the subendocardial region in the normal electrocardiogram. American Journal of Medicine. 1954;16:469-489.

16. Sodi-Pollares D, Bisteni A, Medrano GA, Cisneros F. The activation of the free left ventricular wall in the dog's heart. American Heart Joumal. 1955;49:587-602.

17. Langendorf R, Kovitz B. Acute myocardial infarction without deviation of the S-T segment in the electrocardiogram. American Joumal of the Medical Sciences. 1942;204:239-246.

18. Pardee HEB, Goldenberg M. Electrocardiographic features of myocardial infarction as affected by involvement of septum and by complete and incomplete transmural involvement. American Heart Journal. 1945;30:367-381.

19. Pirani CL, Schlicter JG. Subendocardial myocardial infarction. Annals of Internal Medicine. 1946;25:847-851.

20. Price RK, Janes LR. A case of subendocardial infarction. British Heart Journal. 1943;5:134-138.

21. Levine HD, Ford RV. Subendocardial infarction: Report of six cases and critical survey of the literature. Circulation. 1950;1:246-263.

22. Horn H, Field LE, Dack S, Master AM. Acute coronary insufficiency: Pathological and physiological aspects. American Heart Journal. 1950;40:63-80.

23. Wilson FN, Hill IGW, Johnston FD. The form of the electrocardiogram in experimental myocardial infarction. III. The later effects produced by ligation of the anterior descending branch of the left coronary artery. American Heart Journal. $1935 ; 10: 903$ 
24. Wilson FN, Johnston FD, Hill IGW. The form of the electrocardiogram in experimental myocardial infarction. IV. Additional observations with later effects produced by ligation of the anterior descending branch of the left coronary artery. American Heart Joumal. 1935;10:1025

25. Wilson FN, Johnston FD, Ragenbaum FF, Erianger $H$, Kossmann $C E$, Hecht $H$, Cotrim N, De Oliveira RM, Scarsi R, Barker PS. The precordial electrocardiogram. American Heart Journal. 1944;27:19-85.

26. Yu PNG, Stewart JM. Subendocardial myocardial infarction with special reference to the electrocardiographic changes. American Heart Journal. 1950;39:862-873.

27. Myers GB, Sears C, Hiratzka T. Correlation of electrocardiographic and pathologic findings in ring-like subendocardial infarction of the left ventricle. American Journal of the Medical Sciences. 1951;222:417-426.

28. Abildskov JA, Wilkinson RS, Vincent WA. An experimental study of the electrocardiographic effects of localized myocardial lesions. American Joumal of Cardiology. 1961;8:485-492.

29. Pipberger H, Schwartz L, Massumi RA, Weiner SM, Prinzmetal M. Studies on the mechanism of ventricular activity. XXI. The origin of the depolarization complex with clinical applications. American Heart Journal. 1957;54:511

30. Durrer D, Van Lier AAW, Buller J. Epicardial and intramural excitation in chronic myocardial infarction. American Heart Journal. 1964;68:765-776.

31. Mirvis DM, Ingram L, Holly MK, Wilson JL, Ramanathan KB. Electrocardiographic effects of experimental nontransmural myocardial infarction. Circulation. 1985;71:1206-1214.

32. Cook RW, Edwards JE, Pruitt RD. Electrocardiographic changes in acute subendocardial infarction. I. Large subendocardial and large nontransmural infarcts. Circulation. 1958; 18:603-612.

33. Cook RW, Edwards JE, Pruitt RD. Electrocardiographic changes in acute subendocardial infarction. II. Small subendocardial infarcts. Circulation. 1958;18:613-624.

34. Wilkinson RS, Schaefer JA, Abildskov JA. Electrocardiographic and pathologic features of myocardial infarction in man. American Journal of Cardiology. 1963;11:24-35. 
35. Cernohorsky J, Dusek J. Subendocardial infarctions. Cor et Vasa. 1966;8:185-193.

36. Daniel TM, Boineau JP, Sabiston DC. Comparison of human ventricular activation with a canine model in chronic myocardial infarction. Circulation. 1971;44:74-89.

37. Horan LG, Flowers NC, Johnson JC. Significance of the diagnostic $Q$ wave of myocardial infarction. Circulation. 1971;43:428-436.

38. Abbott JA, Scheinman MM. Nondiagnostic electrocardiogram in patients with acute myocardial infarction. Clinical and anatomic correlations. American Journal of Medicine. 1973;55:608-613.

39. Savage RM, Wagner GS, Ideker RE, Podolsky SA, Hackel DB. Correlation of postmortem anatomic findings with electrocardiographic changes in patients with myocardial infarction. Retrospective study of patients with typical anterior and posterior infarcts. Circulation. 1977;55:279-285.

40. Sullivan W, Vlodaver Z, Tuna N, Long L, Edwards JE. Correlation of electrocardiographic and pathologic findings in healed myocardial infarction. American Journal of Cardiology. 1978;42:724-732.

41. Raunio H, Rissanen V, Romppanen $T$, Jokinen $Y$, Rehnberg $S$, Helin $M$, Pyorala $K$. Changes in the QRS complex and ST segment in transmural and subendocardial myocardial infarctions. A clinicopathologic study. American Heart Journal. 1979;98:176-184.

42. Ideker RE, Wagner GS, Reimer KA, Alonso DR, Bishop SP, Bloor CM, Fallon JT, Gottlieb GJ, Hackel DB, Phillips HR, Roark SF, Rogers WJ, Ruth WK, Savage DB, Selvester RM, Ward RM. $Q$ wave and transmural infarcts: the terms are not the same. American Journal of Cardiology. 1981;47:464

43. Freifield AG, Schuster EH, Healy-Bulkley B. Nontransmural versus transmural myocardial infarction. A morphologic study. American Journal of Medicine. 1983;75:423-432.

44. Uusitupa M, Pyorala K, Raunio H, Rissanen V, Lampainen E. Sensitivity and specificity of Minnesota Code Q-QS abnormalities in the diagnosis of myocardial infarction verified at autopsy. American Heart Journal. 1983;106:753-757.

45. Antaloczy Z, Barcsak J, Magyar E. Correlation of electrocardiologic and pathologic findings in 100 cases of $Q$ wave and non- $Q$ wave myocardial infarction. Journal of Electrocardiology. 1988;21:331-335. 
46. Klein LW, Helfant RH. The Q-wave and non-Q wave myocardial infarction: differences and similarities. Progress in Cardiovascular Diseases. 1986;29:205-220.

47. Baroldi G, Radice F, Schmid G, Leone A. Morphology of acute myocardial infarction in relation to coronary thrombosis. American Heart Journal. 1974;87:65-75.

48. Erhardt LR. Clinical and pathological observation in different types of acute myocardial infarction. A study of 84 patients deceased after treatment in a coronary care unit. Acta Medica Scandinavica. 1974;560:7-78.

49. Roberts WC, Buja LM. The frequency and significance of coronary arterial thrombi and other observations in fatal acute myocardial infarction: a study of 107 necropsy patients. American Journal of Medicine. 1972;52:425-443.

50. Spain DM. Coronary atheromatous disease. Clinical pathologic correlations. Cardiovascular Clinics. 1972;4:53-57.

51. Spodick DH. Q-wave infarction versus S-T infarction. Nonspecificity of electrocardiographic criteria for differentiating transmural and nontransmural lesions. American Joumal of Cardiology. 1983;51:913-915.

52. Boden WE, Spodick DH. Diagnostic significance of precordial ST-segment depression. American Joumal of Cardiology. 1989;63:358-361.

53. DeWood MA, Spores J, Notske RN, Mouser LT, Bukrroughs R, Golden MS, Lang HT. Prevalence of total coronary occlusion during the early hours of transmural myocardial infarction. New England Journal of Medicine. 1980;303:897-902.

54. DeWood MA, Stifter WF, Simpson CS, Spores J, Eugster GS, Judge TP, Hinnen ML. Coronary arteriographic findings soon after non-Q-wave myocardial infarction. New England Journal of Medicine. 1986;315:417-423.

55. DeWood MA. Clinical implications of coronary arteriographic findings soon after non-Q-wave acute myocardial infarction. American Journal of Cardiology. 1988;61:36F-40F.

56. Keen WD, Savage MP, Fischman DL, Zalewski A, Walinsky P, Nardone D, Goldberg S. Comparison of coronary angiographic findings during the first six hours of non-Q-wave and Q-wave myocardial infarction. American Journal of Cardiology. 1994;74:324-328. 
57. Ogawa $H$, Misumi I, Sakamoto $T$, Masuda T, Okubo H, Miyao $Y$, Yasue $H$. Difference in plasminogen activator inhibitor activity between non-Q-wave infarction and Q-wave infarction. International Journal of Cardiology. 1993;41:201-208.

58. Timmis AD, Griffin B, Crick JC, Nelson DJ, Sowton E. The effects of early coronary patency on the evolution of myocardial infarction: a prospective arteriographic study. British Heart Journal. 1987;58:345-351.

59. Shell WE, DeWood MA, Kligerman M, Ganz W, Swan HJ. Early appearance of MB-creatine kinase activity in nontransmural myocardial infarction detected by a sensitive assay for the isoenzyme. American Journal of Medicine. 1981;71:254-262.

60. Gibson RS. Clinical, functional, and angiographic distinctions between $Q$ wave and non- $Q$ wave myocardial infarction: evidence of spontaneous reperfusion and implications for intervention trials. Circulation. 1987;75:V-128-V-138.

61. Gibson RS, Beller GA, Gheorghiade M, Nygaard TW, Watson DD, Huey BL, Sayre SL, Kaiser DL. The prevalence and clinical significance of residual myocardial ischemia 2 weeks after uncomplicated non- $Q$ wave infarction: a prospective natural history study. Circulation. 1986;73:1186-1198.

62. Ogawa H, Hiramori K, Haze K, Saito M, Sumiyoshi T, Fukami K, Goto Y, Ikeda M. Classification of non-Q-wave myocardial infarction according to electrocardiographic changes. British Heart Journal. 1985;54:473-478.

63. Huey BL, Gheorghiade M, Crampton RS, Beller GA, Kaiser DL, Watson DD, Nygaard TW, Craddock GB, Sayre SL, Gibson RS. Acute non-Q wave myocardial infarction associated with early ST segment elevation: evidence for spontaneous coronary reperfusion and implications for thrombolytic trials. Journal of the American College of Cardiology. 1987;9:18-25.

64. Pardee HEB. An electrocardiographic sign of coronary artery obstruction. Archives of Internal Medicine. 1920;26:244-257.

65. Rude RE, Poole WK, Muller JE, Turi Z, Rutherford J, Parker C, Roberts R, Raabe DS, Jr., Gold HK, Stone PH, Willerson JT, Braunwald E, and the MILIS Study Group. Electrocardiographic and clinical criteria for recognition of acute myocardial infarction based on analysis of 3,697 patients. American Journal of Cardiology. 1983;52:936-942.

66. Fuster V, Frye RL, Kennedy MA, Connolly DC, Mankin HT. The role of collateral circulation in the various coronary syndromes. Circulation. 1979;59:1137-1144. 
67. Edson JN. Subendocardial myocardial infarction. American Heart Joumal. 1960;60:323-324.

68. Norris RM, Brandt PWT, Caughey DE, Lee AJ, Scott PJ. A new coronary prognostic index. Lancet. 1969;1:274-278.

69. Likoff W, Bender S, Dreifus $L$. The fate of a patient with so-called mild coronary. Joumal of the American Medical Association. 1961;177:579-581.

70. Lown B, Vassaux C, Hood WB, Jr., Fakhro AM, Kaplinsky E, Roberge G. Unresolved problems in coronary care. American Journal of Cardiology. 1967;20:494-508.

71. Lown B, Sidel VW. Duration of hospital stay following acute myocardial infarction. American Journal of Cardiology. 1969;23:1-3.

72. Friedberg CK. Symposium: Myocardial infarction 1972 (Part 1). Circulation. 1972;45:179-188.

73. Madias JE, Chahine RA, Gorlin R, Blacklow DJ. A comparison of transmural and nontransmural acute myocardial infarction. Circulation. 1974;49:498-507.

74. Rigo P, Murray M, Taylor DR, Weisfeldt ML, Strauss HW, Pitt B. Hemodynamic and prognostic findings in patients with transmural and nontransmural infarction.

Circulation. 1975;51:1064-1070.

75. Cannom DS, Levy W, Cohen LS. The short- and long-term prognosis of patients with transmural and nontransmural myocardial infarction. American Joumal of Medicine. 1976;61:452-458.

76. Strauss $H$, Sobel BE, Roberts $R$. Acute and long-term prognosis in patients with transmural versus subendocardial infarction. Circulation 1978;58:193(Abstract)

77. Schulze RAJ, Pitt B, Griffith LSC, Ducci HH, Achuff SC, Baird MG, Humphries JO. Coronary angiography and left ventriculography in survivors of transmural and nontransmural myocardial infarction. American Journal of Medicine. 1978;64:108-113.

78. Geltman EM, Ehsani AA, Campbell MK, Schechtman K, Roberts R, Sobel BE. The influence of location and extent of myocardial infarction on long-term ventricular dysrhythmia and mortality. Circulation. 1979;60:805-814.

79. Ahmed SS, Brancato RR. Transmural versus nontransmural myocardial infarction. Influence of location on clinical features and mortality. Angiology. 1979;30:240-248. 
80. Coll S, Castaner A, Sanz G, Roig E, Magrina J, Navarro-Lopez F, Betriu A. Prevalence and prognosis after a first nontransmural myocardial infarction. American Journal of Cardiology. 1983;51:1584-1588.

81. Maisel AS, Ahnve S, Gilpin E, Henning H, Goldberger AL, Collins D, LeWinter $M$, Ross J, Jr. Prognosis after extension of myocardial infarct: the role of $Q$ wave or non- $Q$ wave infarction. Circulation. 1985;71:211-217.

82. Ogawa H, Hiramori K, Haze K, Saito M, Sumiyoshi T, Fukami K, Goto Y, Ikeda M. Comparison of clinical features of non- $Q$ wave and $Q$ wave myocardial infarction. American Heart Journal. 1986;111:513-518.

83. Theroux $P$, Bosch $X$, Kouz $S$. $Q$ wave and non- $Q$ wave myocardial infarction, in Califf RM, Mark DB, Wagner GS (eds): Acute Coronary Care in the Thrombolytic Era. Chicago, Year Book Medical Publishers, Inc. 1988, pp 429-443.

84. McLaughlin P, Coates G, Wood D, Cradduck T, Morch J. Detection of acute myocardial infarction by technetium-99m polyphosphate. American Joumal of Cardiology. 1975;35:390-396.

85. Cowley MJ, Mantle JA, Rogers WJ, Russel RO, Jr., Rackley CE, Logic JR. Technetium-99m stannous pyrophosphate myocardial scintigraphy. Reliability and limitations in assessment of acute myocardial infarction. Circulation. 1977;56:192-198.

86. Berman DS, Amsterdam EA, Hines HH, Denardo GL, Salel AF, Ikeda R, Jansholt AL, Mason DT. Problem of diffuse cardiac uptake of technetium-99m pyrophosphate in the diagnosis of acute myocardial infarction: enhanced scintigraphic accuracy by computerized selective blood pool subtraction. American Journal of Cardiology. 1977;40:768-774.

87. Ahmad M, Dubiel JP, Logan KW, Verdon TA, Martin RH. Limited clinical diagnostic specificity of technetium-99m stannous pyrophosphate myocardial imaging in acute myocardial infarction. American Journal of Cardiology. 1977;39:50-54.

88. Henning $H$, Schelbert HR, Righetti A, Ashburn WL, O'Rourke RA. Dual myocardial imaging with technetium-99m pyrophosphate and thallium-201 for detecting, localizing and sizing acute myocardial infarction. American Journal of Cardiology. 1977;40:147-155.

89. Holman BL, Lesch M, Alpert JS. Myocardial scintigraphy with technetrium-99m pyrophosphate during the early phase of acute infarction. American Journal of Cardiology. 1978;41:39-42. 
90. Massie BM, Botvinick EH, Werner JA, Chatterjee K, Parmley WW. Myocardial scintigraphy with technetium-99m stannous pyrophosphate: an insensitive test for nontransmural myocardial infarction. American Journal of Cardiology. 1979;43:186-192.

91. Codini MA, Turner DA, Battle WE, Hassan P, Ali A, Messer JV. Value and limitations of technetium-99m stannous pyrophosphate in the detection of acute myocardial infarction. American Heart Joumal. 1979;98:752-762.

92. Lyons KP, Olson HG, Aronow WS. Sensitivity and specificity of Tc-99m-pyrophosphate myocardial scintigraphy for the detection of acute myocardial infarction. Clinics in Nuclear Medicine. 1980;5:8-12.

93. Olson HG, Lyons KP, Butman S, Piters KM. Validation of technetium-99m stannous pyrophosphate myocardial scintigraphy for diagnosing acute myocardial infarction more than 48 hours old when serum creatine kinase-MB has returned to normal. American Journal of Cardiology. 1983;52:245-251.

94. Corbett JR, Lewis M, Willerson JT, Nicod PH, Huxley RL, Simon T, Rude RE, Henderson E, Parkey R, Rellas JS, Buja LM, Sokolov JJ, Lewis SE.

$99 \mathrm{mTc}$-pyrophosphate imaging in patients with acute myocardial infarction: comparison of planar imaging with single-photon tomography with and without blood pool overlay. Circulation. 1984;69:1120-1128.

95. Zema MJ. Q wave, S-T segment, and T wave myocardial infarction. Useful clinical distinction. American Journal of Medicine. 1985;78:391-398.

96. Wahl JM, Hakki AH, Iskandrian AS, Yacone L. Scintigraphic characterization of $Q$ wave and non-Q-wave acute myocardial infarction. 4merican Heart Journal. 1985;109:769-775.

97. Widimsky P, Gregor P, Cervenka V, Visek V. Two-dimensional echocardiography in acute transmural and non-transmural myocardial infarction. Cor et Vasa. 1984;26:12-19.

98. Horowitz RS, Morganroth J. Immediate detection of early high-risk patients with acute myocardial infarction using two-dimensional echocardiographic evaluation of left ventricular regional wall motion abnormalities. American Heart Journal. 1982;103:814-822.

99. Horowitz RS, Morganroth J, Parrotto C, Chen CC, Soffer J, Pauletto FJ. Immediate diagnosis of acute myocardial infarction by two-dimensional echocardiography. Circulation. 1982;65:323-329. 
100. Sammel NL, Wilson RL, Norris RM, Brandt PW, Stuckey JG. Angiocardiography and exercise testing at one month after a first myocardial infarction. Australian and New Zealand Joumal of Medicine. 1980;10:182-187.

101. Nicod P, Corbett JR, Sanford CF, Mukharji J, Dehmer GJ, Croft CH, Rude RE, Lewis S, Willerson JT. Comparison of the influence of acute transmural and nontransmural myocardial infarction on ventricular function. American Heart Joumal. 1984; 107:28-34.

102. Montague TJ, Johnstone DE, Spencer CA, Lalonde LD, Gardner MJ, O'Reilly MG, Horacek BM. Non-Q-wave acute myocardial infarction: body surface potential map and ventriculographic patterns. American Joumal of Cardiology. 1986;58:1173-1180.

103. Allman KC, Wieland DM, Muzik O, Degrado TR, Wolfe ER, Jr., Schwaiger M. Carbon-11 hydroxyephedrine with positron emission tomography for serial assessment of cardiac adrenergic neuronal function after acute myocardial infarction in humans. Journal of the American College of Cardiology. 1993;22:368-375.

104. Hashimoto T, Kambara H, Fudo T, Hayashi M, Tamaki S, Tokunaga S, Tamaki N, Yonekura $Y$, Konishi J, Kawai C. Non-Q wave versus $Q$ wave myocardial infarction: regional myocardial metabolism and blood flow assessed by positron emission tomography. Journal of the American College of Cardiology. 1988;12:88-93.

105. Willerson JT, Parkey RW, Bonte FJ, Meyer SL, Stokely EM. Acute subendocardial myocardial infarction in patients. Its detection by Technetium 99-m stannous pyrophosphate myocardial scintigrams. Circulation. 1975;51:436-441.

106. Bayley N, Hunt D, Penington C, Sloman JG. Subendocardial myocardial infarction. Australian and New Zealand Journal of Medicine. 1982;12:166-169.

107. Connolly DC, Elveback LR. Coronary heart disease in residents of Rochester, Minnesota. VI. Hospital and posthospital course of patients with transmural and subendocardial myocardial infarction. Mayo Clinic Proceedings. 1985;60:375-381.

108. van Rensburg CJ, Przybojewski JZ, Soolman J. Clinical characteristics of and prognosis in acute transmural anterior, transmural inferior and non-transmural myocardial infarction. A comparative retrospective study. South African Medical Journal. 1985;67:487-495.

109. Varat MA. Non-transmural infarction: clinical distinction between patients with ST depression and those with $T$ wave inversion. Journal of Electrocardiology. 1985; 18:15-20. 
110. Szklo M, Goldberg R, Kennedy HL, Tonascia JA. Survival of patients with nontransmural myocardial infarction: a population-based study. American Joumal of Cardiology. 1978;42:648-652.

111. Berger CJ, Murabito JM, Evans JC, Anderson KM, Levy D. Prognosis after first myocardial infarction. Comparison of $Q$ - wave and non-Q-wave myocardial infarction in the Framingham Heart Study. Journal of the American Medical Association. 1992;268:1545-1551.

112. Hutter AM, DeSanctis RW, Flynn T, Yeatman LA. Nontransmural myocardial infarction: a comparison of hospital and late clinical course of patients with that of matched patients with transmural anterior and transmural inferior myocardial infarction. American Joumal of Cardiology. 1981;48:595-602.

113. Boxall J, Saltups A. A comparison of nontransmural and transmural myocardial infarction. Australian and New Zealand Journal of Medicine. 1980;10:176-179.

114. Marmor A, Geltman EM, Schechtman K, Sobel BE, Roberts R. Recurrent myocardial infarction: clinical predictors and prognostic implications. Circulation. 1982;66:415-421.

115. Karlson BW, Herlitz J, Richter A, Hjalmarson A. Prognosis in acute myocardial infarction in relation to development of $Q$ waves. Clinical Cardiology. 1991;14:875-880.

116. Stone PH, Raabe DS, Jaffe AS, Gustafson N, Muller JE, Turi ZG, Rutherford JD, Poole WK, Passamani E, Willerson JT, Sobel BE, Robertson T, Braunwald E, for the MILIS Group. Prognostic significance of location and type of myocardial infarction: independent adverse outcome associated with anterior location. Journal of the American College of Cardiology. 1988;11:453-463.

117. Roy S, Mukherjee S. Q-wave and non-Q wave myocardial infarction--prospective study. Journal of the Association of Physicians of India. 1993;41:509-510.

118. Bissett JK, Matts J, Sharma B. Residual myocardial jeopardy in patients with Q-wave and non-Q-wave infarctions. British Heart Journal. 1987;58:460-464.

119. Marmor A, Sobel BE, Roberts $R$. Factors presaging early recurrent myocardial infarction ("extension"). American Journal of Cardiology. 1981;48:603-610.

120. Lekakis J, Katsoyanni K, Trichopoulos D, Tsitouris G. Q-versus non-Q-wave myocardial infarction: clinical characteristics and 6-month prognosis. Clinical Cardiology. 1984;7:283-288. 
121. Hollander G, Ozick H, Greengart A, Shani J, Lichstein E. High mortality early reinfarction with first nontransmural myocardial infarction. American Heart Journal. 1984;108:1412-1416.

122. Scheinman MM, Abbott JA. Clinical significance of transmural versus nontransmural electrocardiographic changes in patients with acute myocardial infarction. American Journal of Medicine. 1973;55:602-607.

123. Thanavaro S, Krone RJ, Kleiger RE, Province MA, Miller JP, DeMello VR, Oliver GC. In-hospital prognosis of patients with first nontransmural and transmural infarctions. Circulation. 1980;61:29-33.

124. Mahony C, Hindman MC, Aronin N, Wagner GS. Prognostic differences in subgroups of patients with electrographic evidence of subendocardial or transmural myocardial infarction. The favorable outlook for patients with an initially normal QRS complex. American Journal of Medicine. 1980;69:183-186.

125. Edlavitch SA, Crow R, Burke GL, Baxter J. Secular trends in $Q$ wave and non- $Q$ wave acute myocardial infarction. The Minnesota Heart Survey. Circulation. 1991;83:492-503.

126. Feinstein AR, Sosin DM, Wells CK. The Will Rogers phenomenon: Stage migration and new diagnostic techniques as a source of misleading statistics for survival in cancer. New England Journal of Medicine. 1985;312:1604-1608.

127. Cohen M, Adams PC, Hawkins L, Bach M, Fuster V. Usefulness of antithrombotic therapy in resting angina pectoris or non-Q-wave myocardial infarction in preventing death and myocardial infarction (a pilot study from the Antithrombotic Therapy in Acute Coronary Syndromes Study Group). American Journal of Cardiology. 1990;66:1287-1292.

128. Dewar HA, Stephenson $P$, Horler AR, Cassels-Smith AJ, Ellis PA. Fibrinolytic therapy of coronary thrombosis. Controlled trial of 75 cases. British Medical Journal. 1963;915-920.

129. Khaja F, Walton JA, Jr., Brymer JF, Lo E, Osterberger L, O'Neill WW, Colfer HT, Weiss R, Lee T, Kurian T, Goldberg AD, Pitt B, Goldstein S. Intracoronary fibrinolytic therapy in acute myocardial infarction. Report of a prospective randomized trial. New England Journal of Medicine. 1983;308:1305-1311. 
130. Anderson JL, Marshall HW, Bray BE, Lutz JR, Frederick PR, Yanowitz FG, Datz FL, Klausner SC, Hagan AD. A randomized trial of intracoronary streptokinase in the treatment of acute myocardial infarction. New England Journal of Medicine. 1983;308:1312-1318.

131. Blanke H, Scherff F, Karsch KR, Levine RA, Smith H, Rentrop P. Electrocardiographic changes after streptokinase-induced recanalization in patients with acute left anterior descending artery obstruction. Circulation. 1983;68:406-412.

132. von Essen R, Schmidt W, Vebis R, Edelman B, Effert S, Sinly J, Rau G. Myocardial infarction and thrombolysis: electrocardiographic short term and long term results using precordial mapping. British Heart Journal. 1985;54:6-10.

133. Dioguardi N, Mannucci PM, Lotto A, Rossi P, Levi GF, Lomanto B, Rota M, Mattei G, Proto C, Fiorelli G, Agostoni A. Controlled trial of streptokinase and heparin in acute myocardial infarction. Lancet. 1971;2:891-895.

134. Bett JHN, Biggs JC, Castaldi PA, Chesterman CN, Hale GS, Hirsh J, Isbister JP, McDonald IG, McLean KH, Morgan JJ, O'Sullivan EF, Rosenbaum M. Australian multicentre trial of streptokinase in acute myocardial infarction. Lancet. 1973;1:57-60.

135. Rentrop P, Blanke H, Karsch KR, Kaiser H, Kostering H, Leitz K. Selective intracoronary thrombolysis in acute myocardial infarction and unstable angina pectoris. Circulation. 1981;63:307-317.

136. Taylor GJ, Mikell FL, Moses HW, Dove JT, Batchelder JE, Thull A, Hansen S, Wellons HA, Schneider JA. Intravenous versus intracoronary streptokinase therapy for acute myocardial infarction in community hospitals. American Joumal of Cardiology. 1984;54:256-260.

137. Koren G, Weiss AT, Hasin Y, Appelbaum D, Welber S, Rozenman Y, Lotan C, Mosseri M, Sapoznikov D, Luria MH, Gotsman MS. Prevention of myocardial damage in acute myocardial ischemia by early treatment with intravenous streptokinase. New England Journal of Medicine. 1985;313:1384-1389.

138. Bren GB, Wasserman AG, Ross AM, for the Thrombolysis in Myocardial Infarction (TIMI) Investigators. Coronary perfusion status in $Q$ and non $Q$ wave infarction patients presenting with ST elevation. Circulation 1987;76:IV-123(Abstract)

139. National Heart Foundation of Australia Coronary Thrombolysis Group. Coronary thrombolysis and myocardial salvage by tissue plasminogen activator given up to 4 hours after onset of myocardial infarction. Lancet. 1988;1:203-208. 
140. Gruppo Italiano Per Lo Studio Della Sopravvivenza Nell'Infarto Miocardio. GISSI-2: a factorial randomised trial of alteplase versus streptokinase and heparin versus no heparin among 12,490 patients with acute myocardial infarction. Lancet. 1990;336:65-71.

141. Eisenberg MJ, Barbash Gl, Hod H, Roth A, Schachar A, Zolti L, Rabinowitz B, Kaplinsky E, Laniado S, Modan M. Prognostic importance of delayed Q-wave evolution 3 to 24 hours after initiation of thrombolytic therapy for acute myocardial infarction. American Journal of Cardiology. 1991;67:231-235.

142. Tajer CD, Diaz R, Paolasso EA, van de Werf $F$, on behalf of the investigators of the TPASK Mortality Trial. Non $Q$ wave myocardial infarction after thrombolytic treatment predicts a high rate of reinfarction and death during the follow up. Circulation 1993;88:I-490(Abstract)

143. Barbagelata A, Califf RM, Sgarbossa EB, Goodman SG, Stebbins AL, Granger CG, Suarez LD, Borruel M, Gates K, Starr S, Wagner GS. Thrombolysis and Q wave versus non-Q wave first acute myocardial infarction: A GUSTO-I substudy. Journal of the American College of Cardiology. 1997;29:770-777.

144. Aguirre FV, Younis LT, Chaitman BR, Ross AM, McMahon RP, Kern MJ, Berger PB, Sopko G, Rogers WJ, Shaw L, Knatterud G, Braunwald E, for the TIMI II Investigators. Early and 1-year clinical outcome of patients evolving a non-Q-wave versus Q-wave myocardial infarction after thrombolysis. Results from the TIMI II study. Circulation. 1995;91:2541-2548.

145. Matetzky S, Barbash Gl, Rabinowitz B, Rath S, Har Zahav Y, Agranat O, Kaplinsky $E$, Hod $H$. Q wave and non-Q wave myocardial infarction after thrombolysis. Journal of the American College of Cardiology. 1995;26:1445-1451.

146. Volpi A, DeVita C, Franzosi MG, Geraci E, Maggioni AP, Mauri F, Negri E, Santoro E, Tavazzi L, Tognoni G, and the Ad hoc Working Group of the Gruppo Italiano per lo Studio della Sopravvivenza nell'Infarto Miocardico (GISSI)-2 Data Base. Determinants of 6-month mortality in survivors of myocardial infarction after thrombolysis. Results of the GISSI-2 data base. Circulation. 1993;88:416-429.

147. Fibrinolytic Therapy Trialists' (FTT) Collaborative Group. Indications for fibrinolytic therapy in suspected acute myocardial infarction: collaborative overview of early mortality and major morbidity from all randomised trials of more than 1000 patients. Lancet. 1994;343:311-322. 
148. Boden WE, Scheldewaert R, Walters EG, Whitehead A, Coltart DJ, Santoni JP, Belgrave G, Starkey IR. Design of a placebo-controlled clinical trial of long-acting diltiazem and aspirin versus aspirin alone in patients receiving thrombolysis with a first acute myocardial infarction. Incomplete Infarction Trial of European Research Collaborators Evaluating Prognosis Post-Thrombolysis (diltiazem) (INTERCEPT) Research Group. American Journal of Cardiology. 1995;75:1120-1123.

149. Rogers WJ, Babb JD, Baim DS, Chesebro JH, Gore JM, Roberts R, Williams DO, Frederick M, Passamani ER, Braunwald E, for the TIMI II Investigators. Selective versus routine predischarge coronary arteriography after therapy with recombinant tissue-type plasminogen activator, heparin and aspirin for acute myocardial infarction. Joumal of the American College of Cardiology. 1991;17:1007-1016.

150. Vaisrub S. Subendocardial infarction: a prognostic paradox. Journal of the American Medical Association. 1976;235:943-944.

151. Madias JE, Hood WB, Jr. Nontransmural myocardial infarction. Chest. 1976;70:2-3.

152. Madias JE, Gorlin R. The myth of acute "mild" myocardial infarction. Annals of Internal Medicine. 1977;86:347-352.

153. Gambhir DS. Transmural versus nontransmural myocardial infarction. Indian Heart Journal. 1982;34:113-115.

154. Cheitlin MD. Nontransmural and transmural MI: important clinical differences? Journal of Cardiovascular Medicine. 1984;9:471-485.

155. Moreno $P$, Schocken DD. Non-Q wave myocardial infarction. Pathophysiology and prognostic implications. Chest. 1984;86:905-909.

156. Goldberg RK, Fenster PE. Significance of the $Q$ wave in acute myocardial infarction. Clinical Cardiology. 1985;8:40-46.

157. Anonymous. Subendocardial infarction. Lancet. 1985;i:615-616.

158. Pratt $C M$, Roberts $R$. Non- $Q$ wave myocardial infarction: recognition, pathogenesis, prognosis, and management. Cardiology Series. 1985;5-19.

159. Nixon JV. Non-Q-wave myocardial infarction. American Journal of the Medical Sciences. 1986;292:173-181. 
160. Kouvaras G, Chronopoulos G, Cokkinos DV. Q and non- $Q$ wave myocardial infarction: current views. Angiology. 1988;39:333-340.

161. Montague TJ, Mackenzie BR, Henderson MA, Macdonald RG, Forbes CJ, Chandler BM. Acute non-Q-wave myocardial infarction: a distinct clinical entity of increasing importance. Canadian Medical Association Journal. 1988;139:487-493.

162. Andre-Fouet X, Pillot M, Leizorovicz A, Finet G, Gayet C, Milon H. "Non-Q wave," alias "nontransmural," myocardial infarction: a specific entity. American Heart Journal. 1989;117:892-902.

163. O'Brien TX, Ross J, Jr. Non-Q-wave myocardial infarction: incidence, pathophysiology, and clinical course compared with Q-wave infarction. Clinical Cardiology. 1989;12:III-3-III-9.

164. Genovese MG, Salaki JS, Kennedy RJ, Grace WJ. Subendocardial infarction: what happens later. American Heart Journal. 1976;92:542-543.

165. Nicod $P$, Gilpin $E$, Dittrich $H$, Polikar $R$, Hjalmarson A, Blacky AR, Henning $H$, Ross J, Jr. Short- and long-term clinical outcome after $Q$ wave and non- $Q$ wave myocardial infarction in a large patient population. Circulation. 1989;79:528-536.

166. Bourke S, Conroy RM, Mulcahy R, Robinson K. Aetiological and prognostic correlates of site of myocardial infarction. European Heart Journal. 1988;9:734-739.

167. Herlitz J, Hjalmarson A, Karlson BW. Prognosis during one year for patients with myocardial infarction in relation to the development of $Q$ waves: experiences from the Miami trial. Clinical Cardiology. 1990;13:261-264.

168. Murphy JJ, Connell PA. Prodromal chest pains: clues to the pathogenesis of non- $Q$ wave acute myocardial infarction? International Joumal of Cardiology. 1992;37:188-193.

169. Maeda S. Different clinical implications for ST depression and T wave inversion in non-Q wave myocardial infarction. Journal of Cardiology. 1994;24:357-366.

170. Palagi B, Baroffio R, Picozzi R. Prevalence and prognostic value of left ventricular dysfunction in non-Q-wave myocardial infarction. Nuklearmedizin. 1987;26:135-138.

171. Bosch X, Theroux P, Waters DD, Pelletier GB, Roy D. Early postinfarction ischemia: clinical, angiographic, and prognostic significance. Circulation.

1987;75:988-995. 
172. Greenberg H, Gillespie J, Dwyer EM, Jr. A new electrocardiographic classification for post-myocardial infarction clinical trials. American Joumal of Cardiology. 1987;59:1057-1063.

173. Boden WE, Krone RJ, Kleiger RE, Oakes D, Greenberg H, Dwyer EJ, Jr., Miller JP, Abrams J, Coromilas J, Goldstein R, Moss AJ, and the Multicenter Diltiazem Post-Infarction Trial Research Group. Electrocardiographic subset analysis of diltiazem administration on long-term outcome after acute myocardial infarction. American Journal of Cardiology. 1991;67:335-342.

174. Fox JP, Beattie JM, Salih MS, Davies MK, Littler WA, Murray RG. Non Q wave infarction: exercise test characteristics, coronary anatomy, and prognosis. British Heart Journal. 1990;63:151-153.

175. Moye LA, Pfeffer MA, Wun CC, Davis BR, Geltman E, Hayes D, Farnham DJ, Randall OS, Dinh H, Arnold JMO, Kupersmith J, Hager D, Glasser SP, Biddle T, Hawkins CM, Braunwald E, for the SAVE Investigators. Uniformity of captopril benefit in the SAVE study: subgroup analysis. European Heart Joumal. 1994;15:2-8.

176. Gheorghiade M, Schultz L, Tilley B, Kao W, Goldstein S. Natural history of the first non- $Q$ wave myocardial infarction in the placebo arm of the Beta-Blocker Heart Attack Trial. American Heart Journal. 1991;122:1548-1553.

177. Venkatachalapathy D, Kuhn L, Waxman $\mathrm{H}$. Clinical features, early and later prognosis of acute subendocardial infarction: comparison with transmural infarction. Circulation 1973;48:226(Abstract)

178. Connolly DC, Elveback LR. Comparison of hospital and post-hospital course of patients with transmural and subendocardial myocardial infarction. American Journal of Cardiology 1979;43:370(Abstract)

179. Theroux P, Kouz S, Bosch X, Waters DD, Roy D, Pelletier GB, Dyrda I. Clinical and angiographic features of non-Q-wave and $Q$-wave myocardial infarction. Circulation 1986;74:303(Abstract)

180. Madigan NP, Rutherford BD, Frye RL. The clinical course, early prognosis and coronary anatomy of subendocardial infarction. American Journal of Medicine. 1976;60:634-641.

181. Kossowsky WA, Mohr BD, Rafi S, Lyon AF. Superimposition of transmural infarction following acute subendocardial infarction; how frequent? Chest. 1976;69:758-761. 
182. Smeets JP, Legrand V, Rigo P, Demoulin JC, Boland J, de Landsheere C, Foidart G, Collignon P, Kulbertus HE. Subendocardial myocardial infarction: a follow-up study of 55 cases. European Heart Journal. 1981;2:57-63.

183. Poehlman JH, Silverman ME. Clinical characteristics, electrocardiographic and enzyme correlations, and long-term prognosis of patients with chest pain associated with ST depression and/or T wave inversions. American Heart Joumal. 1980;99:173-180.

184. Kao W, Khaja F, Goldstein S, Gheorghiade M. Cardiac event rate after non-Q-wave acute myocardial infarction and the significance of its anterior location. American Journal of Cardiology. 1989;64:1236-1242.

185. Keltai M, Gara I. The second phase of subendocardial infarction--transmural infarction. Cor et Vasa. 1972;20:95-98.

186. Boden WE, Kleiger RE, Gibson RS, Schwartz DJ, Capone RJ, Schechtman KB, Young PM, Geiger BJ, Roberts R, and the Diltiazem Reinfarction Study Research Group. Electrocardiographic and enzymatic findings in acute non- $Q$ wave myocardial infarction. Results from the Multicenter Diltiazem Reinfarction Study. American Journal of Noninvasive Cardiology. 1988;2:125-133.

187. Nicholson MR, Roubin GS, Bernstein L, Harris PJ, Kelly DT. Prognosis after an initial non-Q-wave myocardial infarction related to coronary arterial anatomy. American Journal of Cardiology. 1983;52:462-465.

188. Schechtman KB, Capone RJ, Kleiger RE, Gibson RS, Schwartz DJ, Roberts R, Boden WE. Differential risk patterns associated with 3 month as compared with 3 to 12 month mortality and reinfarction after non- $Q$ wave myocardial infarction. The Diltiazem Reinfarction Study Group. Journal of the American College of Cardiology. 1990;15:940-947.

189. Cohen $\mathrm{M}$, Xiong J, Parry G, Adams PC, Chamberlain D, Wieczorek I, Fox KA, McBride R, Chesebro JH, Fuster V. Prospective comparison of unstable angina versus non- $Q$ wave myocardial infarction during antithrombotic therapy. Antithrombotic Therapy in Acute Coronary Syndromes Research Group. Journal of the American College of Cardiology. 1993;22:1338-1343.

190. Wong SC, Greenberg H, Hager WD, Dwyer EM, Jr. Effects of diltiazem on recurrent myocardial infarction in patients with non- $Q$ wave myocardial infarction. Journal of the American College of Cardiology. 1992;19:1421-1425. 
191. The RISC Group. Risk of myocardial infarction and death during treatment with low dose aspirin and intravenous heparin in men with unstable coronary artery disease. Lancet. 1990;336:827-830.

192. Yi-jian Q, Jia-hui W, Huan-le T. Zheng-zhong M, Guang Y. Acute non-Q-wave myocardial infarction and its clinicopathological correlation. A long-term follow-up of 21 cases. Chinese Medical Joumal. 1990;103:995-997.

193. Boden WE, Kleiger RE, Gibson RS, Reddy BR, Schechtman KB, Schwartz DJ, Capone RJ, Roberts R, and the Diltiazem Reinfarction Study Research Group. Favourable long term prognosis in patients with non- $Q$ wave acute myocardial infarction not associated with specific electrocardiographic changes. Diltiazem Reinfarction Study Research Group. British Heart Journal. 1989;61:396-402.

194. Boden WE, Gibson RS, Kleiger RE, Schechtman KB, Capone RJ, Schwartz DJ, Roberts R, and the Diltiazem Reinfarction Study Research Group. Importance of early recurrent ischemia on one-year survival after non-Q-wave acute myocardial infarction. American Journal of Cardiology. 1989;64:799-801.

195. Wallentin LC, for the Research Group on Instability in Coronary Artery Disease in Southeast Sweden. Aspirin ( $75 \mathrm{mg} /$ day) after an episode of unstable coronary artery disease: long-term effects on the risk for myocardial infarction, occurrence of severe angina and the need for revascularization. Journal of the American College of Cardiology. 1991;18:1587-1593.

196. Chung MK, Bosner MS, McKenzie JP, Shen J, Rich MW. Prognosis of patients greater than or equal to 70 years of age with non-Q-wave acute myocardial infarction compared with younger patients with similar infarcts and with patients greater than or equal to 70 years of age with Q-wave acute myocardial infarction. American Journal of Cardiology. 1995;75:18-22.

197. Behar S, Goldbourt U, Barbash G, Modan B, for the Secondary Prevention Reinfarction Israeli Nifedipine Trial Study Group, and the Israeli Thrombolytic Survey Group. Twenty-five-year mortality rate decrease in patients in Israel with a first episode of acute myocardial infarction. American Heart Journal. 1996;130:453-458.

198. Pierard LA, Dubois C, Albert A, Chapelle JP, Carlier J, Kulbertus HE. Prognostic significance of a low peak serum creatine kinase level in acute myocardial infarction. American Journal of Cardiology. 1989;63:792-796.

199. Brush JE, Brand DA, Acampora D, Chalmer B, Wackers FJ. Use of the initial electrocardiogram to predict in-hospital complications of acute myocardial infarction. New England Journal of Medicine. 1985;312:1137-1141. 
200. Buda AJ, Macdonald IL, Dubbin JD, Orr SA, Strauss HD. Myocardial infarct extension: prevalence, clinical significance, and problems in diagnosis. American Heart Joumal. 1983;105:744-749.

201. Behar S, Reicher-Reiss H, Abinader E, Agmon J, Friedman Y, Barzilai J, Kaplinsky E, Kauli N, Kishon Y, Palant A, Peled B, Rabinovich B, Reisin L, Schlesinger $Z$, Zahavi I, Zion $M$, Goldbourt $U$. The prognostic significance of angina pectoris preceding the occurrence of a first acute myocardial infarction in 4166 consecutive hospitalized patients. American Heart Journal. 1992;123:1481-1486.

202. Fukui S, Satoh K, Ueki N, Fujii K, Hamano Y, Inoue H, Minamino T, Kusuoka H, Inoue $\mathrm{M}$. Immediate prognosis in acute myocardial infarction: serial changes in immediate mortality rate and cause of death. Japanese Circulation Journal. 1984;48:11-17.

203. Montague TJ, Ikuta RM, Wong RY, Bay KS, Teo KK, Davies NJ. Comparison of risk and patterns of practice in patients older and younger than 70 years with acute myocardial infarction in a two-year period (1987-1989). American Journal of Cardiology. 1991;68:843-847.

204. Manttari M, Romo M, Manninen V, Koskinen P, Huttunen JK, Heinonen OP, Frick $\mathrm{MH}$. Reduction in $\mathrm{Q}$ wave myocardial infarctions with gemfibrozil in the Helsinki Heart Study. American Heart Joumal. 1990;119:991-995.

205. Norris RM, Caughey DE, Deeming LW, Mercer CJ, Scott PJ. Prognosis following acute myocardial infarction. New Zealand Medical Journal. 1973;77:12-18.

206. Pierard LA, Albert A, Kulbertus HE. Predictors of spontaneous predischarge ischemia following acute myocardial infarction. Clinical Cardiology. 1992;15:260-264.

207. Roliag A, Abdelnoor M, Mangschau A, Jonsbu J, Aase O, Erikssen J. First myocardial infarction: 5-year survival predicted from routine clinical, laboratory, and radionuclide findings during the acute stage. European Heart Journal. 1991;12:968-973.

208. Saito M, Fukami K, Hiramori K, Haze K, Sumiyoshi T, Kasagi H, Horibe H. Long-term prognosis of patients with acute myocardial infarction: is mortality and morbidity as low as the incidence of ischemic heart disease in Japan? American Heart Journal. 1987;113:891-897. 
209. Gibson RS, Watson DD, Craddock GB, Crampton RS, Kaiser DL, Denny MJ, Beller GA. Prediction of cardiac events after uncomplicated myocardial infarction: a prospective study comparing predischarge exercise thallium-201 scintigraphy and coronary angiography. Circulation. 1983;68:321-336.

210. Molstad $P$. Prognostic significance of type and location of a first myocardial infarction. Journal of Internal Medicine. 1993;233:393-399.

211. Gheorghiade M, Schultz L, Tilley B, Kao W, Goldstein S. Effects of propranolol in non-Q-wave acute myocardial infarction in the beta blocker heart attack trial. American Journal of Cardiology. 1990;66:129-133.

212. Ng AS, Johan A, Quek SS, Koh TH, Tan AM. Subendocardial versus transmural myocardial infarction: clinical comparison and review. Singapore Medical Journal. 1983;24:324-332.

213. The MIAMI Trial Research Group. MIAMI: Metoprolol in Acute Myocardial Infarction. Mortality. American Journal of Cardiology. 1985;56:15G-22G.

214. Herlitz J, Hjalmarson A, Bengtsson A, Sillfors L. Long-term prognosis in relation to ECG findings in acute myocardial infarction. Acta Cardiologica. 1987;42:79-89.

215. Herlitz J, Hjalmarson A. The relationship between electrocardiographic changes and early mortality rate in acute myocardial infarction. Journal of Electrocardiology. 1984;17:139-144.

216. Goldberg RJ, Gore JM, Gurwitz JH, Alpert JS, Brady P, Strohsnitter W, Chen Z, Dalen JE. The impact of age on the incidence and prognosis of initial acute myocardial infarction: the Worcester Heart Attack Study. American Heart Journal. 1989; 117:543-549.

217. Smith SC, Gilpin E, Ahnve S, Dittrich H, Nicod P, Henning H, Ross JRJ. Outlook after acute myocardial infarction in the very elderly compared with that in patients aged 65 to 75 years. Journal of the American College of Cardiology. 1990;16:784-792.

218. Goldberg RJ, Gore JM, Alpert JS, Dalen JE. Recent changes in attack and survival rates of acute myocardial infarction (1975 through 1981). The Worcester Heart Attack Study. Journal of the American Medical Association. 1986;255:2774-2779.

219. Gilpin E, Ricou F, Dittrich H, Nicod P, Henning H, Ross J, Jr. Factors associated with recurrent myocardial infarction within one year after acute myocardial infarction. American Heart Journal. 1991;121:457-465. 
220. Benhorin J, Moss AJ, Oakes D, Marcus F, Greenberg H, Dwyer EM, Jr., Algeo S, Hahn E, and the Multicenter Diltiazem Post-Infarction Research Group. The prognostic significance of first myocardial infarction type ( $Q$ wave versus non- $Q$ wave) and $Q$ wave location. Joumal of the American College of Cardiology. 1990;15:1201-1207.

221. Rodda BE. The Timolol Myocardial Infarction Study: an evaluation of selected variables. Circulation. 1983;67:101-106.

222. Schechtman KB, Kleiger RE, Boden WE, Capone RJ, Schwartz DJ, Roberts R, Gibson RS. The relationship between 1-year mortality and infarct location in patients with non-Q wave myocardial infarction. American Heart Journal. 1992;123:1175-1181.

223. Miranda CP, Herbert WG, Dubach $P$, Lehmann KG, Froelicher VF. Post-myocardial infarction exercise testing. Non- $Q$ wave versus $Q$ wave correlation with coronary angiography and long-term prognosis. Circulation. 1991;84:2357-2365.

224. The Coronary Drug Project Research Group. The prognostic importance of the electrocardiogram after myocardial infarction. Experience in the Coronary Drug Project. Annals of Internal Medicine. 1972;77:677-689.

225. Akiyama T, Pawitan Y, Greenberg H, Kuo CS, Reynolds-Haertle RA, and the CAST Investigators. Increased risk of death and cardiac arrest from encainide and flecainide in patients after non-Q-wave acute myocardial infarction in the Cardiac Arrhythmia Suppression Trial. American Journal of Cardiology. 1991;68:1551-1555.

226. Klimt CR, Knatterud GL, Stamler J, Meier P. Persantine-Aspirin Reinfarction Study. Part II. Secondary coronary prevention with persantine and aspirin. Journal of the American College of Cardiology. 1986;7:251-269.

227. Dimond GE. Prognosis of men returning to work after first myocardial infarction. Circulation. 1961;23:881-885.

228. Bolson EL, Liman S, Sheehan F, Dodge HT. Left ventricular segmental wall motion - a new method using local direction information, in Computers in Cardiology. New York, IEEE, 1981, pp 245-248.

229. Roberts R, Braunwald E, Muller JE, Croft C, Gold HK, Hartwell TD, Jaffe AS, Mullin SM, Parker C, Passamani ER, Poole WK, Robertson T, Raabe DSJ, Rude RE, Stone PH, Turi ZG, Sobel BE, Willerson JT, and the MILIS Study Group. Effect of hyaluronidase on mortality and morbidity in patients with early peaking of plasma creatine kinase $\mathrm{MB}$ and non-transmural ischaemia. Multicentre investigation for the limitation of infarct size (MILIS). British Heart Journal. 1988;60:290-298. 
230. Norris RM, Caughey DE, Deeming LW, Mercer CJ, Scott PJ. Coronary prognostic index for predicting survival after recovery from acute myocardial infarction. Lancet. $1970 ; 485-488$.

231. Fesmire FM, Percy RF, Wears RL, MacMath TL. Initial ECG in $Q$ wave and non- $Q$ wave myocardial infarction. Annals of Emergency Medicine. 1989;18:741-746.

232. Park SE, Tani A, Minamino T, Azuma J, Kishimoto S. Coronary angiographic features within 48 hours from onset of non- $Q$ wave myocardial infarction with $R$ wave regression and no ST segment depression. Cardiology. 1990;77:121-129.

233. Goldberg RJ, Gurwitz J, Yarzebski J, Landon J, Gore JM, Alpert JS, Dalen PM, Dalen JE. Patient delay and receipt of thrombolytic therapy among patients with acute myocardial infarction from a community-wide perspective. American Joumal of Cardiology. 1992;70:421-425.

234. Dorogy ME, Hooks GS, Cameron RW, Davis RC. Clinical and angiographic correlates of normal creatine kinase with increased MB isoenzymes in possible acute myocardial infarction. American Heart Joumal. 1995;130:211-217.

235. Lofmark R. Clinical features in patients with recurrent myocardial infarction. Acta Medica Scandinavica. 1979;206:367-370.

236. Fabricius-Bjerre N, Munkvad M, Knudsen JB. Subendocardial and transmural myocardial infarction: a five year survival study. American Journal of Medicine. 1979;66:986-990.

237. Krone RJ, Friedman E, Thanavaro S, Miller JP, Kleiger RE, Oliver GC. Long-term prognosis after first $Q$-wave (transmural) or non-Q-wave (nontransmural) myocardial infarction: analysis of 593 patients. American Journal of Cardiology. 1983;52:234-239.

238. Pohjola $S$, Siltanen $P$, Romo M. Five-year survival of 728 patients after myocardial infarction. A community study. British Heart Journal. 1980;43:176-183.

239. Yuksel H, Guzelsoy D, Yazicioglu N, Senocak M, Ozturk M, Demiroglu C. Long-term prognosis after a first myocardial infarction in Turkey: determinants of moitality and reinfarction. Cardiology. 1994;84:345-355.

240. Luria MH, Knoke JD, Margolis RM, Hendricks FH, Kuplic JB. Acute myocardial infarction: prognosis after recovery. Annals of Internal Medicine. 1976;85:561-565. 
241. Taylor GJ, Humphries JO, Mellits ED, Pitt B, Schulze RA, Griffith LSC, Achuff SC. Predictors of clinical course, coronary anatomy and left ventricular function after recovery from acute myocardial infarction. Circulation. 1980;62:960-970.

242. Beta-Blocker Heart Attack Trial Research Group. A randomized trial of propranolol in patients with acute myocardial infarction. I. Mortality results. Journal of the American Medical Association. 1982;247:1707-1714.

243. Overskeid K, Abrahamsen AM, Frisvold OJ, von der Lippe G, Lund-Johansen $P$, Pedersen TR. Timolol after myocardial infarction. New England Joumal of Medicine. 1981;305:407

244. Schor S, Shani M, Modan B. Factors affecting immediate mortality of patients with acute myocardial infarction: a nationwide study. Chest. 1975;68:217-221.

245. Peel AAF, Semple T, Wang I, Lancaster WM, Dall JLG. A coronary prognostic index for grading the severity of infarction. British Heart Journal. 1962;24:745-760.

246. Greenland S, Robins JM. Estimation of a common effect parameter from sparse follow-up data. Biometrics. 1985;41:55-68.

247. Mantel N, Haenszel W. Statistical aspects of the analysis of data from retrospective studies of disease. Journal of the National Cancer Institute. 1959;22:719-748.

248. Maisel AS, Scott N, Gilpin E, Ahnve S, Le Winter M, Henning H, Collins D, Ross J, Jr. Complex ventricular arrhythmias in patients with $Q$ wave versus non- $Q$ wave myocardial infarction. Circulation. 1985;72:963-970.

249. Herlitz J, Hjalmarson A. The relationship between the electrocardiographically estimated infarct size and 1 - and 2-year survival in acute myocardial infarction. Clinical Cardiology. 1985;8:141-147.

250. Aysha MH, Shayib MA. The clinical implications of electrocardiographic changes in first acute myocardial infarction. Journal of Electrocardiology. 1985;18:371-376.

251. Reimer KA, Lowe JE, Rasmussen MM, Jennings RB. The wavefront phenomenon of ischemic cell death. 1. Myocardial infarct size vs duration of coronary occlusion in dogs. Circulation. 1977;56:786-794.

252. Chawla SK, Najafi H, Haklin M. Subendocardial myocardial necrosis: a preventable lesion. Journal of Cardiovascular Surgery. 1976;17:255-260. 
253. Kaplan BM, Berkson DM. Serial electrocardiograms after myocardial infarction. Annals of Intemal Medicine. 1964;60:430-435.

254. L'Abbate A, Carpeggiani C, Testa R, Michelassi C, Biagini A, Severi S. In-hospital myocardial infarction. Pre-infarction features and their correlation with short-term prognosis. European Heart Journal. 1986;7:53-61.

255. Erikssen J, Muller C, Anderssen JN. Atypical case histories and electrocardiograms in myocardial infarctions. Acta Medica Scandinavica. 1970;188:95-102.

256. Stimmel B, Katz AM, Donoso E. Q-wave development in acute subendocardial infarction. Archives of Internal Medicine. 1973;131:676-678.

257. Rothkopf M, Boerner J, Stone MJ, Smitherman TC, Buja LM, Parkey RW, Willerson JT. Detection of myocardial infarct extension by CK-B radioimmunoassay. Circulation. 1979;59:268-274.

258. Norris RM, Barnaby PF, Brandt PWT, Geary GG, Whitlock RML, Wild CJ, Barratt-Boyes BG. Prognosis after recovery from first acute myocardial infarction: determinants of reinfarction and sudden death. American Journal of Cardiology. 1984;53:408-413.

259. Boden WE. Non-Q-wave myocardial infarction: a prognostic paradox. Hospital Practice. 1992;27:129-133.

260. Upton MT, Palmeri ST, Jones RH, Coleman RE, Cobb FR. Assessment of left ventricular function by resting and exercise radionuclide angiocardiography following acute myocardial infarction. American Heart Journal. 1982;104:1232-1243.

261. Lerman J, Bruce RA, Murray JA. Correlation of polarcardiographic criteria for myocardial infarction with arteriographic and ventriculographic findings (substantiation of transmural and presentation of non-transmural criteria). Journal of Electrocardiology. 1976;9:219-226.

262. Yusuf S, Collins R, Peto R, Furberg C, Stampfer MJ, Goldhaber SZ, Hennekens $\mathrm{CH}$. Intravenous and intracoronary fibrinolytic therapy in acute myocardial infarction: Overview of results on mortality, reinfarction and side-effects from 33 randomized controlled trials. European Heart Joumal. 1985;6:556-585. 
263. Mikell FL, Petrovich J, Snyder MC, Taylor GJ, Moses HW, Dove JT, Batchelder JE, Schneider JA, Wellons HA. Reliability of Q-wave formation and QRS score in predicting regional and global left ventricular performance in acute myocardial infarction with successful reperfusion. American Journal of Cardiology. 1986;57:923-926.

264. Risenfors M, Herlitz J, Berg C-H, Deliborg M, Gustavsson G, Gottfridsson C, Lomsky M, Swedberg K, Hjalmarsson A. Early treatment with thrombolysis and beta-blockade in suspected acute myocardial infarction: results from the TEAHAT Study. Journal of Internal Medicine. 1991;229:35-42.

265. Herlitz J, Dellborg M, Hartford M, Karlsson T, Risenfors M, Karlson BW, Luepker R, Holmberg S, Swedberg K, Hjaln arsson A. Mortality and morbidity 1 year after early thrombolysis in suspected AMI: results from the TEAHAT Study. Journal of Internal Medicine. 1991;229:43-51.

266. Barbagelata A, Sgarbossa E, Califf RM, Woodlief L, Granger C, Gates K, Starr S, Wagner GS. Non-Q wave infarction following thrombolytic therapy: prognosis after hospital discharge in GUSTO patients with first myocardial infarction. Circulation 1994;90:I-664(Abstract)

267. AIMS Trial Study Group. Effect of intravenous APSAC on mortality after acute myocardial infarction: preliminary report of a placebo-controlled clinical trial. Lancet. 1988; 1:545-549.

268. Wilcox RG, von der Lippe G, Ollson CG, Jensen G, Skene AM, Hampton JR. Trial of tissue plasminogen activator for mortality reduction in acute myocardial infarction: Anglo-Scandanavian study of early thrombolysis (ASSET). Lancet. 1988;2:525-530.

269. ISIS-2 (Second International Study of Infarct Survival) Collaborative Group. Randomised trial of intravenous streptokinase, oral aspirin, both, or neither among 17,187 cases of suspected acute myocardial infarction. Lancet. 1988;2:349-360.

270. Rossi $P$, Bolognese $L$, on behalf of Urochinasi per via Sistemica nell'Infarto Miocardico (USIM) Collaborative Group. Comparison of intravenous urokinase plus heparin versus heparin alone in acute myocardial infarction. American Journal of Cardiology. 1991;68:585-592.

271. ISIS-3 (Third International Study of Infarct Survival Collaborative Group). ISIS-3: a randomised comparison of streptokinase vs. tissue plasminogen activator vs. anistreplase and of aspirin plus heparin vs. aspirin alone among 41,299 cases of suspected acute myocardial infarction. Lancet. 1992;339:753-770. 
272. EMERAS (Estudio Multicentrico Estreptoquinasa Republicas de America del Sur) Collaborative Group. Randomised trial of late thrombolysis in patients with suspected acute myocardial infarction. Lancet. 1993;342:767-772.

273. Gruppo Italiano per lo Studio della Streptochinasi nell'Infarto Miocardio (GISSI). Effectiveness of intravenous thrombolytic treatment in acute myocardial infarction. Lancet. 1986;1:397-401.

274. The ISAM Study Group. A prospective trial of intravenous streptokinase in acute myocardial infarction (ISAM). New England Journal of Medicine. 1986;314:1465-1471.

275. Schroder R, Neuhaus K, Leizorovicz A, Linderer T, Tebbe U, for the ISAM Study Group. A prospective placebo-controlled double-blind multicenter trial of intravenous streptokinase in acute myocardial infarction (ISAM): long-term mortality and morbidity. Journal of the American College of Cardiology. 1987;9:197-203.

276. Schroder R, Neuhaus K, Linderer T, Leizorovicz A, Wegscheider K, Tebbe U, for the ISAM Study Group. Risk of death from recurrent ischemic events after intravenous streptokinase in acute myocardial infarction: results from the Intravenous Streptokinase in Myocardial Infarction (ISAM) study. Circulation. 1987;76:II-44-II-51.

277. LATE Study Group. Late Assessment of Thrombolytic Efficacy (LATE) study with alteplase 6-24 hours after onset of acute myocardial infarction. Lancet. 1993;342:759-766.

278. Kennedy JW, Fritz JK, Ritchie JL. Streptokinase in acute myocardial infarction: Western Washington randomized trial -protocol and progress report. American Heart Journal. 1982;104:899-911.

279. Kennedy JW, Ritchie JL, Davis KB, Fritz JK. Western Washington randomized trial of intracoronary streptokinase in acute myocardial infarction. New England Journal of Medicine. 1983;309:1477-1482.

280. Kennedy JW, Ritchie JL, Davis KB, Stadius ML, Maynard C, Fritz JK. The Western Washington randomized trial of intracoronary streptokinase in acute myocardial infarction. A 12-month follow-up report. New England Joumal of Medicine. 1985;312:1073-1078.

281. Kennedy JW, Martin GV, Davis KB, Maynard C, Stadius M, Sheehan FH, Ritchie $\mathrm{JL}$. The Western Washington Intravenous Streptokinase in Acute Myocardial Infarction Randomized Trial. Circulation. 1988;77:345-352. 
282. Armstrong PW, Baigrie RS, Daly PA, Haq A, Gent M, Roberts RS, Freeman MR, Liu P, Morgan CD. Tissue Plasminogen Activator: Toronto (TPAT) placebo-controlled randomized trial in acute myocardial infarction. Joumal of the American College of Cardiology. 1989;13:1469-1476.

283. Anderson WD, Wagner NB, Lee KL, White RD, Yuschak J, Behar VS, Selvester $\mathrm{RH}$, Ideker RE, Wagner GS. Evaluation of a QRS scoring system for estimating myocardial infarct size. VI: Identification of screening criteria for non-acute myocardial infarcts. American Journal of Cardiology. 1988;61:729-733.

284. Sevilla D, Wagner N, Anderson WD, Ideker R, Reimer K, Mikat EM, Hackel D, Selvester RH, Wagner GS. Sensitivity of a set of myocardial infarction screening criteria in patients with anatomically documented single and multiple infarcts. American Journal of Cardiology. 1990;66:792-795.

285. Fleiss JL. Statistical Methods for Rates and Proportions. New York, Wiley, 1981, pp 217-234.

286. Blackburn $H$, Keys $A$, Simonson $E$, Rautaharju Punsar $S$. The electrocardiogram in population studies: a classification system. Circulation. 1960;21:1160-1175.

287. DerSimonian R, Laird N. Meta-analysis in clinical trials. Controlled Clinical Trials. 1986;7:177-188.

288. Walker SH, Duncan DB. Estimation of the probability of an event as a function of several independent variables. Biometrika. 1967;54:167-179.

289. Hosmer DW, Lemeshow S. Applied Logistic Regression. New York, John Wiley \& Sons, Inc. 1989.

290. Lee KL, Woodlief LH, Topol EJ, Weaver WD, Betriu A, Col J, Simoons M, Aylward $P$, van de Werf F, Califf RM, for the GUSTO-I Investigators. Predictors of 30-day mortality in the era of reperfusion for acute myocardial infarction. Results from an international trial of 41,021 patients. Circulation. 1995;91:1659-1668.

291. Cerqueira MD, Maynard C, Ritchie JL, Davis KB, Kennedy JW. Long-term survival in 618 patients from the Western Washington Streptokinase in Myocardial Infarction Trials. Journal of the American College of Cardiology. 1992;20:1452-1459.

292. Goodman $S$. $Q$ wave and non- $Q$ wave myocardial infarction after thrombolysis. Journal of the American College of Cardiology. 1996;27:1817-1818. 
293. The GUSTO Angiographic Investigators. The effects of tissue plasminogen activator, streptokinase, or both on coronary-artery patency, left ventricular function, and survival after acute myocardial infarction. New England Joumal of Medicine. 1993;329:1615-1622.

294. The GUSTO Investigators. An international randomized trial comparing four thrombolytic strategies for acute myocardial infarction. New England Journal of Medicine. 1993;329:673-682.

295. Goodman SG, Langer A, Wildermann N, Barbagelata A, Sgarbossa EB, Wagner GS, Granger CB, Califf RM, Ross AM, Armstrong PW, for the GUSTO Investigators. Non- $Q$ vs. $Q$ wave $M l$ following thrombolysis: angiographic insights. Canadian Journal of Cardiology 1995;11:110E(Abstract)

296. Goodman SG, Langer A, Wildermann NM, Barbagelata A, Sgarbossa EB, Wagner GS, Granger CB, Ross AM, Armstrong PW, for the GUSTO Investigators. Non-Q vs. Q wave myocardial infarction post-thrombolysis: angiographic insights. Circulation 1995;92:I-530(Abstract)

297. The TIMI IIIA Investigators. Early effects of tissue-type plasminogen activator added to conventional therapy on the culprit coronary lesion in patients presenting with ischemic cardiac pain at rest. Results of the Thrombolysis in Myocardial Ischemia (TIMI IIIA) Trial. Circulation. 1993;87:38-52.

298. Willich SN, Stone PH, Muller JE, Tofler GH, Crowder J, Parker C, Rutherford JD, Turi ZG, Robertson T, Passamani E, Braunwald E, and the MILIS Study Group. High-risk subgroups of patients with non-Q wave myocardial infarction based on direction and severity of ST segment deviation. American Heart Journal. 1987;114:1110-1119.

299. Sgarbossa EB, Topol EJ. Semantic ambiguity, the "non-" nosology and myocardial infarction. Journal of Clinical Epidemiology. 1994;47:441-446.

300. Kalbfleisch JM, Shadaksharappa KS, Conrad LL, Sarkar NK. Disappearance of the Q-deflection following myocardial infarction. American Heart Journal. 1968;76:193-198.

301. Bateman TM, Czer LS, Gray RJ, Maddahi J, Raymond MJ, Geft IL, Ganz W, Shah PK, Berman DS. Transient pathologic $Q$ waves during acute ischemic events: an electrocardiographic correlate of stunned but viable myocardium. American Heart Journal. 1983;106:1421-1426. 
302. Anderson JL, Marshall HW, Askins JC, Lutz JR, Sorensen SG, Menlove RL, Yanowitz FG, Hagan AD. A randomized trial of intravenous and intracoronary streptokinase in patients with acute myocardial infarction. Circulation. 1984;70:606-618.

303. Hogg KL, Lees KR, Hornung RS, Howie CA, Dunn FG, Hillis WS. Electrocardiographic evidence of myocardial salvage after thrombolysis in acute myocardial infarction. British Heart Journal. 1989;61:489-495.

304. Langer A, Goodman SG, Topol EJ, Charlesworth A, Skene AM, Wilcox RG, Armstrong PW, for the LATE Study Investigators. Late Assessment of Thrombolytic Efficacy (LATE) study: prognosis in patients with non-Q wave myocardial infarction. Journal of the American College of Cardiology. 1996;27:1327-1332.

305. Ganz W, Buchbinder N, Marcus H, Mondkar A, Maddahi J, Charuzi Y, O'Connor L, Shell W, Fishbein MC, Kass R, Miyamoto A, Swan HJC. Intracoronary thrombolysis in evolving myocardial infarction. American Heart Joumal. 1981;101:4-13.

306. Mathey DG, Kuck K, Tilsner V, Krebber H, Bleifeld W. Nonsurgical coronary artery recanalization in acute transmural myocardial infarction. Circulation. 1981;63:489-497.

307. Reduto LA, Smalling RW, Freund GC, Gould KL. Intracoronary infusion of streptokinase in patients with acute myocardial infarction: effects of reperfusion on left ventricular performance. American Journal of Cardiology. 1981;48:403

308. Schroder R, Biamino G, von Leitrer E, Linderer T, Bruggemann T, Heitz J, Vohringer HF, Wegscheider K. Intravenous short-term infusion of streptokinase in acute myocardial infarction. Circulation. 1983;67:536-548.

309. Neuhaus KL, Tebbe U, Sauer G, Kreuzer $H$, Kostering $H$. High dose intravenous streptokinase in acute myocardial infarction. Clinical Cardiology. 1993;6:426-434.

310. Spann JF, Sherry S, Carabello BA, Denenberg BS, Mann RH, McCann WD, Gault $\mathrm{JH}$, Gentzler RD, Belber AD, Maurer AH, Cooper EM. Coronary thrombolysis by intravenous streptokinase in acute myocardial infarction: acute and follow-up studies. American Joumal of Cardiology. 1984;53:655-661.

311. Simoons ML, Serruys PW, van den Brand M, Bar F, De Zwaan C, Res J, Verheugt FWA, Krauss XH, Remme WJ, Vermeer F, Lubsen J. Improved survival after early thrombolysis in acute myocardial infarction. A randomised trial by the Interuniversity Cardiology Institute in The Netherlands. Lancet. 1985;2:578-582. 
312. Simoons $M L$, Serruys $P W$, van den Brand $M$, Res J, Verheugt FWA, Krauss $X H$, Remme WJ, Bar F, De Zwaan C, van der Laarse A, Vermeer F, Lubsen J, for the Working Group on Thrombolytic Therapy in Acute Myocardial Infarction of the Netherlands Interuniversity Cardiology Institute. Early thrombolysis in acute myocardial infarction: limitation of infarct size and improved survival. Journal of the American College of Cardiology. 1986;7:717-728. 
